\title{
Cyclosporine A-induced experimental autoimmunity
}

Citation for published version (APA):

Wodzig, K. W. H. (1993). Cyclosporine A-induced experimental autoimmunity. [Doctoral Thesis, Maastricht University]. Rijksuniversiteit Limburg. https://doi.org/10.26481/dis.19931028kw

Document status and date:

Published: 01/01/1993

DOI:

10.26481/dis.19931028kw

Document Version:

Publisher's PDF, also known as Version of record

\section{Please check the document version of this publication:}

- A submitted manuscript is the version of the article upon submission and before peer-review. There can be important differences between the submitted version and the official published version of record.

People interested in the research are advised to contact the author for the final version of the publication, or visit the DOI to the publisher's website.

- The final author version and the galley proof are versions of the publication after peer review.

- The final published version features the final layout of the paper including the volume, issue and page numbers.

Link to publication

\footnotetext{
General rights rights.

- You may freely distribute the URL identifying the publication in the public portal. please follow below link for the End User Agreement:

www.umlib.nl/taverne-license

Take down policy

If you believe that this document breaches copyright please contact us at:

repository@maastrichtuniversity.nl

providing details and we will investigate your claim.
}

Copyright and moral rights for the publications made accessible in the public portal are retained by the authors and/or other copyright owners and it is a condition of accessing publications that users recognise and abide by the legal requirements associated with these

- Users may download and print one copy of any publication from the public portal for the purpose of private study or research.

- You may not further distribute the material or use it for any profit-making activity or commercial gain

If the publication is distributed under the terms of Article $25 \mathrm{fa}$ of the Dutch Copyright Act, indicated by the "Taverne" license above, 


\section{Cyclosporine A - induced experimental autoimmunity}


Production and design: Marc-Redwart Kok

CIP-GEGEVENS KONINKLIJKE BIBLIOTHEEK, DEN HAAG

Wodzig, Karel Willem Henricus

Cyclosporine A - induced experimental autoimmunity / Karel Willern Henricus Wodzig. - [S.I. : s.n.]. - III.

Proefschrift Maastricht. - Met lit. opg. - Met samenvatting in het Nederlands.

ISBN 90-9006454-0

NUGI 743

Trefw.: Cyclosporine A / Immunologie / sclerodermie

Het in dit proefschrift gepresenteerde onderzoek werd mogelijk gemaakt door subsidie van de Nederlandse Vereniging voor Reumabestrijding

In de drukkosten van het proefschrift werd bijgedragen door de firma Sandoz en de stichting Het Scholten-Cordes Fonds. 


\section{Cyclosporine A - induced experimental autoimmunity}

\section{Proefschrift}

ter verkrijging van de graaď van doctor aan de Rijksuniversiteit Limburg te Maastricht, op gezag van de Pro-Rector, Prof. dr. L. Boon, volgens het besluit van het College van Dekanen, in het openbaar te verdedigen op donderdag, 28 oktober 1993 om 14.00 uur

door

Karel Willem Henricus Wodzig geboren te Kerkrade op 5 februari 1963 
Promotor:

Prof.Dr. P.J.C. van Breda Vriesman

Co-promotor:

Dr. G.D. Majoor

Beoordellngscommissle:

Prof.Dr. J.M.J.P. van der Linden (voorzitter)

Prof.Dr. J.W, Arends

Prof.Dr. G.H. Blijham (Rijksuniversiteit Utrecht)

Prof.Dr. C.G.M. Kallenberg (Rijksuniversiteit Groningen)

Prof.Dr. F.C.S. Ramaekers 
"There is one thing even more vital to science than intelligent methods; and that is, the sincere desire to find out the truth, whatever it may be." C. Peirce, Collected Papers of C.S. Peirce (1935)

Opged ragen aan mijn ouders Voor Gertie en "Jopie" 


\section{Contents}

$\begin{array}{ll}\text { Abbreviations } & 6\end{array}$

Introduction 7

Chapter 1

Cyclosporine A-induced autoimmunity;

An overview of the literature

Chapter 2

Susceptibility and resistance to Cyclosporine A - induced autoimmunity in rats

Chapter 3

Malignant neoplasms in

Cyclosporine A - induced autoimmunity

Chapter 4

Autoantibodies in Cyclosporine A - induced experimental autoimmune scleroderma

Chapter 5

On the localization of effector cells in

Cyclosporine A - induced autoimmunity

Chapter 6

Kinetics of inducer/effector cell generation in the thymus in Cyclosporine A - induced autoimmunity

Summary and general discussion

Samenvatting en algemene discussie

Publications

Dankwoord 


\section{Abbreviations}

$\begin{array}{lll}\text { BMT } & : & \text { Bone marrow transplantation } \\ \text { CD } & : & \text { Cluster designation } \\ \text { CyA } & : & \text { Cyclosporine A } \\ \text { CyA-AI } & : & \text { Cyclosporine A-induced autoimmunity } \\ \text { GVHD } & : & \text { Graft-versus-host disease } \\ \text { GVHR } & : & \text { Graft-versus-host reaction } \\ \text { Gy } & : & \text { Gray (=100 Rad) } \\ \text { MAb } & : & \text { Monoclonal antibody } \\ \text { MHC } & : & \text { Major histocompatibility complex } \\ \text { SPF } & : & \text { Specified pathogen free } \\ \text { SS } & : & \text { Systemic sclerosis } \\ \text { TCR } & : & \text { T cell receptor }\end{array}$




\section{Introduction}

This thesis deals with an experimental animal model of immune disease termed "syngeneic graft-versus-host-like disease" (sGVHD), also referred to as "Cyclosporine A-induced autoimmunity (CyA-AI)" or "bone marrow transplantation-associated immune disease" (BMT-ID). Its relevance to human disease is threefold. First, it is one of the few animal models that generates cutaneous lesions indistinguishable from those of scleroderma in man; this is a disease of obscure but undoubtedly immunological origin. Next, effector cells operative in this model have been advocated and used to treat hematopoietic malignancies, specifically non-Hodgkin's lymphomas, in man. Finally, when the experimental protocol designed in the rat is applied to man, identical autoimmune phenomena are observed. In the LEW rat the disease is brought about by subjecting the animal to lethal X-irradiation, followed by a syngeneic bone marrow transplantation, and transient administration of the immunosuppressive drug Cyclosporine A. The X-irradiation almost destroys the thymus and eradicates the peripheral $\mathrm{T}$ cell compartment. Next, pre-T cells derived from the bone marrow inoculum home into the thymus in order to recapitulate $T$ cell ontogeny and repopulation of the periphery eventually, resulting in immunologically normal animals. However, this thymic and peripheral reprogramming is interfered with by Cyclosporine $\mathrm{A}$, resulting in autoimmune disease.

Chapter 1, which is a literature review, deals with Cyclosporine A-induced autoimmune disease in various mammals and discusses the various mechanisms inclusive the thymus and peripheral effector cells by which autoimmune disease is brought about. The other chapters deal with own work.

For chapter 2, the question was asked whether or not Cyclosporine A-induced autoimmune disease was specific for the LEW rat strain; LEW rats are susceptible to this disease as well as for other cell-mediated autoimmune diseases like experimental allergic encephalomyelitis (EAE) and collagen-induced arthritis to which the $\mathrm{BN}$ rat is resistant. In contrast, $\mathrm{BN}$ rats are susceptible to some antibody-mediated autoimmune diseases (e.g. mercury chloride-induced glomerulonephritis) to which LEW rats are resistant. Although both cell-mediated and antibody-mediated autoimmune reactions are elicited in CyA-AI, LEW rats were shown to be susceptible whereas BN rats were resistant.

As pointed out above the model of CyA-AI has been used in man to treat nonHodgkin's lymphoma. Paradoxically, rats with $\mathrm{CyA}-\mathrm{AI}$ and chronic dermatitis or scleroderma developed malignant tumors in the chronic phase of the disease. This 
issue was examined in chapter 3 . Indeed, LEW rats with chronic CyA-AI may develop a high incidence of sarcomas and adenocarcinomas. These tumors were analyzed histopathologically, immunohistochemically as well as biologically. The pathogenesis of these tumors is discussed.

In chapter 4 we have addressed the issue whether the chronic (cutaneous) scleroderma-like lesions in iats with CyA-AI are associated with autoantibodies to nuclear and/or cytoplasmic proteins. In man, autoantibodies to certain nuclear and/or cytoplasmic antigens are seen in up to $95 \%$ of the patients with systemic sclerosis.

In chapter 5 and 6 the role of the thymus and its putative effector cells in the model of CyA-AI is examined. In chapter 5 we show that the generation of autoreactive T cells - which cause CyA-AI - occurs during Cyclosporine A administration but remain "dormant" due to the immunosuppressive properties of Cyclosporine A. In chapter 6 finally we show that such cells exit from the thymus during recapitulation of $\mathrm{T}$ cell ontogeny that is already within 12 days after $\mathrm{X}$-irradiation and during Cyclosporine A administration. 


\title{
Chapter 1
}

\section{Cyclosporine A-induced}

\section{autoimmunity; An overview}

\author{
of the literature
}

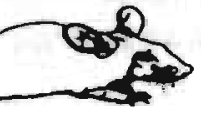




\section{Cyclosporine A-induced autoimmunity; An overview of the literature}

\section{Introduction}

Cyclosporine A (CyA) is a drug with potent immunosuppressive activity which has been used extensively to prevent allograft rejection (White and Calne, 1982; Shevach, 1985; Hess et al., 1986), to suppress graft-versus-host disease (GVHD) secondary to allogeneic bone marrow transplantation (BMT)(Tutschka et al., 1979; Bacigalupo et al., 1990), and in the treatment of several autoimmune diseases (Stiller et al., 1984; Bolton et al., 1982; Von Graffenried et al., 1989). Paradoxically, under certain circumstances CyA may induce specific forms of autoimmunity. At least three experimental models of $\mathrm{CyA}$-induced autoimmune disease have been described: syngeneic or autologous GVHD which occurs after X-irradiation, and syngeneic or autologous bone marrow transplantation provided CyA is given for a period of time after transplantation (Glazier et al., 1983; Jones et al. 1989); organ-specific autoimmune disease in mice which occurs in neonatal mice treated with CyA (Sakaguchi and Sakaguchi, 1989); and organ-specific autoimmune disease in adult athymic mice after engraftment of a CyA-treated thymus (Sakaguchi and Sakaguchi, 1988)(Fig. 1.1). In this overview, mainly the model first mentioned will be dealt with.

Reconstitution of lethally irradiated rodents with autologous or syngeneic bone marrow usually leads to rapid recovery of such animals. A course of administration of the immunosuppressant CyA given for the first 6 weeks during this period of recuperation apparently does not interfere with recovery but elicits, surprisingly, 
a 'T cell-mediated autoimmune disease which develops about 2 weeks after discontinuation of the drug (Glazier et al., 1983). This CyA-induced autoimmune syndrome was originally termed syngeneic GVHD (Glazier et al., 1983) and has also been referred to as $\mathrm{Cy}$ A-induced autoimmune disease (CyA-AI)(Sorokin et al., 1986) or BMT-associated immune disease (BMT-ID)(Bos et al., 1990). The disease has been elicited in certain rat strains (Glazier et al., 1983; Tutschka et al., 1987; Geller et al., 1989) and mouse strains (Cheney and Sprent, 1985; Bryson et al., 1989) and may also occur in humans (Jones et al., 1989).

The thymus has been demonstrated to play a pivotal role in this phenomenon (Sorokin et al., 1986). Most likely, under CyA treatment recovery of thymic medullary stromal cells from the initial irradiation damage is delayed (Beschorner et al., 1987b, 1987c). Probably due to this damage, the thymus fails to delete (or to negatively select) potentially autoreactive $\mathrm{T}$ cells which are also in untreated animals likely to develop in the generation of the (unselected) repertoire (Cheney and Sprent, 1985; Hess et al., 1985; Hess and Fischer, 1989). Moreover, regulatory circuits which are able to suppress autoaggressive $\mathrm{T}$ cells are eliminated as well by the irradiation and apparently fail to recover in due time (Fischer et al., 1989a). Consequently, symptoms develop which mimic the acute GVHD known to occur after transplantation of allogeneic bone marrow to lethally irradiated rats (Glazier et al., 1983b). The model of CyA-AI offers new possibilities to investigate the role of the thymus in $T$ cell development and challenges established concepts about the mechanisms eliciting GVHD.

The concept of CyA-induced syngeneic or autologous autoimmune disease was received with great scepticism (Chow et al., 1988). GVHD is a disease that may develop as a consequence of a graft-versus host reaction (GVHR) upon transplantation across histoincompatibility barriers as postulated by Billingham (1967-1968), but similar pathology has been described in syngeneic or autologous CyA-AI (Glazier et al., 1983b; Jones et al., 1989; Hess et al., 1992). From an immunological point of view, however, a GVHR could not occur in CyA-AI because of a lack of major or minor histoincompatibility differences between donor and recipient as demonstrated in the variant of the model using autologous bone marrow for reconstitution (Hood et al., 1987; Hess et al., 1992). So, other mechanisms must account for the induction of the pathology that is indistinguishable from the classical GVHD.

The precise mechanisms by which CyA induces autoimmune disease are not clear. Presumably, CyA affects immune tolerance by interfering with clonal deletion/anergy in the thymus, and the regeneration of the peripheral autoregulatory system which was eradicated by $\mathrm{X}$-irradiation. 


\section{General features of CyA-Al associated pathology}

CyA-AI has been originally described in the rat. Young female LEW rats which are lethally irradiated, reconstituted with syngeneic or autologous bone marrow and given a course of CyA over a period of about 4-6 weeks almost consistently develop CyA-AI about 2 weeks after discontinuation of the drug (Glazier et al., 1983b; Sorokin et al., 1986; Fischer et al., 1989a; Fischer and Hess, 1990) (Fig. 1.1A). These rats show symptoms reminiscent of those seen in acute graft-versus-host disease: erythroderma of the extremities, a raised fur, a hunched appearance and sometimes diarrhoea (Glazier et al., 1983b; Beschorner et al., 1988c). Soon thereafter they suffer substantial weight loss and lose hair. Provided the animal does not die during this acute phase of CyA-AI, alopecia may progress to yield an almost entirely nude rat (Bos et al., 1989d; Majoor, 1989). Survival of the acute phase of CyA-AI may be influenced by the microbiological status of the animals; i.e. SPF rats are less likely to succumb than conventionally housed animals (Sorokin et al., 1986; Bos et al., 1989d).

Histological abnormalities have been reported for many organs in the acute phase of the disease and include the skin, tongue, thymus, liver, intestine, salivary glands, esophagus, spleen, lymph nodes and the kidney (Glazier et al., 1983a; Beschorner et al., 1988c). In non-lymphoid organs, the abnormalities are confined to cellular infiltration; lymphoid organs show lymphoid atrophy (Glazier et al., 1983a). In the later phase of CyA-AI the histological abnormalities appear to be restricted to the skin, tongue and thymus (Bos et al., 1989d).

\section{CyA-Induced organ-specific autoimmunity}

T cells play a pivotal role in generating various organ-specific autoimmune diseases in humans and animals (Schwartz and Datta, 1989). Hence, a critical issue in elucidating the pathogenetic mechanism of organ-specific autoimmune disease would be to determine how the thymic production of autoreactive $T$ cells and their peripheral expansion/activation are controlled by the normal immune system, and which conditions are required for such self-reactive $T$ cells to become active and elicit autoimmune disease.

An altogether different $\mathrm{CyA}$-induced autoimmune syndrome has been described in mice by Sakaguchi et al. (Sakaguchi and Sakaguchi, 1988, 1989). When CyA was administered to newborn BALB/c mice for 1 week from the day of birth, the mice subsequently developed organ-specific autoimmune diseases including gastritis, oophoritis, thyroiditis, and insulitis 3 months after discontinuation of CyA (Fig. 1.1B). This autoimmune pathology was accompanied by the appearance of serum autoantibodies specific for gastric parietal cells, cocyte, thyroglobulins, and cell surface antigens of the Langerhans islet cells. It was demonstrated for this model that $\mathrm{CyA}$ caused a reduction of $\mathrm{CD4} 4^{+} \mathrm{CD} 8$ and 
Flgure 1.1: Experimental models of CyA-Anduced aurolmmune disease.

A. Cyclosporine A-induced Autoimmune Disease in the Rat

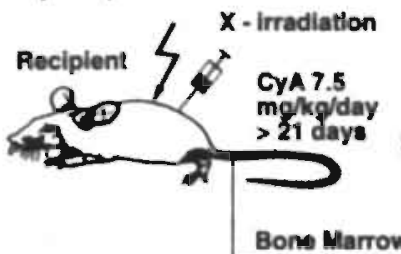

6 - wk - old LEW ret
Donor

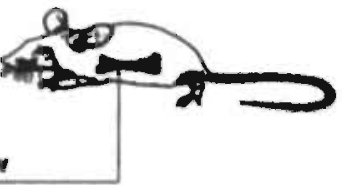

6 - wk - old LEW rat

1. $\mathrm{X}$ - irradiation $(9.6 \mathrm{G}$ ) $)$ on day -1

2. Syngenele bone marrow treneplantation on dey 0

3. CүA $7.5 \mathrm{mg} / \mathrm{kg} / \mathrm{day}$ subcutaneounly for $>21$ daye

4. Developinent of a $T$ cell-mediated eutoimmune dianese (CYA-AI) $2-3$ weike ofter withdriwal of CyA

A Model of CyA-Al in the rat; 6 weeks old LEW are lethally' $X$ imadiated (9.6 Gy), reconstituted with syngeneic bone marrow, and given $7.5 \mathrm{mg} / \mathrm{kg} / \mathrm{day}$ CyA for 6 weeks (at leas! 3 weeks). A T cellmediated autoimmune disease. develops about 2-3' woeks after withdrawal of CyA.
B. Model of CyA-mectated organspecific autoimmune disease in $B A L B / C$ mice; newbom mice are treated with $10 \mathrm{mg} / \mathrm{kg} / \mathrm{day} \mathrm{Cy} A$ for 7 days. Organ-specific autoimmune dsease including gastrits, oophoritis, thyroiditis and hsullis was histokgically confimed about 3 months after CyA discontinuation. Adult $B A L B / c$ mice treated with $20 \mathrm{mg} / \mathrm{kg}$ day CyA did not develop organspecific autoimmune disease.

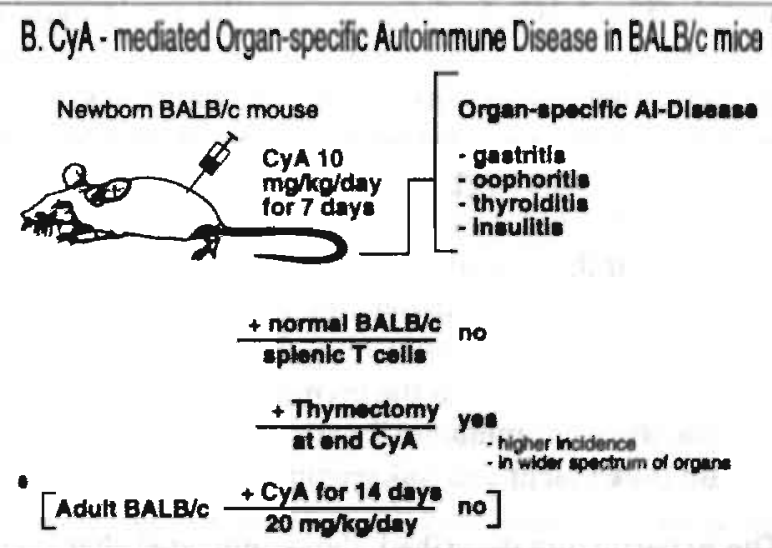

B. CyA - mediated Organ-specific Autoimmune Disease in BALBBC mico" al-Dices:

$\frac{+ \text { nommal BALEV }}{\text { iplanic T colle }}$

+ Thymectomy yoe

- higher hcidence

- h wilder spectrim of organ

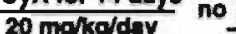

C. CyA - mediated Organ specific Autoimmune Disease Model

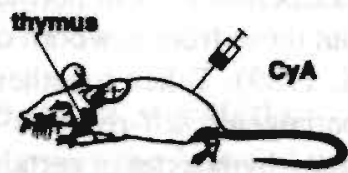

1. Nawborn euthymic nu+ BALE/C moute

OR - Tratment: CyA $10 \mathrm{mr} / \mathrm{kg}$ for 7 days from birth

2. Adull euthrmic $n w /+$ No/c - Treotmont: CyA 20 molkg for 14 dinys
C. Model of CyA-mediated organspeciftc autolmmune disease in athymic $B A L B / C$ mico after engraftmentof a CyA-trated thymus from outhymic mlce. Six weeks old athymic nu/nu BALB/C mice were engrafled with etther one thymus from euthymic nU+ BALB/c mice treated wth $10 \mathrm{mg} / \mathrm{kg} /$ day CyA for 7 days or one thymic lobe from adult euthymic $\mathrm{mV}+\mathrm{BALB} / \mathrm{cm}$ mice treated with $20 \mathrm{mg}$ kglday CyA for 14 days, under the renal capsule. Organ-speclfic autolmmune disease develops as outlined in fig. 1.1B 
$\mathrm{CD} 4{ }^{-} \mathrm{CD} 8^{+}$single-positive mature thymocytes and peripheral lymphoid atrophy. The same dose and period of CyA administration starting from 1 week after birth was less effective, and $\mathrm{CyA}$ administration to adult mice failed to induce organ-specific autoimmune disease. Autoimmune disease was preventable by inoculation of normal splenic $\mathrm{T}$ cells immediately after neonatal administration of CyA. On the other hand, thymectomy immediately following withdrawal of neonatal CyA treatment produced a higher incidence of organ-specific autoimmune disease, as well as disease in a wider spectrum of organs. This indicates that removal of the thymus immediately after neonatal CyA-treatment may permanently sustain a deficiency of suppressor $\mathrm{T}$ cells in the immune system, allowing a variety of self-reactive $\mathrm{T}$ cells to expand more easily and cause autoimmune disease in a wider spectrum of organs (Sakaguchi and Sakaguchi, 1989) (Fig. 1.1B).

Assuming that self-reactive $\mathrm{T}$ cells can be controlled in the periphery by a $\mathrm{T}$ cell-dependent down-regulation, autoimmune disease may develop when pathogenic self-reactive $T$ cells are released from the thymus to the $T$ cell-deficient or -eliminated periphery. Thus, organ-specific autoimmune diseases developed also in athymic nude (nu/nu) mice after engraftment of the thymus from heterozygous $n w+$ mice treated with CyA under the renal capsule (Fig. 1.1C). In the organ-specific autoimmune diseases, $T$ cells produced by and released from the thymus grafts appeared to exert antigen-specific help on the hostderived autoantibody-forming B cells and/or conduct cell-mediated immune reactions towards specific self-antigens. Development of autoimmune disease in the $n w / n u$ mice was prevented by co-inoculation of thymocyte suspensions from normal $n w+$ mice, but not from CyA-treated $n w+$ mice. Co-transplantation of normal $n w /+$ mouse thymus with CyA-treated thymus also prevented development of autoimmune disease. Inoculation of spleen cells from normal adult $n w+$ mice prevented autoimmune disease, but inoculation of those from newborn $n w /+$ mice did not. This indicates once more that CyA appears to interfere selectively with the thymic production of certain suppressor $\mathrm{T}$ cells controlling self-reactive (autoimmune) $\mathrm{T}$ cells, allowing the latter to expand and cause autoimmune disease (Sakaguchi and Sakaguchi, 1988).

The experiments described above indicated that: (a) development of mature singlepositive thymocytes was suppressed by CyA administration; (b) transplantation of thymuses from CyA-treated newborn or adult mice produced organ-specific autoimmune disease in syngeneic nw/nu mice; (c) inoculation of thymocyte suspensions from normal adult mice could inhibit development of autoimmune disease, but those from newborn or CyA-treated mice could not (Sakaguchi and Sakaguchi, 1988, 1989). Taken together, these findings suggest that thymuses of any age can produce pathogenic self-reactive $T$ cells eliciting organ-specific autoimmune disease, however, mature thymocytes or certain $\mathrm{T}$ cells may inhibit peripheral activation and proliferation of self-reactive $\mathrm{T}$ cells. 


\section{Conditions for induction of CyA-Al}

\section{Thymic involvement}

The general features of CyA-AI are suggestive of an autoimmune phenomenon which could at least in part be due to a perturbation of the normal induction of tolerance for 'self' in the thymus. Several studies, using different approaches, have clearly demonstrated an essential role of the thymus in bringing about CyA-Al. Shielding of the thymus from irradiation prevented the development of CyA-AI in recipients further subjected to the usual protocol of BMT and administration of CyA (Glazier et al., 1983a). Furthermore, CyA-AI could not be elicited in adult rats thymectomized prior to $X$-irradiation and BMT. This failure to de velop CyA-AI could not be restored by transfer of various kinds of lymphoid cells (including thymocytes), but was restored after grafting of intact thymic lobes in the axilla prior to X-irradiation and CyA treatment (Sorokin et al., 1986). Further evidence for the essential role of the thymus in $\mathrm{CyA}-\mathrm{Al}$ was derived from a somewhat different mouse model. Female newborn or adult $n w+$ mice were given CyA for 1 or 2 weeks respectively and next their thymuses were grafted to adult $n u / n u$ recipients. In this model, extensive pathology was seen to develop including gastritis, oophoritis, thyroiditis and insulitis (Sakaguchi and Sakaguchi, 1988). The evidence from the studies cited above unequivocally established that the thymus is pivotal in the establishment of CyA-AI. The data from the mouse model further suggest that irradiation as applied in the rat model may serve another purpose than just contributing to the disturbance of correct education of $\mathrm{T}$ cells in the thymus. Apparently, irradiation also contributes to the elimination of a (peripheral) counteractive autoregulatory mechanism. On the other hand, the observation that simply shielding the thymus from irradiation prevents CyA-AI (Glazier et al., 1983a) proves that the combination of irradiation and CyA administration is required to perturbate regular tolerance induction in the thymus. In contrast, Beschorner et al. (1991) have reported acute CyA-AI but not chronic-type CyA-AI in non-irradiated rats treated with CyA for 32 days and thymectomized immediately after discontinuation of CyA. In their view, self-reactive effector lymphocytes migrated to the periphery during CyA treatment. However, thymectomy would prevent development of counteractive regulatory $\mathrm{T}$ cells and thus allow expansion of autoreactive $\mathrm{T}$ cells and consequently tissue damage.

\section{Dose of Irradlation}

Varying the dose and timing of irradiation has yielded additional information about its effects. Firstly, a course of CyA alone does not evoke CyA-AI in a non-irradiated animal (Glazier et al., 1983a; Cheney and Sprent 1985). Secondly, lethal irradiation may be no prerequisite to elicit CyA-AI. A non-lethal dose of $7.5 \mathrm{~Gy}$ without additional bone marrow reconstitution led to mortality in 5/6 animals after withdrawal of CyA, whereas controls not receiving CyA survived indefinitely (Sorokin et al., 1986). In contrast, others have found that execution of the original protocol with $7.5 \mathrm{~Gy}$ irradiation and transplantation of $6 \times 10^{7}$ bone marrow cells induced CyA-AI in only one-third of the rats; a dose of $5.0 \mathrm{~Gy}$ or lower was completely ineffective (Fischer $e t$ al., 1989a). 


\section{Dose of CyA and timespan of administration}

The dose of CyA needed to elicit CyA-AI does not seem to be very critical. Originally, a dose of $7.5 \mathrm{mg} / \mathrm{kg} /$ day for 40 days was reported to suffice, although the same dose for 20 days was only effective in half of the recipients (Glazier et al., 1983a, 1983b). However, the same group of investigators subsequently used $15 \mathrm{mg} / \mathrm{kg} /$ day for 40 (Hess et al., 1985 ) or 30 days (Fischer et al., 1989a). Recent data showed that $5 \mathrm{mg} / \mathrm{kg} /$ day is still effective provided donors and recipients of one month of age were used. A dose of $1 \mathrm{mg} /$ $\mathrm{kg} / \mathrm{day}$ failed to induce CyA-AI (Fischer and Hess, 1990). Extension of the period of treatment to 80 days had neither effect on the kinetics of development of CyA-AI nor on its severity (Bos et al., 1988).

\section{Influence of specles and age}

The rat model as originally described proved to be easily reproducible using young female LEW (RTI') rats; males and females are equally susceptible. In two other studies, female Louvain (Lou/M; RTI") and (LEWXBN)FI rats were shown to be susceptible as well (Tutschka et al., 1987; Geller et al., 1989). On the other hand, the Brown Norway (BN; $\mathrm{RT} \mathrm{I}^{\mathrm{n}}$ ) rat strain is (relatively) resistant to the induction of CyA-AI (Wodzig et al.,1993 this thesis chapter 2). Susceptibility of LEW and (LEWxBN)F1 rats, taken together with the resistance of BN rats, suggests that susceptibility is genetically a dominant trait.

More discussion has been raised about the reproducibility of the model in mice. Originally, Cheney and Sprent (1985) described CyA-AI in C57Bl/6 or (C57Bl/6 x CBA/J)F1 mice after administration of $10 \mathrm{mg} \mathrm{CyA} / \mathrm{kg} /$ day for 5-6 weeks. Next, it was reported, however, that $\mathrm{CyA}-\mathrm{AI}$ could not be elicited in C57BV/6BOM mice by oral administration of even 50 or $100 \mathrm{mg} / \mathrm{kg} /$ day for 40 days after lethal irradiation and syngeneic BMT (Chow et al., 1988). This study was confirmed in CBA/J mice given 25 or $50 \mathrm{mg} \mathrm{CyA}$ / $\mathrm{kg} /$ day subcutaneously (Parfrey and Prud'homme, 1990). In contrast, induction of CyA$\mathrm{AI}$ in DBA/2 and Balb/c mice was demonstrated recently using a dose of $15 \mathrm{mg} \mathrm{CyA} / \mathrm{kg} /$ day and, probably most importantly, using mice aged 3-4 weeks instead of mice 6-8 weeks of age like used in the studies that failed to demonstrate CyA-Al (Bryson et al., 1989). Indeed, also in the rat very young animals (4-6 weeks) develop CyA-AI more readily than animals about 12 weeks of age (Beschorner et al., 1988d; Fischer and Hess, 1990). Therefore, the debate about a different sensitivity of rats and mice to the induction of CyA-AI can probably be ascribed apart from the strains used to the use of too old mice in the studies that failed to demonstrate CyA-AI.

Although the occurrence of CyA-AI has not yet been demonstrated in other species than rats, mice, and humans, at the level of the thymus effects comparable to those observed in rodents (see below) have been demonstrated in chickens (Bucy et al., 1990).

\section{Adoptive transfer of CyA-AI}

The protocol as described above for rodents apparently elicits (or fails to suppress) an autoimmune effector mechanism(s) which may cause severe disease. The similarity of the lesions in CyA-AI with those occurring in GVH disease and the essential role of the thymus suggested involvement of (autoaggressive) $T$ cells. Hence, already the first paper on 
CyA-Al described investigations on the possibility to transier the disease to secondary, syngeneic recipients. It proved impossible to transfer the disease to untreated rats; irradiation ( 4.2 or $10.2 \mathrm{~Gy})$ and bone marrow reconstitution of the recipients was required in order to adoptively transfer CyA-AI (Glazier et al., 1983a, 1983b). Later, the issue of preparation of prospective recipients of CyA-AI effector cells was investigated further by Fischer et al. (1989). In this study, irradiation of the secondary recipient with $7.5 \mathrm{~Gy}$ sufficed for $100 \%$ successful adoptive transfer of the disease; 5.0 Gy yielded success in only 1 out of 7 recipients. Interesting was the demonstration in the same study that Cyclophosphamide ( 100 or $200 \mathrm{mg} / \mathrm{kg}$ ) was also effective in preparing the secondary recipients, whereas it was not so in the induction of CyA-AI. These data suggested that the lethal irradiation applied in the regular protocol for induction of CyA-AI in fact required two targets: one probably residing in the thymus and another one extrnthymically.

Another issue raised was what kind of cells were able to transfer CyA-AI. The earliest study in rats demonstrated that spleen cells were effective, $10^{\text {s }}$ cells being used for these transfers (Glazier et al., 1983a, 1983b). In mice comparable results were obtained; this study demonstrated in addition the effector cells to be T lymiphocytes (Cheney and Sprent, 1985). There is considerable debate concerning the potency of $T$ lymphocytes subsets from CyA-AI rats in transferring disease to secondary recipients. Fischer et al. (1990) demonstrated the requirement for both splenic $\mathrm{CD} 4^{+}$and $\mathrm{CD} 8^{+}$subsets (both $7.5 \times 10^{6}$ ) to transfer CyA-AI effectively. Transfer of large numbers $\left(>3 \times 10^{7}\right)$ of $\mathrm{CD}^{+}$cells from animals with acute $\mathrm{CyA}-\mathrm{AI}$ resulted in the induction of CyA-AI in the secondary recipients. However, lower numbers of $\mathrm{CD} 8^{+}$cells could only transfer $\mathrm{CyA}-\mathrm{Al}$ if accompanied by small numbers of $\mathrm{CD} 4^{+} \mathrm{T}$ cells from donors with CyA-AI. The $\mathrm{CD4}^{+}$subset cells harvested during acute $\mathrm{CyA}-\mathrm{Al}$ were ineffective by themselves. On the other hand, Sorokin et al. (1986) were able to transfer disease with as few as $3 \times 10^{5} \mathrm{CD}^{+}$lymph node cells from animals with active CyA-AI; $B$ cells and $\mathrm{CD} 8^{+}$cells were far less effective. These discrepancies may be due to the fact that in vitro activated $\mathrm{CD} 4^{+}$cells may express the $\mathrm{CD} 8 \alpha \alpha$-chains ( $\left.\mathrm{CD} 4{ }^{+} \mathrm{CD} 8 \alpha^{+} \beta^{-}\right)$to which the anti-CD8 antibody (OX8; used to identify the CD8 subset) is directed; hence, these studies should be repeated using a MAb directed to the CD8B-chain which is not expressed on activated CD4 $4^{+}$cells (Torres-Nagel et al., 1992).

Also $8 \times 10^{7}$ or $1.8 \times 10^{8}$ thymocytes obtained 30 days after discontinuation of CyA from rats with CyA-AI have been successfully used in adoptive transfers to irradiated and bone marrow-reconstituted recipients. Pathology in these recipients at 3-5 weeks post-transfer was reminiscent of chronic graft-versus-host disease and involved the skin and the tongue. In these organs a marked preponderance of $\mathrm{CD} 4^{+}$lymphocytes over CD8 ${ }^{+}$ lymphocytes was noted. In the thymus a moderate loss of epithelial cells was seen in the cortex and a near-total loss of epithelial cells in the medulla (Beschorner et al., 1988a). Inspection of the thymus of irradiated but non-reconstituted rats at 4-48 hrs post-transfer revealed increased lymphocytic exocytosis of Hassall's corpuscles associated with CD8 ${ }^{+}$lymphocytes and epithelial cell injury as compared to controls. These data were interpreted as indicative for the presence of autoreactive cells in the thymus of rats with CyA-AI that are able to damage thymic epithelial cells (Beschorner et al., 1988b). As 
described in this thesis, however, thymocytes harvested up to 14 days after discontinuation of CyA could not transfer the disease (this thesis chapter 6).

Another transfer model has been described by Cheney et al. (1985). In this study, spleen plus lymph node cells from non-irradiated mice given CyA for 5-6 weeks were obtained one day after withdrawal of CyA and transferred to irradiated syngeneic recipients. Acute, fatal CyA-Al developed in these mice but not after transfer of such cells to non-irradiated recipients. In our hands, transfer of $2.5 \times 10^{7}$ spleen and lymph node cells from nonirradiated, CyA treated rats failed to induce disease in secondary, irradiated recipients (Wodzig et al., 1991). However, we harvested the cells 2 weeks after discontinuation of CyA. By that time, the putative effector cells may have shifted from the lymphoid organs to the peripheral tissues and therefore be no longer included in sufficient amounts in the cell population transferred.

The adoptive transfer systems described above also opened the possibility to analyze the cells that were likely to be involved in the suppression of CyA-AI effector cells in nonirradiated or non-Cyclophosphamide treated rats. The first attempts to suppress the effector cells in adoptive transfer experiments by addition of an equivalent amount of spleen cells from normal rats were unsuccessful, as were experiments in which normal spleen cells or intraperitoneal thymus grafts were given simultaneous with the reconstituting bone marrow cells, thus prior to CyA treatment (Glazier et al., 1983a, 1983b). However, by changing the ratio of normal spleen cells to those from CyA-AI rats to 10:1 (Sorokin et al., 1986) or 2:1 (Fischer et al., 1989a, 1989b), suppression of CyA-Al could be demonstrated in adoptive transfers. Furthermore, it was shown that the regulatory component within the normal spleen cell population consisted of T cells (Fischer $e$ t al., 1989 a) and that both $\mathrm{CD}^{+}$and $\mathrm{CD} 8^{+} \mathrm{T}$ cells are needed in this regulatory population in order to be effective (Fischer et al., 1989b; Hess et al., 1989).

In the mouse model in which transplantation of $n u /+$ thymus from CyA-treated mice into $n u / n u$ recipients was performed a counteractive regulatory $T$ cell system is obviously absent from the host. Also in this model the existence of a regulatory mechanism in phenotypically normal $(n w+)$ mice could be demonstrated. Inoculation of adult, normal $n u /+$ thymocytes or spleen cells at the time of transplantation of a CyA-AI nu/ thymus prevented the development of CyA-AI, as did co-transplantation of a normal nu/ + thymus. Spleen cells from newborn $n w /+$ mice were ineffective in this respect. These findings were interpreted to indicate permanent production of potentially autoaggressive $T$ cells and their dominant regulatory counterparts in the thymus (Sakaguchi and Sakaguchi, 1988).

The nature of the effector cells that cause pathology in CyA-AI remains an enigma. Hess et al. (1985) have demonstrated that CyA-AI rats have $\mathrm{CD} 8^{+}$cytotoxic $\mathrm{T}$ cells directed to public determinants on rat MHC class II molecules, including their own. In contrast, the data from adoptive transfer studies (Sorokin et al., 1986), the coincidence of reappearance of $\mathrm{CD}^{+} \mathrm{T}$ cells in the periphery and the development of symptoms of disease (Bos et al., 1988, 1989a), and the prevalence of $\mathrm{CD}^{+}$cells over $\mathrm{CD} 8^{+}$cells in target tis- 
sues (Beschorner et al., 1988a), however, sugges! that CD4 $4^{+} \mathrm{T}$ cells play an important role in bringing about the pathology in CyA-AI

\section{Current understanding of CyA-Al}

Lethal or near-lethal irradiation of young rodents, followed by reconstitution with autologous bone marrow or marrow from young syngeneic donors, and administration of CyA for about 5 weeks yield the disease 2-3 weeks after discontinuation of the drug. About $10 \mathrm{~Gy}$ irradiation and CyA are needed at the level of the thymus to "produce" the autoaggressive T cells; about $7.5 \mathrm{~Gy}$ (or treatment with the immunosuppressive drug Cyclophosphamide) suffices to remove a normally prevailing peripheral regulatory $\mathrm{T}$ cell circuit, which is obviously also eliminated by $10 \mathrm{~Gy}$ whole body irradiation (Fischer $\boldsymbol{e t}$ al., 1989a). This suppressor mechanism apparently does not regenerate concomitantly with the generation of the autoaggressive cells. The requirement to use young recipients may reflect different sensitivity of the thymic medulla of young and old rodents to the regimen for induction of CyA-AI (Beschorner $e t$ al., 1987c, and see below). The use of bone marrow cells from young donors on the other hand is mandatory, since marrow from older donors may contain regulatory $T$ cells and/or their precursors which may suppress CyA-AI in vivo (Fischer and Hess, 1990). Manifestation of pathology coincides with the reappearance of the peripheral $\mathrm{CD}^{+} \mathrm{T}$ cell subset (Bos et al., 1988; Fischer et al., 1991) but the effector mechanisms causing the pathology are not yet clear.

In the next part, we will review the composition of the thymus including its microenvironment.

\section{The thymus}

The mammalian thymus is a bilobal structure that lies on the pericardium, the aortic arch and its branches, and the trachea. Each lobe is surrounded by a collagenous connective tissue capsule (Kendall, 1988). At the histological level, three main thymic areas can be defined in each lobe: the subcapsular zone that lies just under the connective tissue capsule; the cortex, which forms the major outer area; and the centrally located medulla (Fig. 1.2). Each area is characterized by a distinctive lymphoid and stromal cell composition (Ritter and Crispe, 1992). At some places the connective tissue capsule intrudes deep into the tissue to the level of the cortico-medullary junction, thus creating septa that divide the organ into many pseudo-lobules. These septa carry both the vascular and neuronal supply to and from the thymus, while branches from the septa give rise to perivascular spaces within the thymus (Ritter and Crispe, 1992). 


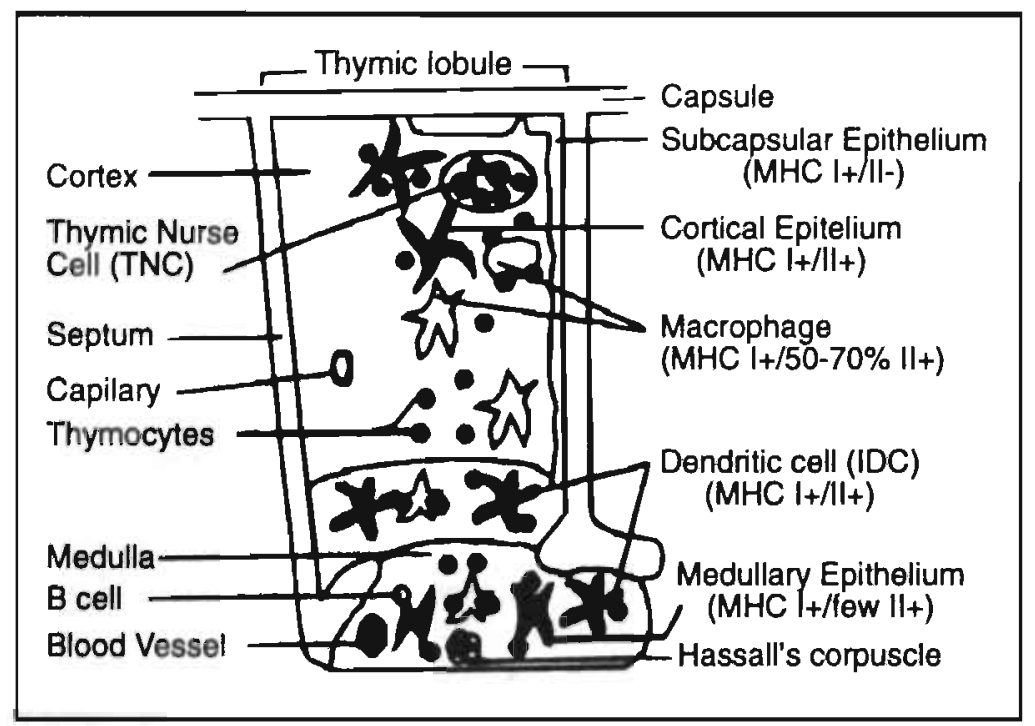

Flgure 1.2: Schematic view of a thymic lobule and its microenvironment. For explanation see text . Reproduced in part from Boyd et al., 1991.

\section{Cellular composition of the thymus}

The most numerous cells in the thymus are (immature) lymphocytes which lie within a framework provided by several types of stromal cells. The major component of this stroma is the epithelium, which is molecularly and functionally heterogenous and provides the structure within which all the other cell types reside (Van Ewijk, 1988; Godfrey et al., 1990).

Monoclonal antibody (MAb) studies have shown 5 major 'clusters of epithelial staining' (CTES) which fit well with morphologically defined epithelial populations within the thymus; expression of MHC antigen depends on the type and localization of epithelial cells. BM-derived macrophages and dendritic cells (interdigitating cells, IDC) form the other major stromal cell populations (Van Ewijk, 1988). Macrophages can be distinguished by differences in their endogenous enzymes, and by their antigenic phenotype defined by MAb's (Milicevic et al., 1989). Additional cell types form minority populations within the thymus, e.g. myoid cells, B lymphocytes, neutro- and eosinophils (Ritter and Crispe, 1992).

\section{Subcapsular region}

Approximately $5 \%$ of thymic lymphoid cells reside in the subcapsular area; these are mainly large blast cells, with high mitotic activity. Epithelial cells in the subcapsular region form a layer one to two cells deep, with the outermost layer lying on the basement membrane. This type of epithelial cells stained with MAb's CTES I and II, expressed 
MHC class I molecules at a high density, but MHC class. II antigen expression was absent (Ritter and Crispe, 1992)(Table 1.1).

Table 1.1: (Sub)populations of thymic cell types.

\begin{tabular}{|c|c|c|}
\hline Cell types & CTES MAb staininga & MHC class it expression 6 \\
\hline \multicolumn{3}{|l|}{ Epithelial cells } \\
\hline subcapsular & 1. 11 & negative \\
\hline cortical (incl. TNC) & I. III & positive \\
\hline medullary & i. IIp, IV, Vp & few positive \\
\hline - Hassall corpuscles & I. II, IV, V & negative \\
\hline Dendritic cells; & & positive \\
\hline \multicolumn{3}{|l|}{ Macrophages } \\
\hline cortical & & $50.75 \%$ positive \\
\hline cortico-medullary & & $50.75 \%$ positive \\
\hline medullary & & $50-75 \%$ positive \\
\hline
\end{tabular}

a CTES, clusters of epithelial staining; p, only a subpopulation is positive. ${ }^{b}$ All cell types expressed MHC class I antigen at a high density on their surface. IReproduced in part from Ritter and Crispe. 19921.

\section{Cortex}

The majority of thymocytes (80-85\%) are found in the cortex. Ninety to $95 \%$ of thymic lymphoid cells are eliminated during $\mathrm{T}$ cell receptor repertoire selection (Scollay et al., 1980). Death occurs by apoptosis, a programmed cell death mechanism whereby endonucleases cleave nuclear DNA into smaller pieces (Wyllie et al., 1984). Cortical thymocytes are mostly small, predominantly non-dividing cells that are closely packed together. Epithelial cells in the cortex (CTES I/III) have very long cytoplasmic processes, forming a network throughout this region of the thymus and expressing both MHC class I and II antigen on their surface (Ritter and Crispe, 1992). Some of these epithelial cells (Thymic Nurse Cells, TNC) appear to completely surround and enclose 10 to 250 lymphocytes (Van Vliet et al., 1984). Macrophages are scattered throughout the cortex and are sometimes surrounded by a rosette of proliferating lymphocytes (Kyewski $e t$ al., 1982). All macrophages expressed MHC class I molecules but only a subpopulation is MHC class II positive (Table 1.1). Fragments of apoptotic cells are predominantly found in cortical macrophages (Kendall, 1990).

\section{Medulla}

The remaining $10 \%$ of thymocytes are located in the medulla. These lymphocytes are very similar to mature peripheral $\mathrm{T}$ lymphocytes in size, phenotype, and functional maturity, and probably represent the end-product of intra-thymic $\mathrm{T}$ cell development. The epithelium of the medulla (CTES I, IIp, IV, V) consists of oval shaped cells with shorter, spatula-like processes that do not form connections with each other as close as 
seen with the epithelial cells in the cortex (Ritter and Crispe, 1992). Medullary epithelial cells are MHC class I positive but only a subpopulation expresses MHC class II antigen on their surface. Concentric whorls of epithelial cells are also found in the medulla. These Hassall's corpuscles vary considerably in size according to the species and are MHC class II negative. Macrophages and dendritic cells are scattered throughout the medulla and both cell types are MHC class I positive. Dendritic cells and a subpopulation of macrophages (50-75\%) expresses also MHC class II antigen on their cell surface (Table 1.1). Myoid cells (containing skeletal muscle-like striations) are found in clusters often closely associated with Hassall's corpuscles. B lymphocytes, many with an immature phenotype, are also found in the medulla (Pabst et al., 1989).

\section{Lymphocyte development}

On entering the thymus from the blood stream, pro-thymocytes ( $\left.\mathrm{CD} 4{ }^{-} \mathrm{CD} 8 \mathrm{CD}^{-}\right)$are induced to undergo a program of proliferation, gene rearrangement, and differentiation under the influence of stromal cells types in various thymic microenvironments and resulting in the production of large numbers of immature double positive $\mathrm{CD} 4^{+} \mathrm{CD} 8^{+}$ (TCR $\alpha B / C D 3$ low) thymocytes expressing a diverse repertoire of $T$ cell receptor (TCR) specificities (Jenkinson et al., 1992). This repertoire is subject to stringent selection and the specificity of the $\alpha \beta$ TCR determines whether cells (1) die a programmed death when the TCR fails to bind to any ligand, (2) are immediately deleted when the TCR binds to self-MHC plus self-peptide (negative selection) or (3) are rescued when the TCR binds to self-MHC ligands in thymic cortical epithelium with foreign peptide (positive selection) (Von Boehmer, 1992). Cortical epithelial cells are involved in "positive selection" of MHC-restricted T cells, whereas interdigitating cells (IDC) and thymic medullary epithelial cells are involved in "negative selection" (Nikolic-Zugic, 1991). Positively selected cells (recognizing self-MHC molecules) are signaled to mature into single positive CD4+CD8 (TCR $\alpha \beta / C D 3$ hi) or $\mathrm{CD} 4{ }^{-} \mathrm{CD}^{+}$(TCR $\alpha \mathrm{B} / \mathrm{CD} 3 \mathrm{hi}$ ) T cells, depending on the specificity of their receptor, i.e. binding specificity for MHC class II-associated peptide or class I-associated peptide respectively (Von Boehmer, 1992).

In the next part, we will review the effects of CyA on the (irradiated) thymus and undertake an attempt to link those to the mechanisms purportedly operative in the CyA-AI model.

\section{Effects of CyA on the non-irradiated thymus.}

The effects of CyA on the thymus are most marked on the medulla; the cortex usually being only marginally affected. One of the earliest observations on the effect of CyA on the thymus was made in mice (Ryffel et al., 1981). Within 4 days after oral administration of a bolus of $250 \mathrm{mg} / \mathrm{kg} \mathrm{CyA} \mathrm{a} \mathrm{marked} \mathrm{reduction} \mathrm{of} \mathrm{thymic} \mathrm{weight} \mathrm{was} \mathrm{recorded.} \mathrm{It}$ 
is striking that in this study the observed effect was ascribed to a depletion of cortical thymocytes, whereas many papers published thereafter stressed the prominent and predominant effect of $\mathrm{CyA}$ on the thymic medulla. Perhaps stress, caused by the single, extremely high dose of CyA used in this study, and its oral administration accounted for this discrepant observation (Clarke and MacLennan, 1986). In favour of the influence of the route of administration is a study in rats in which CyA was administered orally as well at a dose of $100 \mathrm{mg} / \mathrm{kg} / 2$ days for 3 weeks (Thomson et al., 198i). In this report, neither macroscopic or histological abnormalities, nor a significant effect on thymic weight was noticed as compared to controls. Only in the peripheral blood of the CyA-treated rats lymphopenia and the appearance of atypical lymphocytes was recorded. On the other hand, when normal LEW rats were given 7.5-100 mg CyA/kg/day subcutaneously a rapid depletion of the medullary thymocytes was observed (Schuurman et al., 1990). After 50 $\mathrm{mg} \mathrm{CyA} / \mathrm{kg} /$ day for 2 weeks distinct medullary regions were almost absent from the thymus (Beschorner et al., 1988d). Both in this study and in the last afore-mentioned the thymic architecture was restored within 3 weeks after withdrawal of CyA. The observation on the predominant effect of CyA on the thymic medulla was, however, confirmed in a study in which the oral route was used for Cy A administration. After feeding rats a diet containing $0.015 \%$ CyA for $8-10$ weeks thymic involution was evident. Cortical atrophy was only slight, but medullary atrophy was scored as moderate and in some rats even no remnants of the thymic medulla were detected at all (Demetris et al., 1984). Thus, it appears that subcutaneous administration of CyA exerts stronger effects on the thymus than oral administration, although prolonged feeding of CyA may cause comparable damage, especially to the medulla.

\section{Effect on medullary stromal cells}

CyA has been shown to exert its main effect on the thymic medulla which is composed of lymphocytes, epithelial cells, macrophages, dendritic cells, and histiocytes. Although the medulla is considerably reduced in size due to CyA administration, representatives of all normal medullary components were still present. The CyA-induced damage of the medulla was reflected in decreased numbers of macrophages (Kanariou et al., 1989), and loss of dendritic cells and histiocytes (Beschorner et al., 1987b; Kanariou et al., 1989). Probably at least in part associated with the loss of the above-mentioned cell types was a reduced expression of MHC class II molecules in the medulla (Beschomer et al.,1987a, 1987b, 1987c; Kanariou et al., 1989; Schuurman et al., 1990), a general decrease in (keratin ${ }^{+}$) epithelial cells (Hattori et al., 1987, Kanariou et al., 1989), ablation of epithelium of Hassall's corpuscles (Beschorner et al., 1987b, 1987c; Linder, 1987) and reduced MHC class I expression (Linder, 1987; Tanaka et al., 1988; Majoor and Van Breda Vriesman, 1989).

\section{Effect on cortical stromal cells}

The thymic cortex of CyA-treated animals was morphologically indistinguishable from that of control animals although increased numbers of epithelioid cells containing pyknotic nuclear debris (Demetris et al., 1984) and disorganization of the reticular tis- 
sue (Fein et al., 1989) have been reported. Although the distribution of cortical macrophages did not change significantly, their morphology and enzyme histochemistry altered markedly (Milicevic et al., 1989).

Many of the above-cited reports stress the striking reversibility of the aberrations observed; usually within 2-3 weeks after withdrawal of CyA the thymus had regained its normal architecture.

\section{Effects on T lymphocyte development}

Already in early reports on the effects of CyA in vivo a peripheral lymphopenia was noticed which was associated with the appearance of atypical, blast-like lymphocytes (Thomson et al., 1981). Possibly, these cells represented the peripheral lymphocyte population later identified as carrying both the CD4 and the CD8 T cell surface molecules $\left(\mathrm{CD}^{+}{ }^{+}\right)$(Godden et al., 1985). According to this report, both CyA and a (vascularized henrt) graft were necessary to generate these cells, which could constitute up to $40 \%$ of the peripheral leukocyte population. In the study of Thomson et al. (1981) sheep red blood cells, adninistered to evaluate the immunosuppressive effect of CyA, may have substituted for the role of the graft as proposed in the work of Godden et al. (1985).

Double positive $\mathrm{CD} 4{ }^{+} 8^{+} \mathrm{T}$ cells have also been reported to be present in rats with $\mathrm{CyA}-$ AI (Hess et al., 1987). As long as CyA is administered after lethal irradiation and marrow reconstitution the absolute and relative numbers of peripheral $\mathrm{CD} 4^{+}$cells are markedly reduced, whereas CD8 ${ }^{+}$cell numbers are less clearly affected (Hess et al., 1987; Bos et al., 1988; Fischer et al., 1991). However, in the periphery of these rats (and of unirradiated, CyA-treated rats) $20-30 \%$ of the $\mathrm{T}$ cells were shown to have the $\mathrm{CD} 4^{+} \mathrm{CD} 8^{+}$ phenotype (Hess et al., 1987). Most investigators consider the release of $\mathrm{CD}^{+} 8^{+}$ thymocytes into the circulation unusual (Scollay et al., 1984), although others have defended this export from the thymus to play a role in the clearing of $\mathrm{CD} 4{ }^{+} 8^{+} \mathrm{T}$ cells with unwanted specificities from the body (Rothenberg, 1990). On the other hand, the failure of $\mathrm{CD}^{+} 8^{+}$cells to continue their normal development in the thymus in the presence of CyA has been firmly established. In rodents CyA treatment was shown to reduce the number of single positive $\mathrm{CD}^{+}$and especially $\mathrm{CD}^{+}$cells in the thymus (Beschorner $e t$ al., 1987a; Heeg et al., 1989; Hiramine et al., 1988; Hiramine et al., 1989; Kanariou et al., 1989; Sakaguchi and Sakaguchi, 1989; Bucy et al., 1990). These findings were corroborated by studies using mouse fetal thymus organ cultures, which demonstrated an almost complete inhibition of development of single positive $\mathrm{CD}^{+}$and $\mathrm{CD}^{+}$cells in the presence of CyA (Kosugi et al., 1989b; Matsuhashi et al., 1989; Takeuchi et al., 1989, Siegel et al., 1990). Furthermore, these in vitro studies demonstrated that the development of CD $3^{+} 4^{-1}$ TCR $^{-} \mathbf{B}^{-}$(TCR $\gamma^{+}$?) T cells was not interfered with by CyA (Kosugi et al., 1989b; Matsuhashi et al., 1989; Siegel et al., 1990); that MHC class II ${ }^{+}$cells do not disappear under these culture conditions (Takeuchi et al., 1989; Siegel et al., 1990); and finally that IL-1B, IL-2 and IL-4 are unable to reverse the arrest in the development of $\mathrm{CD}^{+}$and $\mathrm{CD}^{+}$single positive cells from their double positive precursors (Siegel et al., 1990). Another recent in vitro observation pertinent to the role of the thymus in T cell development is the observation that $\mathrm{CD}^{+} 8^{+}$thymocytes bind preferentially to thymic 
(medullary) epithelial cell lines and may be eliminated by those cells (Hugo and Potworowski, 1990; Nakashima et al., 1990).

\section{Effects of CyA on the irradiated thymus}

The effects of lethal irradiation on the thymus are most prominent at the level of the cortex where most of the thymocytes are lost (Aoyama et al., 1972). Interdigitating cells and macrophages in both cortex and medulla do not disappear (Duijvestijn et al., 1982). On the other hand, induction of clonal deletion (presumably executed by dendritic cells (Lo and Sprent, 1986)) has been shown to be X-irradiation-sensitive whereas induction of clonal anergy is X-irradiation-resistant (Roberts et al., 1990).

Cortical thymocytes are rapidly reconstituted from a syngeneic bone marrow graft (Beschorner et al., 1982). Apparently, the regeneration of the cortex is not significantly influenced by doses of CyA as used in rodent experimental protocols. With respect to CyA-mediated changes in the thymic medulla, irradiation (whether followed by reconstitution or not) does not significantly alter the picture as described for the non-irradiated thymus (Cheney and Sprent, 1985; Beschorner et al., 1987a, 1987c). However, whereas the non-irradiated thymus recovers within about 3 weeks after discontinuation of CyA, the irradiated thymus at 6 weeks after drug withdrawal still lacks medium-sized thymocytes and contains only very few subcapsular thymocytes, medullary histiocytes and medullary thymocytes. Furthermore, MHC class $\mathrm{II}^{+}$epithelial cells were not detected in the medulla (Beschorner et al., 1987c; Parfrey and Prud'homme, 1990). Thus, although CyA brings about comparable changes in irradiated and non-irradiated thymuses, the main effect of irradiation prior to CyA treatment appears to be on the pace at which the thymus recovers after CyA withdrawal.

T cell maturation in the irradiated, CyA-treated thymus is affected much akin to the way described for the non-irradiated thymus. Hess et al. (1987) noticed a relative increase of CD4 - double negative cells in the thymus concomitant with a relative decrease of $\mathrm{CD}^{+}{ }^{+}{ }^{+}$positive cells as compared with controls. Combined with the virtual absence of single $\mathrm{CD}^{+}$cells from the thymus, these authors suggested an incomplete (or shifted) differentiation of $\mathrm{T}$ lymphocytes in the thymus of CyA-treated rats. These data were soon thereafter corroborated and extended by studies in mice. Irradiated ( $8.5 \mathrm{~Gy}$ ) C57BR mice reconstituted with autologous bone marrow cells were given CyA $(20 \mathrm{mg} / \mathrm{kg} /$ day $)$ for 23 days. Phenotype analysis of the thymocytes shortly after discontinuation of drug administration revealed inhibition of the development of $\mathrm{CD}^{+}$and $\mathrm{CD} 8^{+}$single positive, TCR $\alpha \mathrm{B}^{+}$ thymocytes. On the other hand, the development of $\mathrm{CD} 48$, TCR $\gamma \delta^{+}$thymocytes was not interfered with. Moreover, it was shown that, unlike in controls, cells carrying TCR's of the VB17a family [which are potentially (anti-MHC class II) autoreactive in this strain] were not deleted in the CyA treated mice (Jenkins et al., 1988). This study was almost simultaneously confirmed by Gao et al. (1988) who showed essentially the same phenom- 
enon in $6.0 \mathrm{~Gy}$ irradiated $(\mathrm{B} 6 \times \mathrm{CBA} / \mathrm{Ca}) \mathrm{F} 1$ mice which were not reconstituted and given $10 \mathrm{mg} \mathrm{CyA} / \mathrm{kg} /$ day for 21 days. Also for the mouse strain used in this study, the failure of the thymus to eliminate cells carrying the anti-self MHC class II (I-E) VB11 TCRs was demonstrated. A protocol comparable to that used in the two last-cited studies was also shown to result in a complete absence of mature $\mathrm{T}$ cells from the spleen. Furthermore, in this study no effects were noticed on the generation of $\mathrm{CD}^{+} 8^{+}$thymocytes, on the expression of additional surface molecules on CD4-8 thymocytes (i.e. CD3, Thy-1, the $\Pi-2$ receptor and phagocyte glycoprotein 1 (Pgp-1), and on B cell development (Kosugi et al., 1989a).

The data on the effects of CyA on either the irradiated and the non-irradiated thymus yield a consistent picture. Damage is predominantly inflicted on the medulla and includes both the medullary thymocytes and the stromal cells. The observation that rodents subjected to high-dose irradiation of either the whole body or only the thymus fail to restore the thymic architecture soon after CyA withdrawal suggests a crucial role of the thymic medulla in the development of CyA-AI since non-irradiated animals do not develop disease, although the initial damage to their thymus is comparable (Beschorner $e t$ al., 1987c). This suggestion is supported by the finding that CyA-AI is hard to induce in adult rodents (Beschorner et al., 1988d; Fischer and Hess 1990; Bryson et al., 1989). The thymic medulla of adult rodents is less severely affected by CyA and consequently is still present to some extent at the time of discontinuation of CyA (Beschorner et al., 1987c; Parfrey and Prud'homme, 1990).

Damage to the thymus is associated with a virtually complete arrest of differentiation of $\mathrm{CD}^{+} 8^{+}$thymocytes into $\mathrm{CD}^{+}$and $\mathrm{CD}^{+}$single positive cells in the presence of $\mathrm{CyA}$. However, if in vivo $\mathrm{CyA}$ blood levels decline, especially $\mathrm{CD}^{+}$single positive cells reappear in the periphery, and CyA-AI begins to develop (Bos et al., 1988; Fischer et al., 1991). This CD4+ $\mathrm{T}$ cell subset is capable to transfer the disease to irradiated secondary recipients (Sorokin et al., 1986). The less striking effect on the $\mathrm{CD}^{+} \mathrm{T}$ cell subset may be due to release of cells intermediary in the development of $\mathrm{CD}^{-1} 8^{-}$to $\mathrm{CD}^{+} 8^{+}$, which have the CD4 $8^{+}$phenotype (MacDonald et al, 1988). The work reported by Jenkins $e t$ al. (1988) and Gao et al. (1988) strongly suggests that the medulla of the irradiated thymus may fail to eliminate potentially autoaggressive clones among $\mathrm{CD} 4{ }^{+} 8^{+}$cells when the development of these cells to single positive $\mathrm{T}$ cells is resumed after CyA withdrawal. Also experiments in which CD4 molecules were blocked by antibodies or in which transgenic mice were used indicated that deletion of potentially autoaggressive $T$ cells occurs at the $\mathrm{CD}^{+} 8^{+}$phenotypic stage (Fowlkes, et al., 1988; Kisielow et al., 1988). Provided normally existent regulatory circuits are eliminated (by irradiation or immunosuppressive chemotherapy (Fischer et al., 1989) or are constitutively absent (like in nude mice; Sakaguchi and Sakaguchi, 1988), CyA-AI may become manifest.

The rapidly growing insight into the normal processes of negative and positive selection of $T$ cells in the thymus opens new perspectives to interpret the disturbance of this process by CyA. The last paragraph will deal with this issue and advance some hypotheses on the mechanisms by which autoreactive cells may cause pathology in CyA-AI as well as on 
the induction of the regulatory mechanism normally prohibiting autoreactive cells as active in CyA-AI.

\section{Synthesis and hypotheses}

The elegant work of Von Boehmer, $\mathrm{LO}$, and their colleagues using transgenic mice (Kisielow et al., 1988; Teh et al.; 1988; Sha et al., 1988; Van Ewijk, 1990; Von Boehmer, 1990, 1992) has corroborated and extended earlier work on the role of the thymus in tolerance induction ("negative selection") (Kappler et al., 1987, 1988; MacDonald et al., 1988) and the promotion of useful, MHC-restricted, antigen-reactive T cell clones ("positive selection") (Bevan et al., 1977; Zinkernagel et al., 1978; Marusic-Galesic et al., 1989; Zuniga-Pflucker et al., 1989). In both selection processes MHC molecules expressed in the thymus appear to play a crucial role (Kruisbeek et al., 1985; Rouse et al., 1985; Lo and Sprent 1986; Schuurman et al., 1986, Fowlkes, et al., 1988; Salaun et al., 1990). For instance with respect to $\mathrm{CD}^{+} \mathrm{T}$ cells, those showing too strong affinity for self-MHC class II molecules (either alone or in association with a self-peptide) are deleted (Von Boehmer, 1986; MacDonald and Lees, 1990) and those escaping may be extrathymically suppressed or eliminated (Kimura and Wilson, 1984). On the other hand, TCR's able to recognize MHC molecules alone with low affinity (but which might exhibit high affinity for the same molecule in association with an antigenic peptide) are allowed to proceed their development, to leave the thymus and to become part of the $T$ cell repertoire. The specificity of the TCR for thymic MHC class I or class II molecules determines whether the cell will have the $\mathrm{CD} 48^{+}$or $\mathrm{CD} 4{ }^{+} 8^{-}$phenotype, respectively (Von Boehmer, 1986, 1992; Kruisbeek et al., 1988; Sha et al., 1988; Teh et al., 1988).

The marked and persistent reduction of MHC class II antigen expression in the medulla of irradiated young rodents after a course of CyA suggests a causal relationship with the failure of the thymus to delete autoaggressive $\mathrm{CD}^{+} \mathrm{T}$ cells. As long as $\mathrm{CyA}$ is administered, the arrest in the development of $\mathrm{CD}^{+}$cells might in addition be ascribed to an effect of CyA on TCR-initiated signal transduction for lymphokine synthesis, which may be necessary for T cell differentiation (Gauchat et al., 1986; Bucy et al., 1990; GranelliPiperno, 1990; Kimball et al., 1990). After withdrawal of CyA the block in T cell development might become weaker while the expression of MHC class II molecules is still defective. Under those circumstances, however, one would expect both positive and negative selection to fail or to proceed incompletely. The failure of the thymus in negative selection is clearly demonstrated in the CyA-AI model. The observation that conventionally bred animals are more likely to die from CyA-AI than specific pathogen-free bred rats (Sorokin et al., 1986) might be interpreted as indicative for a defective positive selection. Another effect of CyA on T cell development was suggested by Shi et al. (1989). These authors have demonstrated the inhibition of activation-induced cell death (apoptosis) by CyA. However, if this mechanism would generate the effector cells for CyA-AI, it is 
puzzling why the autoaggressive cells do not manifest themselves prior to the disappearance of CyA from the circulation (Bos et al., 1989d). Others have suggested that CyA might keep these cells dormant when already present in the periphery (Wilson, 1989), and we also proposed that autoaggressive $\mathrm{T}$ cells are generated during $\mathrm{CyA}$ administration, but these inducer/effector cells remain ineffective due to the immunosuppressive activity of CyA (Wodzig et al., 1991; this thesis chapter 5). Further experiments will be needed to dissociate the effects of CyA-mediated reduction of MHC class II antigen expression in the thymic medulla from other effects of $\mathrm{CyA}$ on $\left(\mathrm{CD} 4^{+}\right) \mathrm{T}$ lymphocyte maturation.

The effects of $\mathrm{CyA}$ on the development of $\mathrm{CD} 8^{+}$cells is less clear. Although the development of $\mathrm{CD}^{+} 8^{+}$cells to $\mathrm{CD} 4^{-} 8^{+}$cells is blocked under CyA (Jenkins et al., 1988; Gao et al., 1988), this is not as readily reflected in the periphery as the block in $\mathrm{CD} 4^{+}$thymocyte generation (Hess et al., 1987; Bos et al., 1988). This may partly be due to confusion of mature $\mathrm{CD}^{+}$cells and immature (CD3'?) $\mathrm{CD} 8^{+}$thymocytes (an intermediate in the transition of $\mathrm{CD} 48^{-}$to $\mathrm{CD} 4^{+} 8^{+}$cells) which may escape from the thymus. Moreover, distinct mechanisms for the induction of tolerance to extrathymic antigens have been suggested for class I-restricted (CD8+) and class II-restricted (CD4 ${ }^{+}$) T cells (Morahan et al., 1989). Therefore, we favour the view that in CyA-AI the primary defect is the failure of the thymus to negatively select precursors of autoreactive $\mathrm{CD}^{+} \mathrm{T}$ cells. We have shown that during CyA therapy autoreactive inducer/effector $\mathrm{T}$ cells are generated in and exit from the thymus, because thymectomy immediately after CyA discontinuation could not prevent CyA-AI (Sorokin et al., 1986; Wodzig et al., 1991; this thesis chapter 6). Thus, at the time of CyA withdrawal autoreactive cells reside in a dormant state in the periphery. We suggested that after withdrawal of $\mathrm{CyA}$ and the decline of its in vivo concentration (Bos et al., 1988) the thymus resumes its function of producing mature $\mathrm{CD}^{+}$and $\mathrm{CD} 8^{+} \mathrm{T}$ cells. Due to the failure of the thymic medulla to timely restore adequate $\mathrm{MHC}$ class II expression (Beschorner et al., 1987c), possibly on a certain cell type(s) (Hugo and Potworowski, 1990), $\mathrm{CD}^{+} \mathrm{T}$ cells escape from negative selection. Once these cells enter the periphery they may cooperate with potentially autoreactive lymphocytes which are also present in unmodified individuals. For B cells this assumption is corroborated by data from the model of Sakaguchi and Sakaguchi (1988), in which pathology (by lack of effector T cells?) is predominantly autoantibody-mediated. A comparable mechanism has been proposed to explain humoral immune responses to autoantigens (Mason, 1985). Also in the rat CyA-AI has been demonstrated to be associated with autoantibody responses (Verschuuren et al., 1989; Wodzig et al., 1990; this thesis chapter 4). By analogy, we presume that potentially autoreactive $\mathrm{CD}^{+}$(delayed-type hypersensitivity?) and/or $\mathrm{CD}^{+}$ (cytotoxic) (Hess et al., 1985) T cells (generated during CyA administration) are activated by aberrant $\mathrm{CD} 4^{+}$inducer/helper $\mathrm{T}$ cells to become autoaggressive effector cells which respond to target structures expressing self-MHC antigens.

The data from two studies seem to contradict the hypothesis presented above. The mechanism proposed implies that at the time of discontinuation of CyA 1) the thymus should already have generated autoreactive inducer/effector cells of CyA-AI, and 2) that such cells leave the thymus and reside quiescent in the periphery. Data reported by Beschomer et al. (1988a) showed that thymocytes from rats with $\mathrm{CyA}-\mathrm{Al}$ are able to transfer the 
disease to secondary recipients. However, these thynnocytes were collected 30 days after the discontinuation of $\mathrm{CyA}$ in the primary recipients. Therefore, autoreactive (CD4+ helper) $\mathrm{T}$ cells are likely to have started their attack on target structures. We explained this discrepancy by the presence of migrating effector cells re-entering the thymus to destroy target cells, i.e. expressing MHC class II antigens (Hess et al., 1985). Furthermore, in the secondary recipients disease became manifest only about 5 weeks after the adoptive transfer. Although at that time the thymuses of the secondary recipients had pathological changes, a considerable period must have been available for generating and exporting $\mathrm{T}$ lymphocytes representing the normal TCR repertoire, including potentially autoreactive ones.

The other study which presented data apparently contradicting our hypothesis is that of Cheney and Sprent (1985). These authors showed adoptive transfer of CyA-AI in mice by spleen plus lymph node cells harvested one day after discontinuation of CyA. It was stated that upon adoptive transfer of a non-specified number of lymphoid cells "acute, fatal GVH disease" developed. This observation was presented together with another, quite puzzling one regarding the possibility to transfer $\mathrm{CyA}-\mathrm{AI}$ with lymphoid cells obtained from non-irradiated mice treated with CyA. However, since primary recipients of CyA did not manifest CyA-AI [probably because the peripheral regulatory circuit(s) were not eliminated (Fischer et al., 1989)] it is hard to understand how transfer of effector cells plus regulatory $\mathrm{T}$ cells would permit the development of disease in the secondary recipients. Possibly other factors [e.g. the microbiological status of the mice (Sorokin et al., 1986) influenced the observations made in these transfer experiments. Admittedly, if the data from these experiments were to be reproduced, the model proposed by us would be invalidated.

If one accepts the hypothesis presented above, the search for possible organ-specific target antigens in CyA-AI would become senseless. The finding that pathology (especially in the chronic phase) is confined to certain organs alternatively might be explained by interaction of cell surface molecules invelved in homing or recruitment on local endothelial cells and lymphocytes (Berg et al., 1989; Pals et al., 1989). The striking similarity of the pathology in especially the acute phases of CyA-Al and GVH disease would than become rather an example of homology than of analogy. In GVH disease, damage to thymic medullary epithelial cells (Seemayer et al., 1978) may hamper negative selection in a way akin to that was surmised to occur in CyA-AI and consequently yield very similar pathology (Bos et al., 1989c, 1990; Van Bekkum, 1990).

As an alternative to our hypothesis presented above, Sakaguchi $e t$ al. (1985) have suggested that the pathology in CyA-AI might be caused by Thy $1^{+}$CD $4.8 \cdot\left(\right.$ TCR $_{\gamma} \hat{\sigma}^{+}$?) effector cells. Such cells would normally be controlled by autoregulatory $\mathrm{CD}^{+}$and $\mathrm{CD} 8^{+}$single positive TCR $\alpha B^{+} T$ cells but might become harmful if these regulatory cells are absent or underrepresented (Sakaguchi and Sakaguchi 1988; Marcos et al., 1988; Heeg, et al., 1990). Alternatively, their elimination in the thymus akin to that of TCR $\alpha \mathrm{B}^{+}$autoaggressive T cells might be affected by CyA (Dent et al., 1990). Recently, from a patient with combined immunodeficiency a CD4.CD8 ${ }^{-} \mathrm{TCR}^{-} \mathrm{B}^{+} \mathrm{T}$ cell clone was isolated; this patient 
exhibited GVH-like pathology (Brooks et al., 1990). Both in vivo and in vitro the generation of thymocytes with the CD4.8 phenotype has been shown not to be affected by CyA (Jenkins et al., 1988; Kosugi et al., 1989a; Matsuhashi et al., 1989). The export of $\mathrm{CD}^{+} 8^{+}$cells from the thymus further suggests the possible release of other, earlier developmental stages including CD4-8 thymocytes. Conceivably, their presence in the periphery may be easily overlouked. Therefore, the hypothesis that "uncontrolled" CD4-8 TCR $\gamma \delta^{+}$and/or TCR $\alpha B^{+}$cells are causal to the tissue damage in CyA-AI needs further investigation.

Finally, and possibly most importantly in terms of the clinical relevance of the research on these models, the strong autoregulatory circuit(s) which easily nullifies the effects of transfer of CyA-AI effector cells to normal animals should be discussed. Wilson (1989) has drawn attention to the similarity with a autoregulatory circuit revealed in the model of induced GVH resistance using allogeneic cells. In this model, control of GVH reactivity was shown at least in part to be exerted by cytotoxic $T$ cells directed against $T$ cells carrying a TCR reactive with self MHC class II determinants (Kimura and Wilson, 1984a). In this anti-autoreactive circuit, like in that controlling CyA-AI effector cells (Fischer $e t$ al., 1989b), both $\mathrm{CD}^{+}$and CD8 cells were shown to be involved (Kimura et al., 1984b). However, if such regulatory clones are supposed to be normally elicited in the thymus concomitantly with the generation of positively selected $\mathrm{T}$ cells (Sakaguchi and Sakaguchi, 1988), it is difficult to understand why this process would fail to (re)occur in the recovering thymus in CyA-AI. We suggest, in analogy to the model proposed for the activation of autoaggressive effector mechanisms, that the precursors of this suppressive circuit are generated (as part of the repertoire) in the thymus, but that this circuit is only activated in the periphery upon encountering the antigen, e.g. the anti-self MHC TCR. The data of Sakaguchi and Sakaguchi (1988) showing that co-transplantation of normal thymocytes with a $n w+$ thymus from a CyA-treated donor to a $n w / n u$ recipient prevents the development of CyA-AI are not necessarily contradictive to this hypothesis. In their model, administration of CyA to the donor thymus is abrupted by its transplantation, so thymic recuperation may proceed much faster than observed after withdrawal of CyA in the same host. Consequently, suppressor circuit precursors may be generated in time to prevent CyA-AI. Thus, the data presently available do not contradict "anti-idiotypic" (autoregulatory) responses to autoreactive $\mathrm{T}$ cells in the peripheral lymphoid organs of unmodified animals. In $\mathrm{CyA}-\mathrm{AI}$, where these organs are initially atrophic, the expansion and the effects of autoaggressive clones may have proceeded too far before this counteractive circuit can become adequately activated.

The discussion above confirms that the model of CyA-AI is very intriguing and will in the near future definitely contribute to our understanding of $T$ cell maturation and selection in the thymus. Moreover, it may help to elucidate the mechanisms (in control) of GVH disease and autoimmunity. 


\section{References}

Aoyama T, Kawamoto Y, Furuta I and Kondo T (1972). Early morphological changes in cortical medullary thymocytes of the rat after whole-body irradiation. 1. Electron microscope observations. International Journal of Radiation Biology 6: 545-551.

Bacigalupo A, Malolino A, Van Lint MT, Occhini D, Gualandl F, Clavio M et al. (1990). Cyclosporin A and chronic graft-versus-host disease. Elone Marrow Transplant 6: 341-344.

Belkum DW van (1990). Comments on syngeneic GVHD. Immunology Today 11: 107.

Berg EL, Goldstein LA, Jultila MA, Nackache M, Plcker LJ, Streeteir PR, $t$ al. (1989). Homing receptors and vascular addressins: Cell adhesion molecules that direct lymphocyte traffic. Immunological Reviews 10: 5-18.

Beschorner WE, Tutschka PJ and Santos GW (1982). The sequential morphology of acute graft-versus-host disease in the rat radiation chimera. Clinical Immunology and Immunopathology 22: 203-224.

Beschormer WE, Namnoun JD, Hess AD (1987a). Immunopathology of rat thymus after Cyclosporine A. Transplantation Proceedings 19: 1230-1235.

Beschorner WE, Namnoun JD, Hess AD, Shinn CA and Santos GW (1987b). Cyclosporin A and the thymus. Immunopathology. American Journal of Pathology 126: 487-496.

Beschorner WE, DiGennaro KA, Hess AD, Santos GW (1987c). Cyclosporine and the thymus: Influence of irradiation and age on thymic immunopathology and recovery. Cellular Immunology 110: 350-364.

Beschorner WE, Hess AD, Shinn CA, Santos GW (1988a). Transfer of cyclosporine-associated syngeneic graft-versus-host disease by thymocytes. Resemblance to chronic graft-versushost disease. Transplantation 45: 209-215.

Beschorner WE, Olson JL, Hess AD, DIGenarro KA, Santos GW (1988b). Cyclosporine-induced cell-mediated injury of the thymic medullary epithelium. Transplantation 45: 797 803.

Beschorner WE, Shinn CA, Fischer AC, Santos GW, Hess AD (1988c). Cyclosporine-induced pseudo graft-versus-host disease in the early post-cyclosporine period. Transplantation 46: $112 S-117 S$.

Beschorner WE, Suresch DL, Shinozawa T, Santos GW, Hess AD (1988d). Thymic immunopathology after cyclosporine: Effect of irradiation and age on medullary involution and recovery. Transplantation Proceedings 20: 1072-1078.

Beschorner WE, Ren H, Phillips J, Pulldo, Jr. HB, Hruban RH, Hess AD (1991). Prevention of syngeneic graft-versus-host disease by recovery of thymic microenvironment after cyclosporine. Transplantation 52: 668-674.

Bevan MD (1977). In a radiation chimera host $\mathrm{H}-2$ antigens determine the immune responsiveness of donor cytotoxic T cells. Nature 269: 417-419.

Bllingham RE (1967-1968). The biology of graft-versus-host reactions. Harvey Lectures 62: 2178.

Boehmer $H$ von (1986). The selection of the $\alpha B$-heterodimeric $T$-cell receptor for antigen. Immunology Today 7: 333-336. 
Dochmer H won (1990). Learning by the immune system studied in $T$ cell receptor transgenic mice. In Thymusi Update, volume 3, edited by MD Kendall and MA Ritter, London: Harwood Academic Publishers.

Boehmer H von (1992). Thymic selection: a matter of life and death. Immunology Today 13:454 458.

Bolton C, Allsopp G, Cumer ML (1982). The effect of cyclosporin A on the adoptive transfer of experimental allergic encephalomyelitis in the Lewis rat. Clinical and Experimental Immunology 47: 127-132.

Bos GMJ, Majoor GD, Breda Vriesman PJC van (1988). Cyclosporin A induces a selective, reversible suppression of T-helper lymphocyte regeneration after syngeneic bone marrow transplantation: association with syngeneic graft-versus-host disease in rats. Clinical and Experimental Immunology 74: 443-448.

Bos CMJ, Majoor GD, Breda V riesman PJC van (1989a). Perturbation of T-cell differentiation in lethally irradiated rats reconstituted with syngeneic bone marrow and treated with cyclos porin-A. Thymus 14: 155-161.

Bos GMJ, Majoor GD, Gaar M-J van de, Breda Vriesman PJC van (1989b). T-helper lymphocytes and syngeneic graft-versus-host disease. Transplantation Proceedings 21 : 3016-3017.

Bos GMJ, Majoor GD, Slaat DW, Gaar M-JWH, Weljmer-van Velzen JS, Breda Vriesman PJC van (1989c). Similarity of scleroderma-like skin lesions in allogeneic and syngeneic bone marrow transplantation models. Transplantation Proceedings 21: 3262-3263.

Bos GMJ, Majoor GD, Willighagen RGJ, Breda Vriesman PJC van (1989d). Chronic cyclosporine-induced autoimmune discase in the rat: a new experimental model for scieroderma. Journal of Investigative Dermatology 93: 610-615.

Bos GMJ, Majoor GD, Breda Vriesman PJC van (1990). Graft-versus-host disease: The need for a new terminology. Immunology Today 11: 433-436.

Boyd RL and Hugo P (1991). Towards an intergrated view of thymopoiesis. Immunology Today 12: 71-79.

Brooks EG, Wirt PW, Goldblum RM, Vaidya S, Asuncion MT, Patterson JC, et al. (1990). Double-negative (CD4 ${ }^{-8}$ ) T cells with an $\alpha \beta$ T cell receptor. Non-MHC-restricted cytolytic activity and lymphokine production. Journal of Immunology 144: 4507-4512.

Bryson JC, Jennings CD, Caywood BE, Kaplan AM (1989). Induction of a syngeneic graftversus-host disease-like syndrome in DBA/2 mice. Transplantation 48: 1042-1047.

Bucy RP, Li J, Yan Xu X, Char D, Chen C-H (1990). Effect of cyclosporin A on the ontogeny of different T cell sublineages in chickens. Journal of Immunology 144: 3257-3265.

Cheney RT and Sprent J (1985). Capacity of cyclosporine to induce auto-graft-versus-host disease and impair intrathymic T cell differentiation. Transplantation Proceedings 17: 528530.

Chow LH, Mosbach-Ozmen L, Ryffel B, Borel JF (1988). Syngeneic graft-versus-host disease induced by cyclosporine - a reappraisal. Transplantation 46: 107S-112S.

Clarke AG and MacLennan KA (1986). The many facets of thymic involution. Immunology Today 7: 204-205.

Demetris AJ, Nalesnik MA, Kum HW, GIII TJ III, Shinoeuka S (1984). Sequential analysis of the development of lymphoproliferative disorders in rats receiving cyclosporine. Transplantation 38: 239-246. 
Dent AL, Matis LA, Hooshmand F, WidackI SW, Bluestone JA, Hedrick SM (1990), Selfreactive $\gamma \delta$ T cells are eliminated in the thymus. Nature 343: 714-718.

Duljvestljn AM, Kohler YG, Hoefsmit ECM (1982). Interdigitating cells and macrophages in the acute involuting rat thymus: an electron microscopic study on phagocytic activity and population development. Cell and Tissue Research 224: 291-301.

Ewijk W van (1988). Cell surface topography of thymic microenvironments. Laboratory Investigation 59: 579-590.

Ewijk W van, Kisielow P, Boehmer H von (1990). Immunohistology of T cell differentiation in the thymus of $\mathrm{H}$ - $Y$-specific $\mathrm{T}$ cell receptor $\alpha \beta$ transgenic mice. European Journal of Immunology 20: 129-137.

Fischer AC, Beschorner WE, Hess AD (1989a). Requirements for the induction and adoptive transfer of cyclosporine-induced syngeneic graft-versus-host disease. Journal of Experimental Medicine 169: 1031-1041.

Fischer AC, Laulis MK, Horwitz L, Beschomer WE, Hess AD (1989b). Host resistance to cyclosporine induced syngeneic graft-versus-host disease. Requirement for two distinct lymphocyte subsets. Journal of Immunology 143: 827-832.

Fischer AC and Hess AD (1990), Age-related factors in cyclosporine-induced graft-versus-host disease: regulatory role of marrow-derived T lymphocytes. Journal of Experimental Medicine 172: 85-94.

Fischer AC, Laulis MK, Horwitz L, Hess AD (1991). Effect of cyclosporine on T lymphocyte development. Relationship to syngeneic graft-versus-host disease. Transplantation 51: 252-259.

Fowlkes BJ, Schwartz RH, Pardoll DM (1988). Deletion of self-reactive thymocytes occurs at a CD4+8+ precursor stage. Nature 334: 620-623.

Gao E-K, Lo D, Cheney R, Kanagawa O, Sprent J (1988). Abnormal differentiation of thymocytes in mice treated with cyclosporin A. Nature 336: 176-179.

Gauchat J-F, Khandjian EW, Weil R (1986). Cyclosporin A prevents induction of the interleukin 2 receptor gene in cultured murine thymocytes. Proceedings of the National Academy of Sciences USA 83: 6430-6434.

Geller RB, Eso AH, Beschorner WE, Frondoza CG, Santos GW, Hess AD (1989). Success$\mathrm{ful}$ in vitro graft-versus-tumor effect against an la-bearing tumor using cyclosporin-induced syngeneic graft-versus-host disease in the rat. Blood 74: 1165-1171.

Glazer A, Tutschka PJ, Farmer E (1983a). Studies on the immunobiology of syngeneic and autologous graft-versus-host disease in cyclosporine-treated rats. Transplantation Proceedings 15: 3035-3041.

Glazer A, Tutschka PJ, Farmer ER, Santos GW (1983b). Graft-versus host disease in cyclosporin A-treated rats after syngeneic and autologous bone marrow reconstitution. Journal of Experimental Medicine 158: 1-8.

Godden U, Herbert J, Stewart RD, Roser B (1985). A novel cell type carrying toth Th and Tcl d markers in the blood of cyclosporine-treated, allografted rats. Transplantation 39:624 628.

Godfrey DI, lzon DJ, Tucek CL, Wilson TJ, Boyd RL (1990). The phenotypic heterogeneity of mouse thymic stromal cells. Immunology 70, 66-74.

Fein A, Vechoropoulos M, Nebel L (1989). Cyclosporin-induced embryotoxicity in mice. Biology of the Neonate 56: 165-173. 
Granelli-Piperno A (1990). Lymphokine gene expression in vivo is inhibited by cyclosporin A. Journal of Experimental Medicine 171: 533-544.

Hattorl A, Kunz HW, Gill TJ III, Shinczuka H (1987). Thymic and lymphoid changes and serum immunoglobulin abnormalities in mice receiving cyclosporine. American Journal of Pathology 128: 111-120.

Heeg K, Bendigs S, Wagner H (1989). Cyclosporine A prevents the generation of single positive (Lyt2+ L3T4; , Lyt2 ${ }^{-} \mathrm{L3T}^{+}$) mature T cells, but not single positive (Lyt2+T3) immature thymocytes, in newborn mice. Scandinavian Journal of Immunology 30: 703-710.

Hess AD, Horwitz L, Beschorner WE, Santos GW (1985). Development of graft-versus-host disease-like syndrome in cyclosporine-treated rats after syngeneic bone marrow transplantation. I. Development of cytotoxic $\mathrm{T}$ lymphocytes with apparent polyclonal anti-la specificity, including autoreactivity. Journal of Experimental Medicine 161: 718-730.

Hess AD, ColombanI PM, Esa AH (1986). Cyclosporine and the immune response: basic aspects. Critical Reviews in Immunology 6: 123-149.

Hess AD, Vogelsang GB, Heyd J, Beschorner WE (1987). Cyclosporine-induced syngeneic graft-versus-host disease: assessment of $T$ cell differentiation. Transplantation Proceedings 19: 2683-2686.

Hess AD, Fischer AC, Beschorner WE (1989). Regulation of syngeneic graft-versus-host disease by autosuppressor mechanisms. Transplantation Proceedings 21: 3013-3015.

Hess AD and Fischer AC (1989). Immune mechanisms in cyclosporine-induced syngeneic graftversus-host disease. Transplantation 48: 895-900.

Hiramine C, Hojo K, Matsumoto $\mathbf{H}$ (1988). Abnormal distribution of T cell subsets in the thymus of Cyclosporin A (CsA)-treated mice. Thymus 11: 243-252.

Hiramine C, Hojo K, Matsumoto H, Koseto M, Itoh M (1989). Differential effect of cyclosporine in vivo on the distribution of T cell subsets in the thymus, spleen, and lymph nodes. Transplantation 47: 499-503.

Hugo P and Potworowskl EF (1990). Selection of CD4 ${ }^{+} \mathrm{CD} 8^{+}$thymocytes by complex formation with medulla-derived epithelial cells. Cellular Immunology 126: 143-154.

Jenkins MK, Schwartz R, Pardoll DM (1988). Effects of cyclosporine A on T cell development and clonal deletion. Science 241: 1655-1658.

Jenkinson EJ, Anderson G, Owen JJT (1992). Studies on T cell maturation on defined thymic stromal cell populations in vitro. Journal of Experimental Medicine 176: 845-853.

Jones RJ, Hess AD, Mann RB, Plantadosi S, Vogelsang GB, Farmer ER, Geller RB, Santos GW (1989). Induction of graft-versus-host-disease after autologous bone marrow transplantation. Lancet 1: 754-757.

Kanariou M, Huby R, Ladyman H, Colic M, Sivolapenko G, Lampert I et al. (1989). Immunosuppression with cyclosporin A alters the thymic microenvironment. Clinical and Experimental Immunology 78: 263-270.

Kappler JW, Roehm N, Marrack PC (1987). T cell tolerance by clonal elimination in the thymus. Cell 49: 273-280.

Kappler JW, Staerz U, White J, Marrack PC (1988). Self-tolerance eliminates T cells specific for Mls-modified products of the major histocompatibility complex. Nature 332: 35-40.

Kendall MD (1988). Anatomical and physiological factors influencing the thymic microenvironment. In Thymus Update, volume 1, edited by MD Kendall and MA Ritter. London: Harwood Academic Publishers. 
Kendall MD (1990). The cell biology of cell death in the thymus. In Thymus Update, volume 3: p.53-76, edited by MD Kendall and MA Ritter. London: Harwood Academic Publishers.

Kimura $\mathbf{H}$ and Wilson DB (1984a). Anti-idiotypic cytotoxic T cells in rats with graft-versus-host disease. Nature 308: 463-464.

KImura H, Pickard A, Wilson DB (1984b). Analysis of T cell populations that induce and mediate specific resistance to graft-versus-host disease in rats. Journal of Experimental Medicine 160: 652-658.

Kisielow P, Bluethmann H, Staerz UD, Steinmetz M, Boehmer H von (1988). Tolerance in T-cell-receptor transgenic mice involves deletion of nonmature $\mathrm{CD}^{+}{ }^{+} \mathrm{CD} 8{ }^{+}$thymocytes. Nature 333: 742-746.

Kimball PM, Kerman RH, Kahan BD (1990). Sensitivity of intracellular signals responsible for cellt cycle progression to cyclosporine. Transplantation 49: 186-191.

Kosugi A, Sharrow SO, Shearer GM (1989a). Effect of cyclosporin A on lymphopoiesis. I. Absence of mature T cells in thymus and periphery of bone marrow transplanted mice treated with cyclosporin A. Journal of Immunology 142: 3026-3032.

Kosugi A, Zuniga-Pnucker JC, Sharrow SO, Krulsbeek AM, Shearer GM (1989b). Effect of cyciosporin A on lymphopoiesis. II. Developmental defects of immature and mature thymocytes in fetal thymus organ cultures treated with cyclosporin A. Journal of Immunology 143: 3134-3140.

Kruisbeek AM, Zuniga-Pfucker JC, Marusic-Galesic S, Weston MA, Tentorl L, Longo DL (1988). Thymic selection of the T Cell repertoire. Immunological Research 7: 318-328.

Kruisbeek AM, Mond JJ, Fowlkes BJ, Carmen JA, Bridges S, Longo DL (1985). Absence of the Lyt2-,L3T4+ lineage of T cells in mice treated neonatally with anti-I-A correlates with absence of intrathymic I-A-bearing antigen-presenting cell function. Journal of Experimental Medicine 161: 1029-1047.

Kyewski BA, Rouse RV, Kaplan HS (1982). Thymocyte rosettes: multicellular complexes of lymphocytes and bone marrow-derived stromal cells in the mouse thymus. Proceedings of the National Academy of Sciences USA 79: 5646.

Linder J (1987). The thymus gland in secondary immunodeficiency. Archives of Pathology and Laboratory Medicine 111: 1118-1122.

Lo D and Sprent J (1986). Identity of cells that imprint H-2-restricted T-cell specificity in the thymus. Nature 319: 672-675.

MacDonald HR, Howe RC, Pedrazalni T, Lees RK, Budd RC, Schneider R, et al. (1988). T-eell lineages, repertoire selection and tolerance induction. Immunological Reviews 104: 157-182.

MacDonald HR and Lees RK (1990). Programmed death of autoreactive thymocytes. Nature 343: 642-644.

Majoor GD (1989). Cyclosporin-induced autoimmunity in the rat. Rat News Letter 21: 6-8.

Majoor GD and Breda Vriesman PJC van (1989). Cyclosporin A and the thymus. In: Thymus Update, volume 3, edited by M.D. Kendall and M.A. Ritter, London: Harwood Academic Publishers.

Marcos MAR, Hera A De La, Gaspar ML, Marquez C, Bellas C, Mampaso F, Torbidio ML, Martinez-A C (1986). Modification of emerging repertoires by immunosuppression in immunodeficient mice results in autoimmunity. Immunological Reviews 94:51-74. 
Marcos MAR, Toribio M-L, Hera A de la, Marquez C, Gaspar M-L, Martinez-A C (1988). Mutual cell interactions and the selection of immune repertoires: implication in autoimmunity. Immunology Today 9: 204-213.

Maruslc-Galesic S, Longo DL, Kruisbeek AM (1989). Preferential differentiation of T cell receptor specificities based on the $\mathrm{MHC}$ glycoproteins encountered during development. Evidence for positive selection. Journal of Experimental Medicine 169: 1619-1630.

Mason DW (1985). The possible role of class II major histocompatibility complex antigens in self tolerance. Scandinavian Journal of Immunology 21: 397-400.

Matsuhashi N, Kawase Y, Suzuki G (1989). Effects of Cyclosporine A on the thymocyte differentiation in fetal thymus organ culture. Cellular Immunology 123: 307-315.

Millcevic NM, Milicevic Z, Colic M (1989). Macrophages of the rat thymus after cyclosporin treatment. Histochemical, enzymehistochemical and immunohistochemical study. Virchows Archiv B: Cell Pathology 57: 237-244.

Morahan G, Allison J, Miller JFAP (1989). Tolerance of class I histocompatibility antigens expressed extrathymically. Nature 339: 622-624.

Nakashima M, Morl K, Maeda K, Kiskd H, HIrata K, Kawabuchi M et al. (1990). Selective elimination of double-positive immature thymocytes by a thymic epithelial cell line. European Journal of Immunology 20: 47-53.

Nikolic-Zugic J (1991). Phenotypic and functional stages in the intrathymic development of $\alpha \beta$ T cells. Immunology Today 12: 65-70.

Pabst R, Binns RM, Westerman J (1989). What is the function of peripheral lymphocytes migrating to the thymus and of B lymphocytes proliferating in the thymus? Thymus 13:149.

Pals ST, Horst E, Scheper RJ, Meljer CJLM (1989). Mechanisms of human lymphocyte migration and their role in the pathogenesis of disease. Immunological Reviews 108: 111134.

Parfrey NA and Prud'homme GJ (1990). Patterns of MHC antigenic modulation in cyclosporin-induced autoimmunity. Implications for pathogenesis. American Journal of Pathology 136: 479-486.

Parkman R (1989). Graft-versus host disease: an alternative hypothesis. Immunology Today 10 : 362-364.

RItter MA and Crispe NI (1992). The Thymus (In Focus), edited by D Male. Oxford: Oxford University Press.

Roberts JL, Sharrow SO, Singer A (1990). Clonal deletion and clonal anergy in the thymus induced by cellular elements with different radiation sensitivities. Joumal of Experimental Medicine 171: 935-940.

Rothenberg EV (1990). Death and transfiguration of cortical thymocytes: a reconsideration. Immunology Today 11: 116-119.

Rouse RV, Ezine S, Weissman IL (1985). Expression of major histocompatibility complex antigens in the thymuses of chimeric mice. Transplantation 40: 422-426.

Ryffel B, Deyssenroth H, Borel JF (1981). Cyclosporin A: effects on the mouse thymus. Agents and Actions 11, 373-379.

Sakaguchi S, Fukuma K, Kribayashi K, Masuda T (1985). Organ-specific autoimmune disease induced in mice by elimination of a $\mathrm{T}$ cell subset. I. Evidence for the active participation of $\mathrm{T}$ cells in natural self-tolerance; deficit of a $\mathrm{T}$ cell subset as a possible cause of autoimmune disease. Journal of Experimental Medicine 161: 72-87. 
Sakaguchi S and Sakaguchi N (1988). Thymus and autoimmunity. Transplantation of the thymus from cyclosporin A-treated mice causes organ-specific autoimmune disease in athymic nude mice. Journal of Experimental Medicine. 167: 1479-1485.

Sakaguchi $\mathbf{S}$ and Sakaguchi $\mathbf{N}$ (1989). Organ-specific autoimmune disease induced in mice by elimination of $T$ cell subsets. V. Neonatal administration of cyclosporin A causes autoimmune disease. Journal of Immunology 142: 471-480.

Sakaguchi S, Sakaguchi N (1990). Thymus and autoimmunity: Capacity of the normal thymus to produce pathogenic self-reactive $\mathbf{T}$ cells and conditions required for their induction of autoimmune disease. Journal of Experimental Medicine 172: 537-545.

Sakaguchi S, Sakaguchi N (1992). Causes and mechanisms of autoimmune disease: Cyclosporin $\mathrm{A}$ as a probe for the investigation. Journal of Investigative Dermatology $98: 70 \mathrm{~S}-76 \mathrm{~S}$

Saluun J, Bandeira A, Khazaal I, Calman F, Coltey M, Coutinho A, el al. (1990). Thymic epithelium tolerizes for histocompatibility antigens. Science 247: 1471-1474.

Schevach EM (1985). The effect of cyclosporin A on the immune system. Annual Reviews in Immunology 3: 397-423.

Schuurman H-J, Vaessen LMB, Vos JG, Hertogh A, Geertzema JGN, Brandt CJWM, et al. (1986). Implantation of cultured thymic fragments in congenitally athymic nude rats: ignorance of thymic epithelial haplotype in generation of alloreactivity. Journal of Immunology 137: 2440-2447.

Schuurman H-J, Loveren H van, Rozing J, DiJk A van, Loeber G, Vos JG (1990).Cyclosporin and the rat thymus. An immunohistochemical study. Thymus 16: 235-254.

Schwartz RS and Datta SK (1989). Autoimmunity and autoimmune diseases. In: Fundamental Immunology, 2nd ed. Blackwell Scientific Publications Ltd., Oxford: 238-273.

Scollay R, Jacobs S, Jarabek L, Butcher E, Weissman I (1980). Thymus migration: quantitative studies on the rate of migration of cells from the thymus to the periphery in mice. European Journal of Immunology 10: 210-218.

Scollay R, Bartlett P, Shortman K (1984). T cell development in the adult murine thymus: changes in the expression of the surface antigens Ly2, L3T4 and B2A2 during development from early precursor cells to emigrants. Immunological Reviews 82: 79-103.

Seemayer TA, Lapp WS, Bolande RP (1978). Thymic epithelial injury in graft-versus-host reactions following adrenalectomy. American Journal of Pathology 93: 325-338.

Sha WC, Nelson CA, Newberry RD, Kranz DM, Russell JH, Loh DY (1988). Selective expression of an antigen receptor on CD8-bearing $\mathrm{T}$ lymphocytes in transgenic mice. Nature 335: 271-274.

Shi Y, Sahal BM, Green DR (1989). Cyclosporin A inhibits activation-induced cell death in T-cell hybridomas and thymocytes. Nature 339: 625-626.

Slegel RM, Yui K, Teneholz DE, Kubo R, Greene MI (1990). Inhibition of T cell development in thymic organ culture: implications for the mechanism of action of cyclosporin $\mathbf{A}$. European Journal of Immunology 20. 753-757.

Sorokin R, Kimura H, Schroder K, Wilson DH, Wilson DB (1986). Cyclosporine-induced autoimmunity. Conditions for expressing disease, requirement for intact thymus, and potency estimates of autoimmune lymphocyles in drug-treated rats. Journal of Experimental Medicine 164: 1615-1625.

Stiller CR, Dupre J, Gent R, Jenner MR, Keown PA (1984). Effects of cyclosporine immunom suppression in insulin-dependent diabetes mellitus of recent onset. Science 223: 1362 1367. 
Takeuchl Y, Habu S, Okomura K, Suzuki G (1989). Cyclosporin A and anti-la antibody cause a maturation defect of $\mathrm{CD}^{+} 8^{-}$cells in organ-cultured fetal thymus. Immunology 66: 362 367.

Tanaka M, Shinohara K, Fukumoto T, Tanaka H, Kaneko T (1988). Effect of cyclosporin A on rat thymus: time course analysis by immunoperoxidase technique and flow cytofluorometry. Clinical and Experimental Immunology 72: 216-221.

Teh HS, Kisielow P, Scott B, Klshi H, Uematsu Y, Bluethmann H, et al. (1988). Thymic major histocompatibility complex antigens and the alpha-beta $T$-cell receptor determine the CD4/CD8 phenotype of T cells. Nature 335: 229-233.

Thomson AW, Whiting PH, Blair JT, Davidson RJL, Simpson JG (1981). Pathological changes developing in the rat during a 3-week course of high dosage cyclosporin $\mathrm{A}$ and their reversal following drug withdrawal. Transplantation 32: 271-277.

Torres-Nagel N, Kraus E, Brown MH, Tlefenthaler G, Mitnacht R, Willams AF, Hünig T (1992). Differential thymus dependence of rat CD8 isoform expression. European Journal of Immunology 22: 2841-2848.

Tutschka PJ, Beschorner WE, Allison AC, Burns WH, Santos GW (1979). Use of cyclosporine $A$ in allogeneic bone marrow transplantation in the rat. Nature 280: 5718 5719.

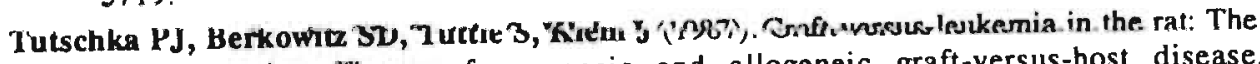
antileukemic efficacy of syngeneic and allogeneic graft-versus-host disease. Tranplantation Proceedings 19: 2668.

Verschuuren JJGM, Bos GMJ, Majoor GD, Baets MH de, Breda Vriesman PJC van (1989). Syngeneic bone marrow-dependent, cyclosporin A-mediated, myasthenia gravis. In Proceedings of the 7th International Congress of Immunology, Berlin: p. 555.

Vliet van E, Melis M, EwlJk van W (1984). Immunohistology of thymic nurse cells. Cellular Immunology 87: 101 .

Von Graffenried B, Friend D, Shand N, Schiess W, Timonen P (1989). Cyclosporin A (Sandimmun $^{R}$ ) in autoimmune disorders. In: Thomson AW, ed. Cyclosporin. Mode of action and clinical implications. London: Kluwer Academic, 1989: 213-50.

White DJ and Calne RY (1982). The use of cyclosporin A. Immunosuppression in organ grafting. Immunological Reviews 65: 115-131.

Wilson DB (1989). Idiotypic regulation of T cells in graft-versus-host disease and auto-immunity. Immunological Reviews 107: 159-177.

Wodzig KWH, Majoor GD, Gaar M-JWH van de, Breda Vriesman PJC van (1990). Autoantibodies in cyclosporine A-induced autoimmune disease. Transplantation Proceedings 22: 2586-2587.

Wodzig KWH, Majoor GD, Breda Vriesman PJC van (1991). On the localization of effector cells in cyclosporin-induced autoimmunity. Autoimmunity 10: 275-283.

Wodzig KWH, Majoor GD, Breda Vriesman PJC van (1993). Susceptibility and resistance to Cyclosporin A - induced autoimmunity in rats. Autoimmunity, in press 
Wyllie AH, Morris RG, Smith AL, Dunlop D (1984). Chromatin cleavage in apoptosis: association with condensed chromatin morphology and dependence on macromolecular synthesis. Journal of Pathology 142: 67-77.

Zinkernagel RM, Callahan GN, Althage A, Cooper S, Kleln PA, Klein J (1978). On the differentiation of "H-2 self-recognition" by T cells: evidence for dual recognition? Journal of Experimental Medicine 147: 882-896.

Zuniga-Pflucker JC, Longo DL, Kruisbeek AM (1989). Positive selection of CD4 CD8 T cells in the thymus of normal mice. Nature 338: 76-78. 



\title{
|Chapter 2
}

\section{Susceptibility and resistance}

\author{
to Cyclosporine A - induced
}

autoimmunity in Rats

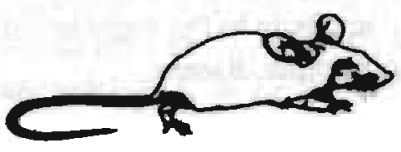




\section{Susceptibility and resistance to Cyclosporine A - induced autoimmunity in rats}

\section{Abstract}

Lethally irradiated Lewis (LEW) rats, reconstituted with syngeneic bone marrow and next given Cyclosporine A (CyA) for several weeks, develop disease (Cyclosporine A-induced autoimmunity; CyA-AI) after withdrawal of CyA. This disease resembles in terms of dermal changes the acute dermatitis and chronic scleroderma also seen in graft-versus-host disease (GVHD). In this study we report the relative resistance of the Brown Norway (BN) rat strain to the induction of CyA-AI.In contrast to LEW rats, in which CyA-AI was originally described, BN rats showed no acute dermatitis or scleroderma-like skin pathology in spite of comparable changes in the thymus and a maturation arrest of $\mathrm{CD4} 4^{+} \mathrm{T}$ cells. The difference was also demonstrated functionally for whereas in LEW rats delayedtype hypersensitivity (DTH) reactions could not be elicited during CyA-AI, these were within normal limits in BN rats subjected to the same protocol; NK activity on the other hand was unaffected in both strains. The observation that BN rats developed very mild late disease as evidenced by a slight though significant weight loss suggests that the BN strain is relatively susceptible to the disease but that lesser effector cell generation or, alternatively, stronger suppressor cell responses may prevent dermal disease. These observations may contribute to the elucidation of the mechanisms involved in this experimental autoimmune disease. 


\section{Introduction}

Cyclosporine $\mathrm{A}(\mathrm{CyA})$ is a drug with potent immunosuppressive activity and effective in preventing allograft rejection (White and Calne, 1982; Shevach, 1985; Hess et al., 1986), suppressing graft-versus-host disease (GVHD) secondary to allogeneic bone marrow transplantation (BMT) (Tutschka et al., 1979; Bacigalupo er al., 1990), and in the treatment of several autoimmune diseases (Stiller et al., 1984; Bolton ef al., 1982; Von Graffenried, 1989). On the other hand, CyA administration after lethal $\mathrm{X}$-irradiation and reconstitution with syngeneic or autologous bone marrow may, 2-3 weeks after withdrawal of CyA, elicit a T cell-mediated autoimmune syndrome with pathology similar to that seen in acute GVHD after allogeneic BMT (Glazier et al., 1983). This CyA-induced

autoimmune syndrome was originally termed syngeneic GVHD (Glazier et al., 1983) and has also been referred to as CyA-induced autoimmune disease (CyA-AI) (Sorokin et al., 1986) or BMT-associated immune disease (BMT-ID) (Bos et al., 1990. The disease has been elicited in certain rat (Glazier et al., 1983) and mouse strains (Cheney and Sprent, 1985; Bryson et al., 1989) and may also occur in humans (Jones et al., 1989). The rat model as originally described proved to be easily reproducible using young LEW (RTI') rats; males and females are equally susceptible (Glazier $e t$ al., 1983; Fischer and Hess, 1990). In two other studies, female Louvain (Low/M; RT1") and (LEWXBN)F1 rats were shown to be susceptible as well (Tutschka et al., 1987; Geller et al., 1989); we also reproduced the model using female DA (RT1") rats. This paper confirms the susceptibility of LEW rats to CyA-AI and documents the resistance of BN (RT1 ${ }^{\mathrm{D}}$ ) rats to this acquired autoimmune disease.

\section{Materials and methods}

\section{Animals}

Female, specific pathogen-free LEW (RT1 $\left.{ }^{1}\right)$ and BN $\left(\mathrm{RT}^{\mathrm{a}}{ }^{\mathrm{a}}\right)$ rats were used at the age of 4-6 weeks. Rats were obtained from our own breeding stock.

\section{Protocol for induction of CyA-Al}

The experimental protocol has been described before (Bos et al., 1988). In brief, rats were given a lethal dose of $8.5 \mathrm{~Gy}$ at $0.5 \mathrm{~Gy} / \mathrm{min}$ using a Röntgen irradiation machine (Philips MG320, Hamburg, Germany) and next day received a syngeneic BMT (see below). Starting from the day of BMT rats received $7.5 \mathrm{mg}$ CyA/kg/day for 42 days. CyA (kindly donated by Sandoz Co. Ltd., Basel, Switzerland) was dissolved in olive oil at a concentration of $7.5 \mathrm{mg} / \mathrm{ml}$ and administered subcutaneously. CyA-AI usually developed 2-3 weeks after cessation of CyA administration. LEW or BN rats subjected to this protocol are referred to as LEW/XCYA and BN/XCYA. 


\section{Bone marrow transplantation}

Bone marrow donor rats were killed by cervical dislocation under ether anesthesia. Bone marrow was collected from tibias and femurs in Dulbeccos balanced salt solution supplemented with $2 \%$ heat-inactivated fetal calf serum (iFCS), penicillin $(100 \mathrm{U} / \mathrm{ml}$ ) and streptomycin $(100 \mu \mathrm{g} / \mathrm{ml})$ (DBSS). Recipient rats received $6 \times 10^{7}$ viable syngeneic bone marrow cells in $1.0 \mathrm{ml}$ DBSS intravenously into a tail vein.

\section{Scoring of macroscopic pathology}

After withdrawal of CyA, development of CyA-AI was assessed by examination of the rats 1-2 times a week for signs and symptoms of disease. Macroscopic pathology usually developed in the following order: red acra (hyperemia of the skin of the ears, feet, and tail), inflammation of the eyelids, dermatitis, and alopecia (Table 2.1). Furthermore, rats were weighed daily to assess changes in body weight. Loss of body weight in LEW rats with CyA-AI corresponds with the severity of dermal signs of disease and dermal histopathological changes (Wodzig et al., 1991). Change in body weight was expressed as percent of body weight determined on the day of BMT. Skin biopsies were taken on day $0,21,56$, and 84 after withdrawal of CyA.

Tabis 2.1: Coding of macroscopic pathology in CyA-Al.

\begin{tabular}{|cl|}
\hline Code & Pathology \\
\hline$E$ & Erythroderma of the acra (hyperemia of the skin of the ears, feet and tail) \\
$D$ & $\begin{array}{l}\text { Dermatitis, usually starting around the eves and with brown/red discoloring of } \\
\text { the fur of the neck, front and/or hind legs. Expansion is initially restricted } \\
\text { to the ventral part of the body. }\end{array}$ \\
$A_{V}$ & Ventral alopecia \\
$A_{g}$ & Generalized alopecia \\
$T$ & $\begin{array}{l}\text { Thin fur, usually dorsal (consequence of slowly progressive disease or recovery } \\
\text { from alopecia) }\end{array}$ \\
\hline
\end{tabular}

\section{Control groups}

Three different control groups were included in this study: X-irradiated and bone marrow-transplanted LEW and BN rats given olive oil (LEW/XOil and BN/XOil); agematched LEW and BN rats treated with CyA (cyalEW and cyaBN); age-matched nontreated LEW and BN rats (nLEW and $\mathrm{nBN}$ ). 


\section{Immunoperoxidase}

Thymuses were frozen in cold isopentane and $4 \mu \mathrm{m}$ sections were cut, air dried, and fixed in aceton for $10 \mathrm{~min}$. Slides were air dried and incubated with an optimal dilution of mouse monoclonal antibodies (MAbs) in PBS $/ 0.05 \% \mathrm{BSA}$ for $60 \mathrm{~min}$ at room temperature. The specific MAb from ascites fluid or supernatant consisted of OX6 (RT1.B, MHC class II antigen), OX17 (RT1.B, MHC class II antigen), OX18 (RT1 .A, MHC class I antigen), OX19 (CD5, panspecific for rat T lymphocytes), OX62 (rat dendritic cells), R73 (T cell receptor $\alpha \beta$ ), and ED-1 (rat macrophages, dendritic cells). Antibodies in the OX series were kindly donated by Dr. A. Williams, Oxford, UK except for OX62 (kindly provided by Dr. M. Brenan, Oxford, UK); ED-1 (by Dr. C. Dijkstra, Amsterdam, The Netherlands); and R73 (by Dr. T. Hünig. Heidelberg, Germany). The slides were washed 3 times with cold PBS followed by incubation with horse radish peroxidase (HRP)conjugated rabbit anti-mouse IgG, to which $3 \%$ normal rat serum was added. After washing the slides 3 times with cold PBS, a substrate containing $0.05 \%$ diaminobenzidine (DAB) and $0.05 \% \mathrm{H}_{2} \mathrm{O}_{2}$ in $50 \mathrm{mM}$ Tris- $\mathrm{HCl} \mathrm{pH} 7.6$ was added. The slides were counterstained with hematoxylin, dehydrated, and coverslipped with Entallan (Merck, Darmstadt, Germany).

\section{Langerhans cell identification}

Langerhans cells in the skin were identified by ATP-ase staining and immunoperoxidase staining for rat MHC class II antigens (Thorbecke et al., 1980). Skin biopsies were frozen in cold isopentane and $4 \mu \mathrm{m}$ sections were cut, air dried, and fixed either in neutral formaiin- $\mathrm{CaCl}_{2}-$ Macrodex for ATP-ase staining or in aceton for 10 min for immunoperoxidase staining.

ATP-ase: Slides were washed with aqua bidest and incubated for $45 \mathrm{~min}$ at $42^{\circ} \mathrm{C}$ with $0.05 \%$ adenosin-5-triphosphate/0.08 $\mathrm{M}$ Tris $(\mathrm{HCl})$-malein acid buffer $\mathrm{pH} 7.2 / 0.12 \%$ $\mathrm{Pb}\left(\mathrm{NO}_{3}\right)_{2} / 0.02 \mathrm{M} \mathrm{MgSO}_{4}$. Control slides were incubated with the same solution without adenosin-5-triphosphate. The slides were washed with water, incubated $30 \mathrm{sec}$ with $2 \%$ $\mathrm{Na}_{2} \mathrm{~S}$, and washed with water. Thereafter, slides were stained for $10 \mathrm{~min}$ with eosin, rinsed with water, dehydrated with aceton and diethylether, and mounted with Entallan. Immunoperoxidase: Slides were washed 3 times with cold PBS and incubated with an optimal dilution of MAb OX6 and treated according to the protocol of immunoperoxidase staining (see above).

\section{Cytofluorometry}

Peripheral blood lymphocytes from $\mathrm{BN}$ rats were analysed or the relative concentrations of $\mathrm{CD4}^{+}$and $\mathrm{CD} 8^{+} \mathrm{T}$ cells, and $\mathrm{B}$ cells on day 35 after BMT (under $\mathrm{CyA}$ ), and on days 60 and 82 days after BMT ( 18 and 40 days after discontinuation of CyA). Cells were labeled using mouse MAbs to rat CD4 (W3/25), CD8 (OX-8), IgM (MARK, kindly donated by Dr. G. Voisin), and goat $F\left(a^{\prime}\right)_{2}$ anti-mouse IgG-FITC absorbed with rat Ig (CappeVOrganon Teknika, Turnhout, Belgium) as described before (Bos et al., 1988). Cytofluorometry was performed on a Becton-Dickinson FACScan flow cytometer using LYSYS II software. 


\section{Cell-mediated immune reactivity}

Cell-mediated (type IV) hypersensitivity to a contact allergen was elicited according to Wijsbek et al. (1991). In brief, rats were sensitized to toluene di-isocyanate (TDI; Merck Schuchardt, Hohenbrunn, Germany) by two epicutaneous applications. For the first sensitization a total volume of $500 \mu \mathrm{l} 5 \%$ TDI solution was stepwise applied along the whole length of the tail. One week later $500 \mu \mathrm{l} 5 \%$ TDI solution was applied to a shaven area on the back of the rat. Control rats received the solvent only. Seven days after the second immunization, experimental rats were challenged under anesthesia by application of $20 \mu 11 \%$ TDI solution to the outside of the left ear. Just prior to challenge measurements of left ear thickness were performed using a digital micrometer (Digimatic type ID-110M; Mitutoya, Tokyo, Japan). Each determination was performed 10 times; standard deviations of series of 10 determinations did not exceed $10 \%$ of the mean. Increment of ear thickness was expressed as percent of ear thickness determined prior to challenge. Control rats were challenged in the same fashion, but in fact encountered the allergen for the first time. The respons to TDI was expressed as the mean increase of ear thickness (MIET) of experimental rats $(n=5)$ minus the MIET of control animals $(n=3)$.

\section{Natural killer (NK) cell activity}

Blood samples of approximately $1.0 \mathrm{ml}$ were obtained by retro-orbital puncture and added to 50 IE heparin (Leo Pharmaceuticals, Weesp, The Netherlands). Peripheral blood leukocytes (PBL) were recovered by lysis of the erythrocytes with $25 \mathrm{ml} 0.84 \% \mathrm{NH}_{4} \mathrm{Cl}$ and centrifugation ( $30 \times \mathrm{xg} ; 10 \mathrm{~min}$ ) of the suspension on a cushion of $5 \mathrm{ml}$ iFCS. Pelleted cells were washed and the suspension adjusted to contain $5 \times 10^{6}$ viable PBLml.

Five million K562 (target) cells were suspended in $0.2 \mathrm{ml} \mathrm{RPMI} 1640$ with $2 \%$ iFCS and 7.4 $\mathrm{MBq} \mathrm{Na}{ }^{51} \mathrm{CrO}_{4}$ and incubated at $37^{\circ} \mathrm{C}$ for $60 \mathrm{~min}$. After labelling the target cells were washed and adjusted to a concentration of $5 \times 10^{4}$ cells $/ \mathrm{ml}$ in RPMI 1640 with $10 \%$ iFCS. A range of 100 to 3-fold excess of PBL was added to $5 \times 10^{3}{ }^{51} \mathrm{Cr}$-labeled target cells in a final volume of $0.2 \mathrm{ml}$ medium per round-bottom microtiter well. All determinations were set up in duplicate. Microtiter plates were centrifuged (30xg, $5 \mathrm{~min}$ ) and incubated for $6.5 \mathrm{hrs}$ at $37^{\circ} \mathrm{C}$ in air with $5 \% \mathrm{CO}_{2}$. Thereafter, the plates were centrifuged again and the supernatants collected by absorption (Skatron Harvesting System, Costar, Cambridge, USA). Radioactivity present in the supernatants was measured in a gamma counter. Maximum release of ${ }^{51} \mathrm{Cr}$ was determined by incubation of $5 \times 10^{3}$ target cells with $100 \mu$ Cetavlon shampoo. Percent specific lysis was calculated according to the formula:

$$
\begin{aligned}
& \text { \% specific } \\
& \text { release }
\end{aligned}=\frac{\text { cpm experimental release }-\mathrm{cpm} \text { spontaneous release }}{\mathrm{cpm} \text { maximum release }-\mathrm{cpm} \text { spontanecus release }} \times 100
$$

\section{Statistics}

Differences in the weights of rats from different groups were tested for statistical significance by Wilcoxons rank sum test. Statistical analysis of cell-mediated hypersensitivity responses was also performed by Wilcoxons rank sum test. 


\section{Results}

\section{Development of CyA-AI In LEW versus BN rats}

Female LEW $(n=30)$ and BN $(n=27)$ rats were treated for induction of CyA-AI (LEW/ $X C y A$ and $B N / X C y A)$; control LEW $(n=20)$ and $B N(n=19)$ rats received $X$-irradiation, sBMT and the CyA-solvent only (LEW/XOil and BN/XOil). On day 20 after withdrawal of CYA the mean body weight of the LEW/XCYA rats had decreased $14 \%$ when compared to the mean body weight on day 0 (range of individual weight losses: 5-30\%). In contrast, the mean body weight of LEW/XOil rats showed an increase of $4 \%$ as compared to day 0 (range of individual weight gains: $1-9 \%$ ). The difference in mean body weight of LEW/ XCYA and LEW/XOil rats was statistically significant on day 14 after CyA withdrawal and remained so for the duration of the experiment $(P<0.001)$ (Fig. 2.1).

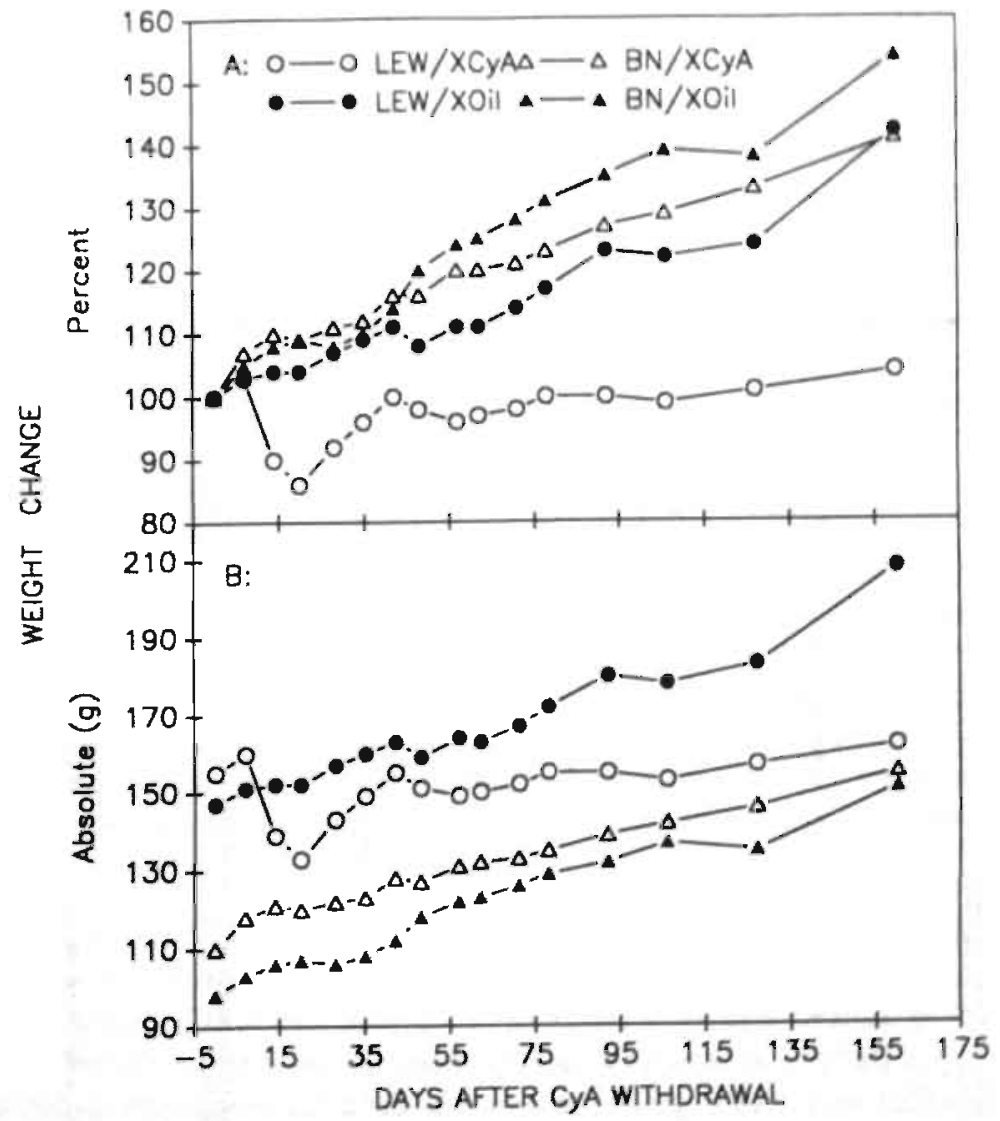

Figure 21.: Wolght chenges of LEWXCYA, BNXCYA, and control LEWXXOll and BNXXII rets atter CyA whichural PanelA: Mean relative uvelghts as compared io the weight on the day of CyA discontinuation (day $0=100 \%$ ); panel $B$ : Mean absolute waights in g. 
On day 20 after cessation of CyA administration the group of BN/XCyA rats showed a mean increase in body weight of $9 \%$ as compared to day 0 (range $2-15 \%$ ). BN/XOil rats showed a comparable weight gain over the same period (mean: $9 \%$; range $5-17 \%$ ). From day 40 after $C y A$ withdrawal a slight but significant difference in the relative mean body weights of $\mathrm{BN} / \mathrm{XCYA}$ and $\mathrm{BN} / \mathrm{XO}$ Oil rats developed $(\mathrm{P}<0.04)$ (Fig. 2.1).

On day 20 after Cy A withdrawal 26 out of 29 experimental LEW/XCyA rats exhibited severe macroscopic skin pathology like dermatitis (6/26) and alopecia (20/26); one rat showed symptoms associated with the onset of CyA-AI like erythroderma of the acra whereas two rats showed no macroscopic signs of CyA-AI (Table 2.2). From day 20 after cessation of CyA all LEW/XCyA rats eventually developed skin pathology; in most of the animals dermatitis and ventral alopecia progressively evolved to generalized alopecia. LEW/XOil rats showed no signs of disease over the same period. ATP-ase staining and anti-MHC class II immunoperoxidase staining of skin biopsies from LEW/XCyA and LEW/XOil rats showed comparable densities of stained cells in biopsies from both groups.

$\mathrm{BN} / \mathrm{XCyA}$ and $\mathrm{BN} / \mathrm{XOil}$ rats for the period of observation of over 160 days showed no signs of CyA-AI, although in some of the BN/XCyA rats the fur was more grayish than that of BN/XOil animals. Microscopic examination of skin biopsies obtained from BN/ $\mathrm{XCyA}$ rats revealed no abnormalities when compared to biopsies taken from $\mathrm{BN} / \mathrm{XOil}$ animals.

Table 2.2: Development of CYA - induced macroscopic skin pathology in LEW/XCYA rats.

\begin{tabular}{|c|c|c|c|c|c|c|c|}
\hline \multirow[t]{2}{*}{ Day } & \multirow[t]{2}{*}{$\mathrm{N}^{\mathrm{b}}$} & \multicolumn{6}{|c|}{ Macroscopic pathology of $C_{Y A-A \mid C}$} \\
\hline & & absent & $\mathrm{E}$ & $\mathrm{D}$ & $A_{v}$ & $\mathrm{Ag}_{\mathrm{g}}$ & $T$ \\
\hline 0 & 30 & 30 & & & & & \\
\hline 6 & 30 & 27 & & 3 & & & \\
\hline 14 & 30 & 8 & & 11 & 11 & & \\
\hline 20 & 29 & 2. & 1 & 6 & 20 & & \\
\hline 28 & 29 & 3 & & & 24 & 2 & \\
\hline 35 & 29 & 4 & & & 10 & 11 & 4 \\
\hline 42 & 27 & 2 & & & 12 & 9 & 4 \\
\hline 48 & 26 & 2 & & & 3 & 15 & 6 \\
\hline 57 & 26 & 2 & & & 1 & 18 & 5 \\
\hline 62 & 26 & 2 & & & 2 & 18 & 4 \\
\hline 71 & 25 & 2 & & & 2 & 17 & 4 \\
\hline 78 & 25 & 2 & & & & 18 & 5 \\
\hline 92 & 25 & 1 & & & & 19 & 5 \\
\hline 106 & 25 & 1 & & & & 19 & 5 \\
\hline 160 & 24 & & & & & 21 & 3 \\
\hline 169 & 24 & & & & & 21 & 3 \\
\hline 181 & 24 & & & & & 21 & 3 \\
\hline 189 & 23 & & & & & 20 & 3 \\
\hline 202 & 23 & & & & 10 & 20 & 3 \\
\hline
\end{tabular}

AAfter discontinuation of CYA. bLoss of animals occurred accidentally due to manipulation. ${ }^{C E}$, erythroderma; $D$, dermatitis; $A_{v}$ ventral alopecia; $A_{g}$ generalized alopecia; $T$, thin fur isee also Table 2.11. 


\section{Effect of CyA treatment on thymlc archltecture}

Thymic samples obtained on days 14 and 28 after BMT and on day 56 after BMT (14 days after withdrawal of $\mathrm{CyA}$ ) from LEW/XCyA, LEW/XOil, and cyaLEW were conpared with BN/XCYA, BN/XOil, and cyaBN by histology and immunohistochemistry. As compared to LEW/XOil and BN/XOil, thymuses from LEW/XCYA and cyaLEW as well as BN/XCYA and cyaBN showed a marked ablation of the medulla during CyA administration (days 14 and 28 after BMT), which was associated with loss of epithelium resulting in markedly reduced MHC class II antigen expression. Furthermore, lymphocytes with a mature $\mathrm{T}$ cell phenotype (high TCR $\alpha \beta^{+}$) and dendritic cells were also reduced due to medullary involution. Thymic cortical areas appeared hardly affected by $\mathrm{CyA}$ treatment. On day 56 after BMT (14 days after cessation of CyA) changes in thymuses of cyalLEW, LEW/XCYA, cyaBN, and BN/XCYA rats had reversed to normal, but persisted in thymuses of LEW/XCYA and BN/XCYA rats.

\section{Phenotyplc analysis of BN peripheral blood lymphocytes}

Lymphocytes from BN/XCyA $(n=6)$, BN/XOil $(n=6)$, cyaEN $(n=4)$, and $n B N(n=4)$ rats were subjected to FACS analysis on day 35 after BMT (under Cy/A adminisiration) and on days 60 and 82 after BMT ( 18 and 40 days after discontinuation of CyA) (Fig.2.2). On day 35 relative numbers of both $C D 4^{+}$and $C D 8^{+}$cells were suppressed in BN/XCy.A, cyaBN, and $\mathrm{BN} / \mathrm{XOil}$ rats as compared to $\mathrm{nBN}$ rats, albeit most strikingly so for $\mathrm{CD} 4^{+}$ cells in BN/XCYA (4.9\% versus $45 \%$ ). At day 82 after BMT, relative numbers of CD4 ${ }^{*}$ and $\mathrm{CD} 8^{+}$cells had recovered to near-normal values. Consequently, $\mathrm{CD} 4^{+} 10 \mathrm{CD} 8^{+}$ratios remained nearly constant (3.5 to 4.6) for all groups except for BN/XCyA rats in which the ratios were 1.1 (day 35 ), 1.8 (day 60) and 3.6 (day 82 ) respectively.

\section{Cell-medlated Immunity In LEW versus BN rats}

Although the absence of pathology from BN/XCyA rats treated according to the standard protocol suggested relative resistance to $\mathrm{CyA}-\mathrm{Al}$ in this strain, the decrease in weight observed subsequently suggested a low grade disease to be present. In order to verify whether BN skin differed from LEW also in terms of function, DTH reactions were elicited during CyA-AI. LEW/XCYA, LEW/XOil, BN/XCYA, and BN/XOil rats randomly selected from these groups were tested at 6 , and other rats at 15 weeks after cessation of CyA (or solvent) administration. Responses were compared to those of age-matched nLEW and $\mathrm{nBN}$ rats.

Five nLEW and 5 LEW/XOil rats taken at 6 weeks post-CyA showed comparable DTH reactivity. At 24 hrs after challenge, thickness of the challenged ears had strongly increased (MIET: nLEW rats 65\%; LEW/XOil rats $81 \%$ ) and declined over the next $48 \mathrm{hrs}$. Five LEW/XCyA rats taken randomly at 6 weeks post-CyA (and all suffering of $\mathrm{CyA}-\mathrm{AI}$ ) mounted no response over $72 \mathrm{hrs}$ after challenge (Fig. 2.3A). Five LEW/XCyA rats taken randomly at 15 weeks, however, showed a weak response that peaked at $48 \mathrm{hrs}$ (MIET: 27\%). This response at $48 \mathrm{hrs}$ was not significantly different from the response at that time point in LEW/XOil and nLEW rats (Fig. 2.3B). 

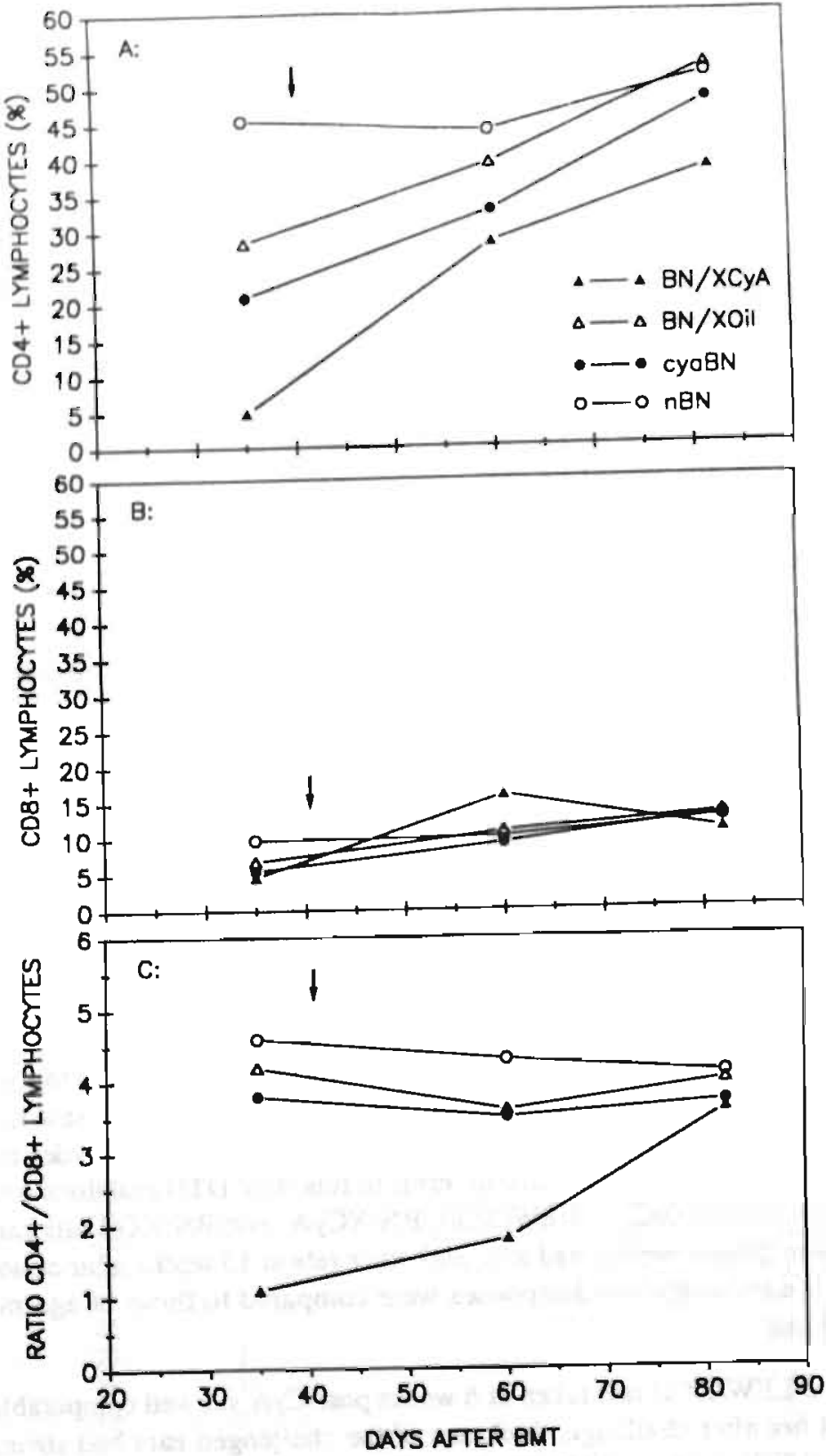

Flgure 22: Repopulation of hmphocyts subeats in perlpheral blooci curing and after cescetion of CyA or solvent administration. $\triangle, B N X C Y A$ : X-imadiated, BMT, BN rats given CyA for 42 days; $\triangle, B N$ $X O l l: X$-irraclated, BMT, BN rats given olve oil for 42 days; $\bullet, c y a B N$ : ago-maiched BN rats treated with CyA for 42 days; 0, nBN: age-matched non-treated BN rats. Panel A: percentage ol CD4* ymphocytes (T-helper); panel B: percentage of CD8* hmphocytes (T-cytotoxic/suppressor); penel C: ratios of CD4+ $10 \mathrm{CD} 8^{*}$ Iymphocytes. Arrows indicate day of CyA withdrawal. 
DTH responses of $\mathrm{nBN}$ rats were significantly lower than that of $\mathrm{nLEW}$ rats $(\mathrm{P}<0.03)$. Furthermore, responsiveness in $\mathrm{nBN}$ rats appeared to decline with age (MIET in 18 weeks old rats: $44 \%$, and in 27 weeks old rats: $25 \%$ at $24 \mathrm{hrs}$ ). Five BN/XOil rats taken at 6 weeks after discontinuation of the solvent (aged 18 weeks) displayed a significantly weaker response than $5 \mathrm{nBN}$ rats (MIET 20\% at $24 \mathrm{hrs}$; P<0.04), but this difference was not found at 15 weeks. In two groups of $5 \mathrm{BN} / \mathrm{XCyA}$ rats taken at 6 and 15 weeks after cessation of CyA strongest DTH responses were detected at $24 \mathrm{hrs}$ after challenge (MIET $9 \%$ and $23 \%$, respectively). These responses were not significantly different from those of BN/XOil rats. A statistically significant difference was, however, detected between responses at $48 \mathrm{hrs}$ after challenge of $\mathrm{BN} / \mathrm{XCYA}$ and $\mathrm{BN} / \mathrm{XO}$ Oil rats taken at 15 weeks after CyA administration ( $P<0.04)$ (Fig. 2.3B).

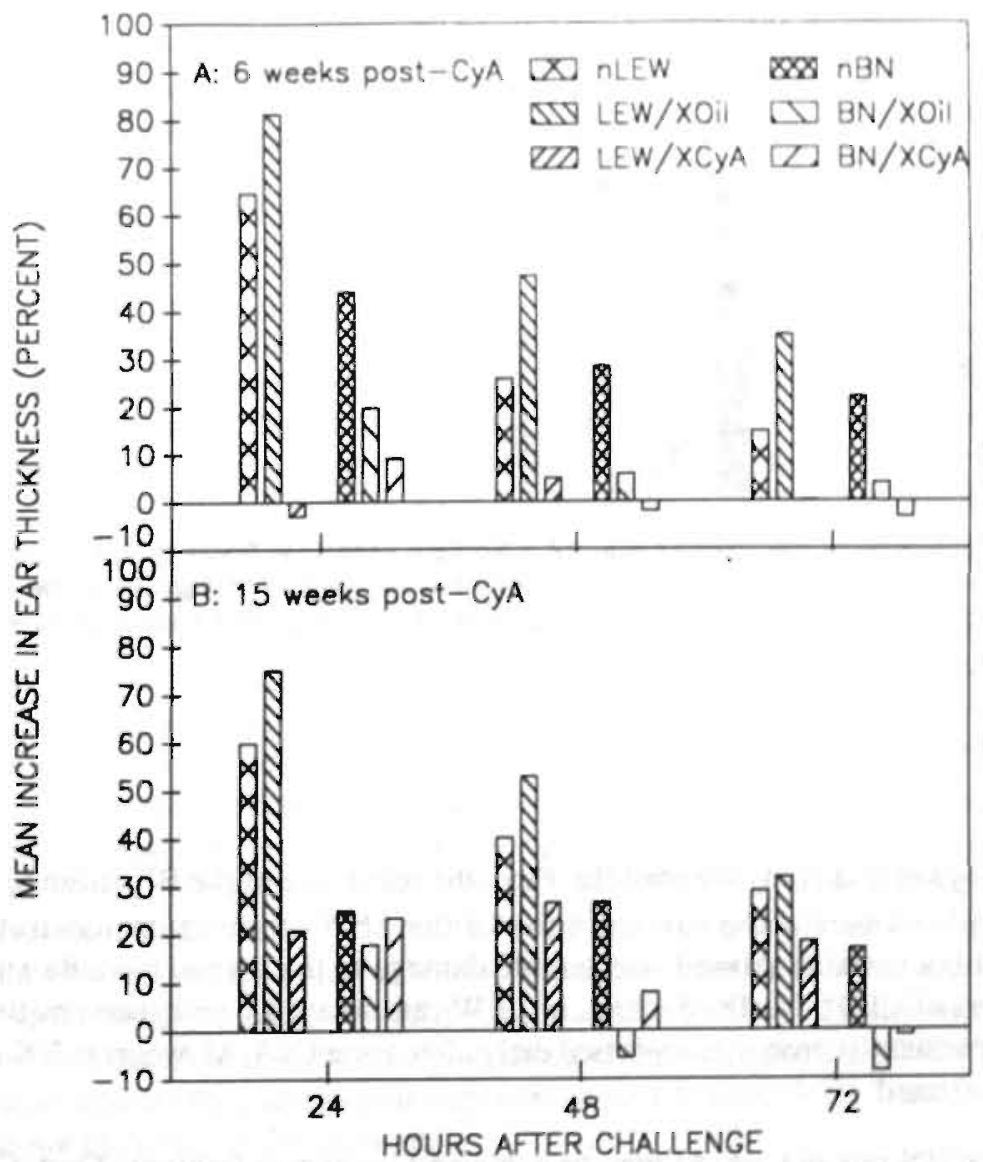

Figure 2.3: DTH to TDI In the left ears of LEWXCYA, BNXCYA, LEWXOli, BNXOII, nLEW and $n B N$ rats (for explenation see logend to Fig. 22). OTH was monitored by ear swelling at 24,48 and $72 \mathrm{hrs}$ after challenge. Panel A: DTH to TDlat 6 weeks after CyA discontinuation; panel B: 15 wogks after disconthuation. 


\section{NK-actlvity}

Since weak cell-mediated immunity in some models appears to be compensated for by NK cell activity, this parameter was investigated as well (Herberman, 1982). NK-activity was determined in PBL 8 weeks after CyA withdrawal. At an effector:target cell ratio of 100:1 NK-activity in 5 LEW/XCyA rats (mean specific lysis $8.1 \%$; rang 4-13.3\%) was not significantly different of that of 2 LEW/XOil (mean specific lysis $6.4 \%$; values 5 and $7.7 \%$ ) and 2 age-matched nLEW rats (mean specific lysis $5.4 \%$; values 5.0 and 5.7\%)(Fig. 2.4).

In $5 \mathrm{BN} / \mathrm{XCyA}$ rats NK activity (mean specific lysis 5.8\%; range 1.4-13.1\%) was not significantly different of that in $3 \mathrm{BN} / \mathrm{XO}$ il rats (mean specific lysis $4.3 \%$; range 2.2 $7.9 \%$ ) and 2 age-matched $\mathrm{nBN}$ rats (mean specific lysis $8.1 \%$; values 6.2 and $9.9 \%$ ) (Fig. 2.4).

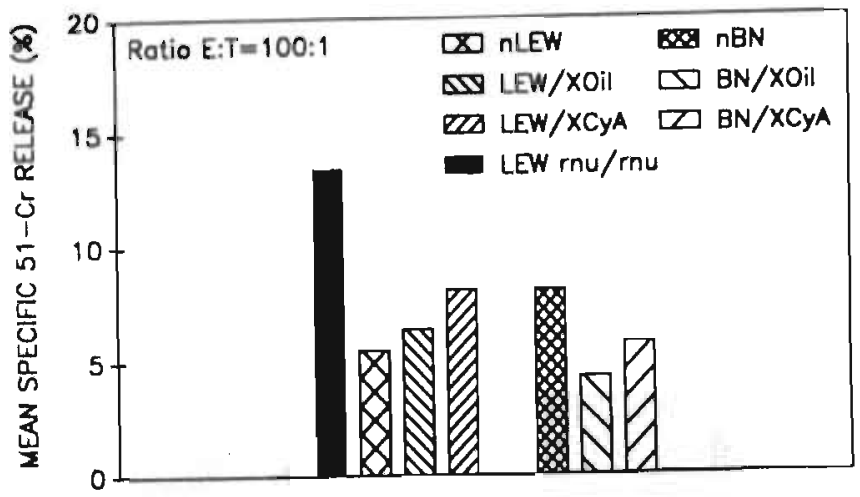

Flgure 2.4: NK cell activity in PBL from LEW/XCYA, BNXCYA, LEW/XOll, BNXOII, nLEW and $n B N$ rats at 8 woeks after CyA discontinuation (for explanation see legend to $\mathrm{Fg}$ 22). in the same experiment, for comparison NK cell activity in PQL from a LEW r nu/r nu congenic rat was determined.

\section{Discussion}

The main findings of this study are twofold. First, the resistance of the BN strain to the induction of CyA-AI versus the susceptibility of the LEW strain is demonstrated, although rats of both strains showed comparable damage to the thymic medulla and a maturation arrest of $\mathrm{CD} 4^{+} \mathrm{T}$ cells. Second, in LEW rats delayed-type hypersensitivity reactions were transiently strongly suppressed early after acute CyA-AI, whereas NK cell activity was unaffected.

The resistance of BN rats to CyA-AI may be explained in diverse fashions. First, CyA metabolism in BN and LEW rats may differ. This is an unlikely explanation, however, since CyA is equally effective in suppressing first set renal allograft rejection in both LEW and BN recipients (Steinbrüchel et al., 1991; Brüning et al., 1989). Furthermore, in both 
LEW and BN rats CyA caused a comparable ablation of the medulia during administration, which was associated with loss of epithelium, dendritic cells, lymphocytes with a mature $\mathrm{T}$ cell phenotype (high TCR $\alpha \beta^{+}$), and MHC class II antigen expression. These thymic changes are reversed after cessation of CyA. Thymic cortical areas appeared not to be affected by CyA treatment. Comparable thymic changes are described for CyAtreated LEW (Beschorner et al., 1987a, 1991), PVG (RT I ${ }^{c}$ ) and WAG/CPB (RTI") rats (Schuurman et al., 1990). Furthermore, in BN rats CyA caused a maturation arrest of T cells as evidenced by a marked reduction of peripheral $\mathrm{CD} 4^{*} \mathrm{~T}$ cells during $\mathrm{CyA}$ administration and a rebound of these cells only after cessation of $\mathrm{CyA}$ administration. In the LEW model of CyA-AI, a comparable delayed recovery of the CD4 ${ }^{*} \mathrm{~T}$ lymphocyte subset under CyA administration has been described (Bos et al. 1988; Fischer et al., 1991). In LEW rats this rebound of $\mathrm{CD}^{+}$cells is associated with the onset of disease, regardless of the duration of CyA administration (Bos et al., 1988, 1989; Fischer et al., 1991).

Recently it has been shown that in the rat the $\mathrm{CD} 4^{+} \mathrm{T}$ cells can be divided into two subpopulations based on the expression of the antigens CD45RC (as recognized by monoclonal antibody $\mathrm{OX}-22$ ) and RT6. The CD45RC+RT6 subset of rat CD4+ T cells has a $\mathrm{T}$ helper $1\left(\mathrm{~T}_{\mathrm{H}} 1\right)$-like lymphokine repertoire (high $\mathrm{IL}-2$ and IFN $\gamma$ production but low IL-4) and provides cell-mediated immune responses, whereas the CD45RC RT $6{ }^{+}$population has characteristics of $\mathrm{T}$ helper $2\left(\mathrm{~T}_{\mathrm{H}}\right.$ )-type cells (the provision of $\mathrm{B}$ cell help, IL4 production, and suppression of cell-mediated responses but low IL-2 and IFN $\gamma$ production) (Fowell et al., 1991; Fowell and Mason, 1993). Furthermore, it has been demonstrated in a model for diabetes that the CD45RC $\mathrm{RT}^{+}$= subset contains the autoagressive cells, whereas the CD45RC RT6 $^{+}$subset inhibits this autoimmune potential (Fowell and Mason, 1993). In this context, it is interestingly to see that normal BN rats (known to respond in a $T_{H}$ 2-like fashion) have a preponderance of the $T_{H}$ 2-like subset over $T_{H} 1$, whereas for $\mathrm{LEW}$ rats (known to respond in a $\mathrm{T}_{\mathrm{H}} 1$-likefashion) the opposite is the case (Groen et al., 1993). The repertoire of cytokines produced can promote the development of either $T_{H} 1$ - or $T_{H^{2}}$-type responses. Most significantly, IL-4, a product of $T_{H^{2}}$-type $T$ cells, inhibits the induction of $T_{H} 1$-type responses, suggesting that a potent $T_{H} 2$ reaction, as present in BN rats, is likely to decrease cell-mediated immunity (Fowell and Mason, 1993). By analogy, adoptive transfer of unfractionated $C D 4^{+} T$ cells from untreated $B N$ rats to syngeneic secondary irradiated recipients would not lead to induction of autoimmune disease because this unfractionated population in normal $\mathrm{BN}$ rats consists of a mixture of predominating CD45RC.RT6 $6^{+}$cells $\left(\mathrm{T}_{\mathrm{H}}\right.$ 2-like) with autoregulatory (suppressor) activity and inferior CD45RC $+R T 6$ cells $\left(T_{H} 1\right.$-like) with autoreactive potential in a ratio of $28: 1$, whereas in LEW rats the CD4 $4^{+} \mathrm{T}$ cells showed a preponderance of CD45RC ${ }^{+}$RT6 (autoreactive) cells (Groen et al., 1993). We assume therefore that in the BN strain which was resistant to induction of CyA-AI, the CD45RC-RT6 ${ }^{+} \mathrm{T}$ cells were able to regulate the pathological responses of the CD45RC $\mathrm{RT}^{+} \mathrm{T}$ cell population, which was not the case for the LEW rats.

Second, BN rats may lack the target antigen(s) to which the autoimmune effector cells are directed. MHC class II molecules possibly represent one of these antigens, since in 
rats with acute CyA-AI cytotoxic T cells directed to public MHC class II epitope(s), including self-epitopes, have been demonstrated (Hess et al., 1985). This explanation, however, is also unlikely since apart from LEW also Lou/M rats (Tutschka et al., 1987), (LEWxBN)F1 rats (Geller et al., 1989), and DA rats (personal communication) are susceptible to induction of $\mathrm{CyA}-\mathrm{AI}$. There is no reason to assume that $\mathrm{MHC}$ class II antigen expression in BN rats would be significantly different from that in the susceptible rat strains. Susceptibility of LEW and (LEW XBN)F1 rats, taken together with the resistance of BN rats, suggests that susceptibility is genetically a dominant trait.

Third, resistance of BN rats to induction of CyA-AI might be due to weaker cell-mediated effector mechanisms leading to skin disease as compared to LEW. Others have shown a preponderance of CD4 over CD8 cells in cutaneous lesions in CyA-AI (Beschorner et al., 1988), which suggests that DTH effector T cells may be involved in bringing about the skin lesions.

Our data demonstrate that the dermal pathology of CyA-AI in LEW evolves even in the absence of DTH reactivity. On the other hand normal numbers of Langerhans cells were observed. Others have shown that CyA abolishes MHC class II expression on dendritic cells in the thymus, but does not influence peripheral MHC class II expression (Schuurman et al., 1990). DTH non-responsiveness in LEW rats could be due to dermal pathology or, alternatively, to absence of CD4 $4^{+}$DTH effector T cells. The latter hypothesis is unlikely since peripheral $\mathrm{CD}^{+} \mathrm{T}$ cells increased upon withdrawal of CyA and $\mathrm{CD}^{+} \mathrm{T}$ cells, presumably involved in mediating dermal changes, can be found at the site of the lesions in the skin (Bos et al., 1988; Fischer et al., 1991; Beschorner et al., 1988). In accordance with the former hypothesis, also in man, skin DTH reactions may be decreased in scleroderma patients, even when the antigen is applied subcutaneously (Glinsky and Jablonska, 1985). In contrast, others failed to demonstrate generalized defects of immune responsiveness in patients with systemic sclerosis (Lupoli et al., 1990). Finally, NK activity in LEW and BN rats was similar and not influenced by CyA-AI. Therefore, NK cell activity is unlikely to be involved in the mechanism(s) explaining resistance of $\mathrm{BN}$ rats to induction of CyA-AI.

The fourth and last hypothesis to be forwarded here rests on our observation that administration of CyA for either 3,6, or 12 weeks does not increase the severity of CyAAI after drug withdrawal (Bos et al., 1988). Apparently, when the potentially autoreactive $T$ cells generated under CyA administration have left the thymus during the first 2-3 weeks after BMT, even under prolonged $\mathrm{CyA}$ administration abberant negative selection in the thymus is corrected, although intrathymic MHC class II molecule expression remains suppressed (Beschorner et al., 1987b, 1988a, 1988b). This might be effected by the intrathymic generation of a $\mathrm{T}$ cell population counteracting the autoreactive $\mathrm{T}$ cells (Kimura and Wilson, 1984; Wilson, 1989). If this intrathymic balance would earlier be restored in the BN strain than in CyA-AI susceptible strains, the net effect in the BN strain would be a failure to release enough autoreactive effector $\mathrm{T}$ cells to cause CyA-AI. 


\section{Acknowledgements}

The excellent technical assistance of Marie-José van de Gaar is gratefully aknowledged. This study was finacially supported by the Dutch League against Rheumatic Diseases. 


\section{References}

Bacigalupo A, Malollno A, Van Lint MT, Occhini D, Gualandi F, Clavio M, et al.(1990), Cyclosporin A and chronic graft versus host disease. Bone Marrow Transplant 6: 341-344

Beschorner WE, Namnoun JD, Hess AD, ShInn CA, Santos GW (1987a). Cyclosporin A and the thymus. Immunopathology. Am J Pathol 126: 487-496

Beschorner WE, DI Gennaro KA, Hess AD, Santos GW (1987b). Cyclosporine and the thymus: Influence of irradiation and age on thymic immunopathology and recovery. Cell Immunol 110: 350-364

Beschorner WE, Hess AD, Shinn CA, Santos GW (1988a). Transfer of Cyclosporine-associated syngeneic graft-versus-host disease by thymocytes. Resemblance to chronic graftversus-host disease. Transplantation 45: 209-215

Beschorner WE, Olson JL, Hess AD, Di Gennaro KA, Santos GW (1988b). Cyclosporineinduced cell-mediated injury of the thymic medullary epithelium. Transplantation 45: 797803

Beschorner WE, Armas OA (1991). Loss of medullary dendritic cells in the thymus after cyclosporine and irradiation. Cell Immunol 132: 505-514

Bolton C, Allsopp G, Cumer ML (1982). The effect of cyclosporin A on the adoptive transfer of experimental allergic encephalomyelitis in the Lewis rat. Clin Exp Immunol 47: 127 32

Bos GMJ, Majoor GD, Van Breda Vriesman PJC (1988). Cyclosporin A induces a selective, reversible suppression of $T$-helper lymphocyte regeneration after syngeneic bone marrow transplantation: association with syngeneic graft-versus-host disease in rats. Clin Exp Immunol 74: 443-448

Bos GMJ, Majoor GD, Van de Gaar M-J, Van Breda Vriesman PJC (1989). T-helper lymphocytes and syngeneic graft-versus-host disease. Tranplant Proc 21 : 3016-3017

Bos GMJ, Majoor GD, Van Breda Vriesman PJC (1990). Graft-versus-host disease: the need for a new terminology. Immunol Today $11: 433-436$

Brining JH, Bruggeman CA, Van Breda Vriesman PJC (1989). The effect of cyto-megalovirus infection on renal allograft function and rejection in a rat model. Transplantation 47: 742744

Bryson JS, Jennings CD, Caywood BE, Kaplan AM (1989). Induction of a syngeneic graftversus-host disease-like syndrome in DBA/2 mice. Transplantation 48: 1042- 1047

Cheney RT, Sprent J (1985). Capacity of Cyclosporine to induce auto-graft-versus-host disease and impair intrathymic T cell differentiation. Transplant Proc 17: 528-530

Fischer AC, Hess AD (1990). Age-related factors in Cyclosporin-induced syngeneic graft-versus-host disease: regulatory role of marrow-derived T lymphocytes. J Exp Med 172: 8594

Flscher AC, Laulls MK, Horvitz L, Hess AD (1991). Effect of Cyclosporine on T lymphocyte development. Relationship to syngeneic graft-versus-host disease. Transplantation 51: 252-259 
Fowell D, McKnight A.J, Powrie F, Dyke R, Mason D (1991). Subsets of CD4* T cells and their Roles in the induction and prevention of autoimmunity. Immunol Rev 123:37-64

Fowell $\mathbf{D}$ and Mason $\mathbf{D}$ (1993). Evidence that the T cell repertoire of normal rats contains cells with the potential to cause diabetes. Characterization of the CD4* $\mathrm{T}$ cell subset that inhibits this autoimmune potential. J Exp Med 177: 627-636

Geller RB, Esa AH, Beschorner WE, Frondoza CG, Santos GW, Hess AD (1989). Successful in vitro graft-versus-tumor effect against an la-bearing tumor using cyclosporin induced syngeneic graft-versus-host disease in the rat. Blood 74:1165-1171

Glonier A, Tutschka PJ, Farmer ER, Santos GW (1983). Graft-versus-host disease in Cyclosporin A-treated rats after syngeneic and autologous bone marrow transplantation. I Exp Med 158: 1-8;

Glinsky W, Joblonskn S (1985). Subsets of systemic sclerosis (SSc) with respect to experimental sensitization of patients to dinitrochlorobenzene (DNCB). Connect Tissue Res 4: 15-30

Groen $H_{4}$ Katter FA, Van Petersen AS, Pater JM, Nleuwenhuis P, Kampinga J (1993). Composition of rat $\mathrm{CD}^{*}$ resting memory $\mathrm{T}$ cell pool is influenced by MHC. Transplant Proc, in press

Herberman RB (1982). Natural killer cells and their possible relevance to transplantation biology. Transplantation $34: 1-7$

Hess AD, Horwitz L, Beschomer WE, Santes GW (1985). Development of graft versus-host disease-like syndrome in Cyclosporine-treated rats after syngeneic bone marrow transplantation. I. Development of cytotoxic T lymphocytes with apparent polyclonal anti-Ia specificity, including autoreactivity. J Exp Med 161:718-730

Hess AD, Colombani PM, Esa AH (1986). Cyclosporine and the immune response: basic aspects. Crit Rev Immunol 6: 123-149

Jones RJ, Hess AD, Mann RB, Plantadosi S, Vogelsang GB, Farmer ER, Geller RB, Santos GW (1989). Induction of graft-versus-host disease after autologous bone marrow transplantation. Lancel 1: 754-757

Kimura H, Wilson DB (1984). Anti-idiotypic cytotoxic T cells in rats with graft-versus-host disease. Nature 308: $463-464$

Lupoli S, Amlot P, Black C (1990). Normal immune responses in systemic sclerosis. J Rheumatol $17: 323-327$

Schuurman H-J, Van Loveren H, Rozing J, Van Dijk A, Loeber JG, Vos JG (1990). Cyclosporin and the rat thymus. An immunohistochernical study. Thymus 16: 235-254

Shevach EM (1985). The effect of cyclosporin A on the immune system. Ann Rev Immunol 3: $397-423$

Soroldn R, KImura H, Schroder K, WIIson DH, WIson DB (1986). Cyclosporin-induced autoimmunity. Conditions for expressing disease. Requirement for intact thymus, and potency estimates of autoimmune lymphocytes in drug-treated rats. J Exp Med 164: 1615. 1625

Steinbrichel DA, Koch C, Krtstensen T, Kemp E (1991). Monoclonal antibody treatunent (antiCD4 and anti-Interleukin-2 receptor) combined with Cyelosporin $A$ has a positive but not. simple dose-dependent effect on rat renal allograft survivall. Scand J Immunol 34: 627-633

Stiller CR, Dupre J, Gent R, Jenner MR, Keown PA (1984). Effects of cyclosporine immunosuppression in insulin-dependent diabetes mellitus of recent onset. Science 223: 1362 1367 
Thorbecke GJ, Silberberg-SInakln I, F lotte TJ (1980). Langerhans cells as macrophages in skin and lymphoid organs. I Invest Dermatol 75: 32-43

Tutschka PJ, Beschomer WE, Allson AC, Burns WH, Santos GW (1979). Use of Cyclosporine $A$ in allogeneic bone marrow transplantation in the rat. Nature 280: 5718-5719

Tutschka PJ, Berkowitz SD, Tuttle S, Klein J (1987). Graft-versus-leukemia in the rat: The antileukemic efficacy of syngeneic and allogeneic graft-versus-host disease. Transplant Proc 19: 2668-2673

Von Graftenried B (1989). Sandimmun ${ }^{\mathfrak{R}}$ (Cyclosporin) in autoimmune diseases. Overview on early experience (status September 1987). Am J Nephrol 9 (Suppl 1): 51-56

WhIte DJ, Calne RY (1982). The use of cyclosporin A. Immunosuppression in organ grafting. Immunol Rev 65: 115-131

Wysbek AM, Majoor GD, Slanf DW, Bos GMJ, Meljers-Jellema R, Weljmer-van Velzen JS, Van Breda Vriesman PJC (1991). Detection of contact dermatitis in rat skin by intravital microscopy. Int J Microcirc Clin Exp 10: 193-204

Wilson DB (1989). Idiotypic regulation of $\mathrm{T}$ cells in graft-versus-host disease and autoimmunity. Immunol Rev 107: 159-177

Wodzig KWH, Majoor GD, Van Breda Vriesman PJC (1991). On the localization of effector cells in cyclosporin-induced autoimmunity. Autoimmunity 10: 275-283 


\title{
|Chapter 3
}

\section{Malignant neoplasms in}

\section{Cyclosporine A-induced}

\author{
autoimmunity
}

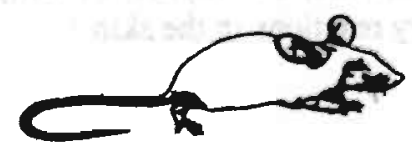




\section{Malignant neoplasms in Cyclosporine A - induced autoimmunity}

\section{Abstract}

Lethally irradiated LEW rats reconstituted with syngeneic bone marrow and given Cyclosporine A (CyA) for 6 weeks following syngeneic bone marrow transplantation (BMT) develop, 2-3 weeks after withdrawal of CyA, symptoms of disease resembling graft-versus-host disease (GVHD) as seen after allogeneic bonemarrow transplantation. Symptoms of disease include acute dermatitis, chronic disease resembling scleroderma, and occasionally antibody-mediated myasthenia gravis.

This study shows that animals treated according to this protocol may, after cessation of CyA administration, in addition develop malignant neoplasms. In one experiment, 27 out of 35 experimental animals developed rapidly progressive subcutanoous and/or intracutaneous tumors commencing at 6 weeks $(n=1), 13$ weeks $(n=1)$, and about 6 months $(n=25)$ after cessation of CyA. None of the 21 control animals developed tumors during a follow-up period of over one year. In 19 experimental rats mesenchymal tumors, mostly high grade sarcomas, were present, and in 5 adenocarcinomas. The majority of tumors expressed either class I or both class I and class II MHC antigens. Tumors were both as explants and as cell suspensions transferable to syngeneic LEW but not to allogeneic BN, and congenic LEW.1N or BN.1L rats, demonstrating that both major and minor histocompatibility antigens are required for tumor growth. This study shows that malignant neoplasms may arise as a late complication of CyA-induced, thymusdependent autoimmune disease. The genesis of these malignancies might be explained by the conjunction of X-irradiation and thymus ( $T$ cell)-dependent immune-mediated chronic inflammatory reactions in the skin. 


\section{Introduction}

Cyclosporine $\mathrm{A}(\mathrm{CyA})$ has been shown to be an effective immunosuppressive agent acting primarily on $T$ lymphocyte-dependent immune responses. It has been used extensively to suppress allograft rejection (Shevach, 1985; Hess et al., 1986), acute graft-versus-host disease (GVHD) associated with allogeneic bone marrow transplantation (BMT) (Tutschka et al., 1979; Bacigalupo et al., 1990) and treatment of several autoimmune diseases, i.e. diabetes mellitus, multiple sclerosis and lupus erythematosus (Stiller $e t$ al., 1984; Von Graffenried et al., 1989). By contrast, administration of CyA after X-irradiation and syngeneic bone marrow transplantation (BMT) may induce thymus-dependent autoimmune disease (CyA-AI) resembling GVHD as seen after allogeneic BMT (Glazier et al., 1983). For example, lethally X-irradiated LEW rats reconstituted with syngeneic bone marrow and given CyA for 5 weeks following BMT develop, usually 2-3 weeks after withdrawal of CyA, symptoms of disease. These symptoms may include acute disease resembling GVHD, chronic disease resembling scleroderma, and antibody-mediated disease like myasthenia gravis. This phenomenon (also referred to as syngeneic GVHD) can be reproducibly elicited in young animals of certain rat and mouse strains (Fischer $e t$ al., 1990; Cheney and Sprent, 1985; Bryson et al., 1989), and may also occur in humans (Jones et al., 1989). The central role of the thymus in CyA-AI has been unequivocally established. Shielding of the thymus during total-body X-irradiation (TBI), as well as thymectomy prior to TBI, prevented the induction of CyA-AI (Sorokin et al., 1986).

The unmodified thymus plays a key role in the generation of T lymphocytes involved in immune surveillance and cytotoxic activity versus foreign and/or transformed cells (Melief and Kast, 1991). Under the experimental conditions described, CyA has been reported to disturb induction of tolerance to self. In our model, CyA is only administered transiently during the period of recapitulation of thymic ontogeny after $\mathrm{X}$-irradiation, resulting in an arrest of maturation of thymic $\mathrm{T}$ cells to CD4 and CD8 single positive cells (Beschorner et al., 1987; Gao et al., 1988; Jenkins et al., 1988; Hiramine et al., 1989; Kosugi et al., 1989; Fischer et al., 1991) and in aberrant negative selection (Hess et al., 1985; Hess and Fischer, 1989). The development of CyA-AI appears to be associated with the reappearance of $\mathrm{CD} 4^{+} \mathrm{T}$ cells in the peripheral blood about two weeks after withdrawal of CyA (Bos et al., 1988; Fischer et al., 1991) and/or the induction of cytolytic T lymphocytes (CTLs) recognizing a public MHC class II determinant (Hess et al., 1985). On the basis of this observation the model of CyA-AI has been propagated in man as a therapeutic manoeuvre for treating class II MHC positive hematopoietic neoplasms, e.g. non-Hodgkin's lymphomas (Jones et al., 1989; Hess et al., 1992).

We now report, paradoxically, the development of malignant neoplasms as a late symptom of CyA-AI. In the present study we have investigated some parameters like the incidence, onset, and type of tumors, and we addressed the question whether development of tumors was related to X-irradiation, CyA administration, or the presence of CyA-AI. 


\section{Materials and methods}

\section{Animals}

Fernale, specific pathogen-free (SPF) Lewis (LEW, $\left.R T 1^{l}\right)$ and $B N\left(R T l^{n}\right)$ rats were used. LEW rats were purchased from Charles River (Sulzfeld, Germany) and BN rats were obtained from our own breeding stock (Department of Central Animal Facilities, University of Limburg, Maastricht). Congenic female LEW. IN (possessing the BN MHC on the LEW genetic background) and BN.1L rats (genetically reciprocal to LEW.1N) were purchased from the Zentralinstitut für Versuchstierzucht, Hannover, Germany. Animals were used at the age of 4-6 weeks.

\section{Protocol for induction of CyA-Al}

LEW rats were given $8.5 \mathrm{~Gy}$ at $0.5 \mathrm{~Gy} / \mathrm{min}$. using a Röntgen irradiation machine (Philips MG320, Hamburg, Germany) one day prior to syngeneic BMT. Bone marrow(BM) donor rats were killed by cervical dislocation under ether anaesthesia. BM was collected from tibias and femurs in Dulbeccos balanced salt solution supplemented with $2 \%$ heatinactivated fetal calf serum (iFCS), penicillin $(100 \mathrm{U} / \mathrm{ml})$ and streptomycin $(100 \mu \mathrm{g} / \mathrm{ml})$ (DBSS). Recipient rats received $6 \times 10^{7}$ viable syngeneic bone marrow cells in $1.0 \mathrm{ml}$ DBSS intravenously into a tail vein. CyA, a gift from Sandoz Co. Ltd., Basel, Switzerland, was dissolved in olive oil at a concentration of $7.5 \mathrm{mg} / \mathrm{ml}$. Rats were weighed daily and received $7.5 \mathrm{mg} / \mathrm{kg} /$ day CyA subcutaneously for 6 weeks starting on the day of BMT. CyA-AI usually developed 2-3 weeks after cessation of CyA administration (Wodzig et al., 1991).

\section{Design of the experiment}

A cohort of 35 experimental LEW rats received X-irradiation, syngeneic BMT, and CyA and are referred to as LEW/XCYA (Table 3.1). Age-matched control LEW rats $(n=21)$ included 7 rats that received X-irradiation, syngeneic BMT, and olive oil (LEW/XOil); 7 rats that received only CyA (cyaLEW); and 7 non-treated rats (nLEW).

\section{Scoring of macroscopic pathology}

After withdrawal of CyA, development of CyA-AI was assessed by examination of the rats twice a week for signs and symptoms of disease: red acra (hyperemia of the skin of the ears, feet and tail), inflammation of the eyelids, dermatitis, alopecia and weight loss (Wodzig et al., 1991).

\section{Histology of tumors}

Tumors were isolated from rats treated for induction of CyA-AI by sterile surgical procedures. Tumor fragments were either fixed in $4 \%$ neutral buffered formalin, embedded 
in paraffin, and stained with hematoxylin and eosin or frozen in isopentane at $-70^{\circ} \mathrm{C}$ for immunohistochemical studies.

\section{Immunohistochemistry}

Frozen tumor fragments were cut at $4 \mu \mathrm{m}$, fixed in cold acetone, and air dried. Sections were washed 3 times for $5 \mathrm{~min}$ with PBS. Incubations were performed at room tempera= ture in wet chambers. Sections were incubated for 60 min with primary mouse monoclonal antibodies (MAbs) diluted in phosphate buffered saline (PBS) with $0.05 \%$ bovine serum albumin (BSA) according to previously determined magnitude. Primary MAbs included OX18 (detecting rat MHC class I antigen, RT1.A), OX6 (rat MHC class II antigen, RT1.B), RECA-1 (rat endothelial cells), MDE II (human desmin; cross-reactive with rat desmin and localizes desmin in tumors derived from muscle tissue), and MVI (bovine vimentin; cross-reactive with rat and staining vimentin in fibroblasts, endothelial cells, lymphoid tissue and melanocytes as well as tumors derived from such cells). Furthermore, a rabbit antiserum (Z311) directed to bovine S-100 A and B antigens (cross-reactive with rat and human S-100 A and B antigens present in glial and ependymal cells in the brain, Schwanns cells of the peripheral nervous system, skin melanocytes, and Langerhans cells) was used. Antibodies of the OX series were kindly donated by Dr. A. Williams, Oxford, UK and RECA-1 by Dr. A.M. Duijvestijn, Maastricht, The Netherlands. MAbs to desmin and vimentin were purchased from Organon Teknika (Oss, The Netherlands) and the antiserum Z311 from DAKO (Glostrup, Denmark). After incubation with primary antibodies, sections were washed with PBS and incubated with horse radish peroxidase (HRP)-conjugated rabbit anti-mouse IgG (DAKO, Glostrup, Denmark) diluted in PBS supplemented with 3\% normal rat serum. After washing with PBS, sections were stained by incubation with $0.05 \%$ diaminobenzidine (DAB) and $0.06 \%$ hydro. gen peroxide in $50 \mathrm{mM}$ Tris- $\mathrm{HCl} \mathrm{pH} 7.6$ for $10 \mathrm{~min}$. Sections were counterstained with hematoxylin, dehydrated, and mounted with Entallan.

\section{Transfer of sarcoma explants and cell suspensions}

LEW sarcomas were cut in cubicles of $3 \times 3 \times 3 \mathrm{~mm}$ and 2 fragments were transplanted subcutaneously to the left and 2 to the right side of syngeneic LEW, LEW, IN, BN.1L and BN rats. In case of tumor "take", increased tumor size was usually palpable 2-3 weeks after transplantation. Animals were monitored for tumor growth up to 2 months after transplantation. In case no tumor growth was detected by palpation, obduction was performed two months after transplantation to confirm failure of tumor "take". For single cell suspensions, LEW sarcomas were cut in cubicles of $5 \times 5 \times 5 \mathrm{~mm}$ and incubated with collagenase type I (200 U/mg; Sigma, St.Louis, USA) and DNase I (400-600 U/mg; Sigma) in $10 \mathrm{ml}$ Eagles medium for $20 \mathrm{~min}$ at $37^{\circ} \mathrm{C}$ under gentle rotation. Thereafter, $35 \mathrm{U} / \mathrm{ml}$ hyaluronidase type IV (800-2,000 U/mg; Sigma) was added for $5 \mathrm{~min}$ to complete dissociation. The digest was poured through nylon gauze screens $(100 \mu \mathrm{m}$ mesh) to separate single cells from non-dissociated tumor fragments. The resulting single cell suspension was centrifuged for $10 \mathrm{~min}, 490 \mathrm{~g}$, at $4^{\circ} \mathrm{C}$, washed $2 \mathrm{x}$ with Hanks's Balanced Salt Solution (HBSS) and cell viability assessed by trypan blue exclusion. Five to 60 million tumor cells were transferred to LEW rats by subcutaneous injection at each flank. 


\section{Statistics}

Differences in the weights of rats from different groups were tested for statistical significance by Wilcoxons rank sum test.

\section{Results}

\section{Induction of CyA-Induced autolmmunity (CyA-Al)}

A group of 35 experimental LEW rats was treated according to the protocol for induction of CyA-AI (LEW/XCyA); control LEW rats were included in the experiment (LEW/ XOil, cyaLEW, and nLEW). After discontinuation of CyA animals were monitored for signs and symptoms of disease as described above. On day 7 after cessation of CyA, both the LEW/XCYA and all control LEW rats on average had gained $2 \%$ and $3 \%$ in body weight respectively as compared to day 0 . On day 14 after withdrawal of CyA, the mean body weight of the LEW/XCYA rats had dropped $1 \%$ as compared to the mean body weight on day 0 (range of individual weight change: $-15 \%$ to ${ }^{*} 4 \%$ ). In contrast, the mean body weight of all control rats showed an increase of $5 \%$ as compared to day 0 (range of individual weight gain: $1-10 \%$ )(Fig. 3.1). The difference in mean body weight of LEW/ $\mathrm{XCYA}$ and pooled controls was statistically significant on day 14 after $\mathrm{CyA}$ withdrawal and remained so for the duration of the experiment $(P<0.001)$. The weight loss of the LEW/XCYA rats in the acute phase of disease coincided with the appearance of the clinical symptoms of CyA-AI.

Twenty-three out of $35(66 \%)$ LEW/XCyA rats developed macroscopic symptoms of CyA-AI 2-4 weeks after withdrawal of CyA. Seven weeks after cessation of CyA, 32 out of $35(91 \%)$ LEW/XCyA rats showed signs of CyA-AI. None of the controls developed any macroscopic abnormality (Table 3.1 ).

\section{Incldence of mallgnant neoplasms In CyA - A}

During follow-up of the LEW/XCyA animals for 12 months 27 out of 35 rats (77\%) developed neoplasins, whereas in 21 controls no tumors were found. Within the LEW/XCYA group, tumors occurred with comparable incidence in rats showing no symptoms of CyAAI $(2 / 3 ; 66 \%)$, in rats with severe alopecia $(20 / 24 ; 83 \%)$, and in rats with partial alopecia (thin fur ) $(5 / 8 ; 63 \%)$. The earliest development of neoplasms, however, was observed in rats progressing to full alopecia after an episode of acute dermatitis, at $6(n=1)$ and 13 weeks $(n=1)$ after cessation of CyA respectively; all other tumors were observed more than 24 weeks after cessation of CyA (Table 3.2). 


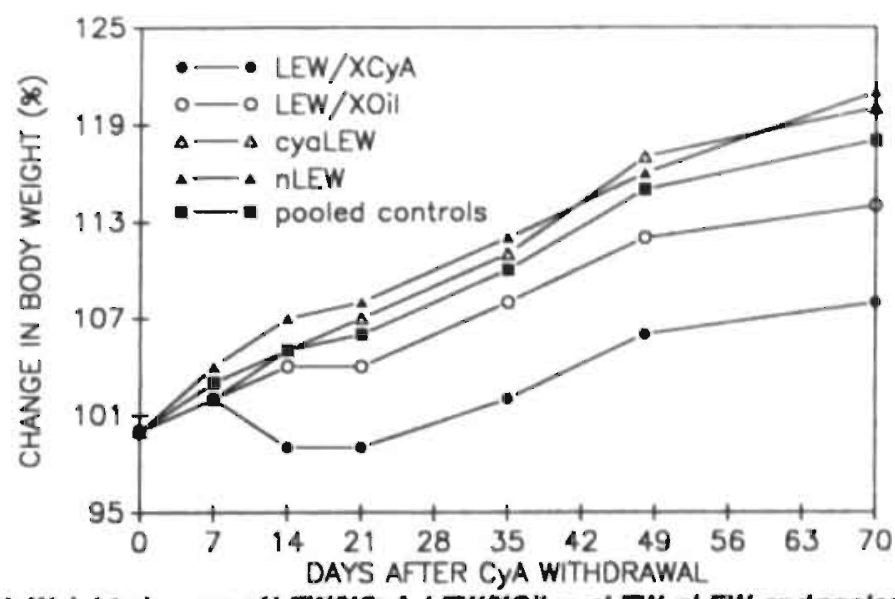

Flgure 3.1: Weight changes of LEW/XCYA, LEW/XOll, cyal.EW, nLEW, and pooled controls after CYA withdrawal. Mean relative weights are shown as compared to the weight on the day of CyA discontinuation (day $0=100 \%$ ). From day 14 onward LEW/XKCyA versus pooled controls $p<0.001$ and for $L E E W / X C Y A$ versus LEW/XOII $p<0.05$.

Table 3.1: Design of the experiment and incidence of $C y A$-induced autoimmune disease.

\begin{tabular}{|c|c|c|c|c|c|c|}
\hline \multirow[t]{2}{*}{ Group } & \multirow[t]{2}{*}{$N$} & \multicolumn{2}{|c|}{ Treatment ${ }^{3}$} & \multicolumn{3}{|c|}{ Onset of $\left.C y A \cdot A\right|^{b}$} \\
\hline & & $X \cdot i r r+s B M T$ & CyA & acute ${ }^{\mathrm{C}}$ & subacute ${ }^{c}$ & absent: \\
\hline \multicolumn{7}{|l|}{ Experimental } \\
\hline LEW/XCYA & 35 & . & • & 23 & 9 & 3 \\
\hline \multicolumn{7}{|l|}{ Controls } \\
\hline LEW/XOII & 7 & + & . & & & 7 \\
\hline cyatEW & 7 & - & • & & & 7 \\
\hline nLEW & 7 & . & $=$ & & & 7 \\
\hline
\end{tabular}

aX-irr, X.irradiation; SBMT, syngeneic bane marrow transplantion; CyA. Cyclosporine $A$ administra. tion $(7.5 \mathrm{mg} / \mathrm{kg} /$ day 10 ; 5 weeks). DCyA-Al was established by erythroderma, dermatitis, alopecia, and weight loss. ${ }^{C}$ Acute: within 4 weeks after cessation of $C y A$; subacute: more than 4 weeks after withdrawal of CYA.

Table 3.2: Indidence and onset of neoplasms in CyA - Al.

\begin{tabular}{|c|c|c|c|c|c|}
\hline \multirow[t]{2}{*}{ Group } & \multirow[t]{2}{*}{$\mathrm{N}$} & \multirow{2}{*}{$\begin{array}{l}\text { Tumor } \\
\text { Incidence }(\%)\end{array}$} & \multicolumn{3}{|c|}{ Onset of tumor after CVA withdrawal } \\
\hline & & & 6 weeks & 13 weeks & $>24$ weeks \\
\hline Controls & 21 & $0 / 21(0)$ & & & \\
\hline \multicolumn{6}{|l|}{ EXp. LEW/XCYA } \\
\hline $\begin{array}{l}\text { No symptoms } \\
\text { of CyA-Al }\end{array}$ & 3 & $2 / 3(66)$ & & & $2^{a}$ \\
\hline Alopecia & 24 & $20 / 24(83)$ & 1 & 1 & 18 \\
\hline Thin Fur & 8 & $5 / 8(63)$ & & & 5 \\
\hline All LEW/XCYA & 35 & $27 / 35(77)$ & & & \\
\hline
\end{tabular}

ane of these tumors is an iradiation-inducedlosteosarcoma; due to extensive necrosis of the second tumor no histological diagnosis covid be made. 


\section{Characterization of Mallgnant Neoplasms in CyA-A}

\section{Histopathology}

Subcutaneous and/or intracutaneous tumors developed in 27 LEW/XCyA rats. Mesenchymal tumors were present in 19 rats, epithelial tumors in 5 rats, and an epithelial as well as a mesenchymal tumor in 2 rats. Due to extensive necrosis, in one case no distinct histological diagnosis of the tumor could be made.

Of the 19 rats developing a mesenchymal tumor, one was a benign neurofibroma. The others were malignant with characteristics of, usually high grade, sarcomas showing histological patterns of malignant fibrous histiocytoma $(\mathrm{MFH})(\mathrm{n}=5)($ fig. 3.2), fibrosarcoma ( $n=4)$ (fig. 3.3), round cell sarcoma not otherwise specified $(n=2)$, malignant schwannoma ( $n=2$; characterized by histology and abundant expression of the $S-100$ antigen), osteosarcoma $(n=1)$, and rhabdomyosarcoma ( $n=4$; characterized by histology and expression of desmin) (Table 3.3). The osteosarcoma and the tumor without diagnosis had developed in rats with no clinical symptoms of CyA-AI.

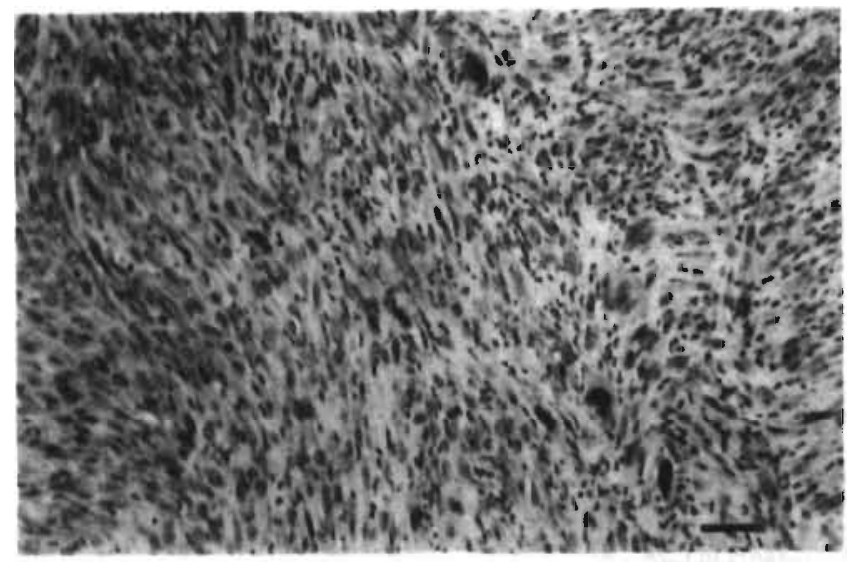

Flg 3.2: Malignant fibrous histiocytoma; glantcellsh a spindie coll tumor (Bar represents $50 \mu \mathrm{m}$ )

Flg 3.3: Fibrosarcoma; spindlo celltumor (Bar represents $50 \mu \mathrm{m}$ )

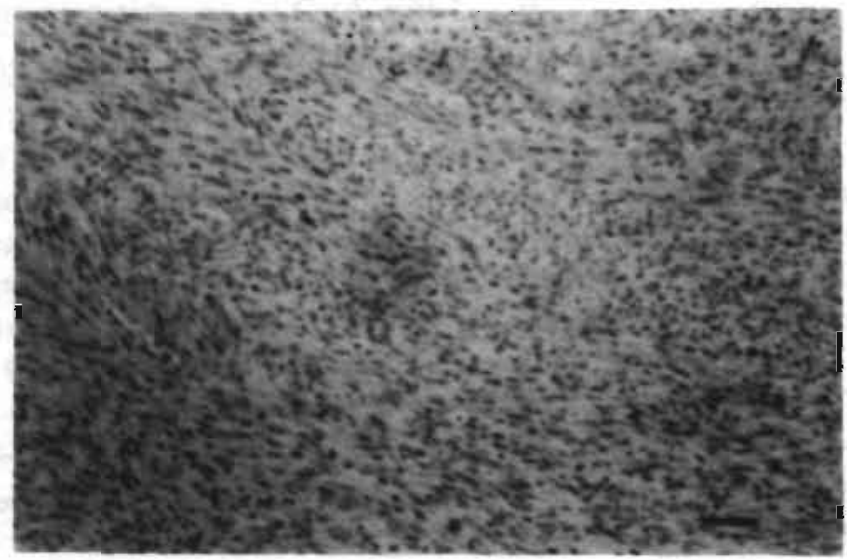


Table 3.3: Characterization of tumors in LEW/XCYA rats.

\begin{tabular}{|l|l|}
\hline Tumor type (total tumors in each (subigroup) & \\
\hline $\begin{array}{l}\text { Mesenchymal (19) } \\
\text { benign neurofibroma }\end{array}$ & 1 \\
high grade sarcoma (18) & 5 \\
malignant fibrous histiocytoma (MFH) & 4 \\
fibrosarcoma & 2 \\
round cell sarcoma not otherwise specified & 2 \\
malignant schwannoma & 1 \\
osteosarcoma & 4 \\
rhabdomyosarcoma & \\
Epithelial (5) & 2 \\
sebaceous carcinoma & 1 \\
syringocystadenocarcinoma & 1 \\
adenoid cystic carcinoma & 1 \\
carcinoma not further classified & \\
Mesenchymal + Epithelial (2) & 1 \\
benign fibroadenoma + fibrosarcoma & 1 \\
sebaceous carcinoma + round cell sarcoma & \\
No diagnosis (1) a & \\
\hline
\end{tabular}

a The osteosarcoma and the tumor without diagnosis developed in LEWIXCYA rats with no symproms of CYA-Al (see Table 3.2).

The epithelial tumors were all adenocarcinomas $(n=5)$ presumably of skin appendageal origin. These tumors showed features of sebaceous carcinoma $(n=2)$, syringocystadenocarcinoma papilliferum $(n=1)$, adenoid cystic carcinoma in $(n=1)$, whereas the remaining adenocarcinoma could not be further classified. Of the 2 rats that developed a mesenchymal as well as a separate epithelial tumor, one had a benign epithelial tumor localized in the breast, showing features of a fibroadenoma, and a fibrosarcoma. The other rat developed a tumor with characteristics of a sebaceous carcinoma and a separate mesenchymal tumor specified as a round cell sarcoma.

All tumors developed as rapidly progressive subcutaneous and/or intracutaneous tumors at different sites (Table 3.4). Tumor localization was not related to the sites of CyA injection. Tumors did not metastasize to other organs as verified macroscopically at autopsy, with the exception of the osteosarcoma which was prominent in the knee-joint and had metastasized to the kidney and stomach.

\section{Immunohistochemistry}

Mesenchymal tumors were heterogeneous with respect to $\mathrm{MHC}$ antigen expression. Eleven out of 18 high grade sarcomas expressed only MHC class I (60\%), 5 expressed both MHC class I and class II (28\%), 1 expressed only MHC class II (6\%), and I - the osteosarcoma - expressed neither MHC class. I nor class II antigens (6\%). MHC antigens 
Table 3.4: Localization and characterization of neoplasms in CyA - Al.

\begin{tabular}{|c|c|c|c|c|c|c|c|c|c|c|}
\hline \multirow[t]{2}{*}{ Localization } & \multirow[t]{2}{*}{$N$} & \multicolumn{7}{|c|}{ Mesenchymal tumora } & \multirow{2}{*}{$\begin{array}{l}\text { Epithelial } \\
\text { Tumor }\end{array}$} & \multirow{2}{*}{$\begin{array}{l}\text { Mes + Ep } \\
\text { Tumorb }\end{array}$} \\
\hline & & NF & $\mathrm{MFH}$ & FS & RCS & Sw & 0 & $\mathrm{Rh}$ & & \\
\hline \multirow{3}{*}{$\begin{array}{l}\text { Medial/lateral } \\
\text { right sidec } \\
\text { left side }\end{array}$} & & & & & & & & & & \\
\hline & 11 & & 3 & & & 1 & & 4 & & 2 \\
\hline & 4 & & 2 & & 2 & & & & & \\
\hline Head & 1 & & & 1 & & & & & & \\
\hline Hind leg/anus & 3 & & & & & & & & 3 & \\
\hline Hind leg & 2 & & & 1 & & & 1 & & & \\
\hline Front leg & 4 & 1 & & 1 & & 1 & & & 1 & \\
\hline Chest/neck & 2 & & & 1 & & & & & 1 & \\
\hline Total tumors & 27 & & & & & & & & & \\
\hline
\end{tabular}

oNF, neurofibroma; MFH, malignant fibrous histiocytoma; FS, fibrosarcoma; RCS, round cell sarcoma; SW, schwannoma; $O$, osteosarcoma; $R$, rhabdomyosarcoma. $b_{M e s}+E \rho$, both mesenchymal and epithelial tumor. CThe tumor without diagnosis developed ot the right side.

could not be detected on benign neurofibroma cells. Four out of 5 epithelial tumors expressed only MHC class I antigen ( $80 \%$ ), and 1 expressed both MHC class I and II antigens (20\%)(Table 3.5 ).

Table 3.5: MHC antigen expression of neoplasms in CyA - A.

\begin{tabular}{|c|c|c|c|c|c|}
\hline \multirow{2}{*}{ Tumor type } & \multirow[t]{2}{*}{$\mathrm{N}$} & \multicolumn{4}{|c|}{ Incidence of MHC expression in tumors } \\
\hline & & class I & class II & class $1 / 11$ & none \\
\hline \multirow{3}{*}{$\begin{array}{l}\text { Mesenchymal } \\
\text { Neurofibroma } \\
\text { Sarcoma }\end{array}$} & & & & & \multirow{3}{*}{$\begin{array}{l}1(100)^{a} \\
1(6)\end{array}$} \\
\hline & 1 & & & & \\
\hline & 18 & $11(60)$ & $1(6)$ & $5(28)$ & \\
\hline \multicolumn{6}{|l|}{ Epithelial } \\
\hline Adenocarcinoma & 5 & $4(80)$ & & $1(20)$ & \\
\hline
\end{tabular}

a/f percentage of tumors expressing either MHC or no MHC antigens.

Mesenchymal and epithelial tumors were well vascularized as assessed by staining with the MAb RECA-1.

All epithelial tumors showed cytoplasmic expression of keratin, whereas all mesenchymal tumors had cytoplasmic expression of vimentin. In addition, malignant schwannornas expressed the $\mathrm{S}-100$ antigen, the rhabdomyosarcomas expressed desmin. 


\section{Transfer of LEW sarcoma to different rat strains}

LEW sarcomas were transplanted to syngeneic LEW, allogeneic BN, and congenic LEW.IN and BN.IL rats. Growth of the explant was usually palpable 2-3 weeks after transplantation in syngeneic LEW, but not in allogeneic BN, congenic LEW. $1 \mathrm{~N}$ and BN.1L rats. BN, LEW. 1 N and BN. IL rats were checked for tumor growth up to 2 months after transplantation and obduction at two months confirmed failure of tumor "take" (Table 3.6).

Sixty million LEW fibrosarcoma cells were transferred as cell suspension to LEW, BN, LEW.IN, BN.1L, and immunocomprized (X-irradiated, BM-reconstituted) LEW and BN rats. LEW fibrosarcomas were transferable both as explants and as cell suspensions to untreated and immunocomprized LEW rats, but not to LEW.IN, BN. IL, BN or immunocomprized BN rats (Table 3.6).

Table 3.6 : Passive transfer of LEW sarcoma to different rat strains.

\begin{tabular}{|lcccccc|}
\hline Strain & LEW/Xa & LEW & LEW. 1N & BN. 1L & BN/Xa & BN \\
\hline MHC & 1 & 1 & $n$ & 1 & $n$ & $n$ \\
Genetic background & 1 & 1 & 1 & $n$ & $n$ & $n$ \\
Tumor "take" & + & + & - & & & \\
\hline
\end{tabular}

${ }^{2} L W / X$ and $B N / X$ rats are lethally irradiated and reconstituted with syngeneic bone marrow cells.

\section{Discussion}

The main findings of this study are fourfold. First, a substantial number of LEW rats treated for induction of CyA-AI (LEW/XCyA) developed malignancies, notably sarcomas including malignant fibrous histiocytoma (MFH). The latter is a tumor of heterogenous histogenesis with a widely dispersed immunohistochemical profile; the etiology is still unknown (Dehner, 1988). Second, these soft-tissue tumors developed late in the natural history of $\mathrm{CyA}-\mathrm{Al}$ and seem to be associated with cutaneous disease. Third, the majority of the tumors expressed to a variable extent either MHC class I or both MHC class I and class II antigens. Finally, the osteosarcoma excepted, no metastases were observed.

Although the pathogenesis of the neoplasms observed in this study is obscure, possible factors included the way in which the rats were $\mathrm{X}$-irradiated, the dose of syngeneic bone marrow administered, the dose and duration of CyA therapy, and the strain of rats used. There is circumstantial evidence to support the hypothesis that in the experimental setting used by us, these neoplasms are specific for CyA-Al for two reasons. First, no 
malignancies were observed in X-irradiated and syngeneic bone marrow-reconstituted animals nor in CyA-treated rats; this suggests (1) an indirect role for the manipulated thymus in the pathogenesis of these tumors and/or (2) interference of CyA with DNA-repair after $\mathrm{X}$-irradiation. Second, to our best knowledge there are no other rodent models which describe these tumors after $\mathrm{X}$-irradiation and/or $\mathrm{CyA}$ administration. Although Hess et al. $(1989,1992)$ also used the model of CyA-AI, they used different dosages of X-irradiation and $\mathrm{CyA}$; this resulted usually in progressive disease within two to four weeks after cessation of CyA and thus - compared to our model - less chronicity of lesions (Beschorner et al., 1988b).

Although in man tumors may develop following therapeutic or accidental X-irradiation, these are usually epithelial tumors, lymphoreticular neoplasms, and bone tumors (Hajdu, 1979; Land, 1987; Smith, 1987). Sarcomas have a tendency to 0 ccur in areas previously exposed to ionizing irradiation but arise uncommon in the field of X-irradiation; of the sarcomas osteosarcomas are most commonly induced by $\mathrm{X}$-irradiation (Smith, 1987; Chang et al., 1989). In other mammalian species the types of neoplasms observed after $\mathrm{X}$-irradiation may be different from those listed above for man. The types of neoplasms induced may be X-irradiation dose-dependent (Uptun, 1984) but tumors as described here for the model of CyA-AI have not been observed after X-irradiation alone.

A potent immunosuppressant like CyA also may have considerable side-effects; in general immunosuppression is often associated with increased incidence of malignancies (Penn, 1987). In man, the incidence of lymphoproliferative disorders and other malignant diseases is higher in CyA-immunosuppressed patients than in the population as a whole (Ryffel, 1992). The effect of CyA on carcinogenesis has been addressed in animal studies following the observation in man that high dosages of CyA given to renal allograft patients induced (non-Hodgkin's) lymphomas (Calne et al., 1979). In OF-1 mice and OFA rats high dosages of Cy A (between 8 and $16 \mathrm{mg} / \mathrm{kg}$ ) administered for 78 weeks or longer as a single agent did not increase tumor incidence when compared to controls (Ryffel et al., 1983). However, when mice were manipulated by X-or ultraviolet light (UV)-irradiation prior to chronic administration of CyA, a reduction in the latency period of lymphoma and/or cutaneous squamous cell carcinoma was observed, but the incidence of tumors was not increased (Hattori et al., 1987, 1988; Kelly et al., 1987). In contrast, another study failed to demonstrate a synergistic effect of X-irradiation and CyA administration (up to $100 \mathrm{mg} / \mathrm{kg}$ ) on either latency or incidence of murine lymphoma (Hooghe et al., 1989). In rats, chronic administration of Cy A accelerated the growth of chemically-induced gastrointestinal tumors (Ryffel, 1992). In man, in the setting of allogeneic kidney transplantation, CyA treatment may increase the incidence of nonHodgkin's lymphoma, squamous cell carcinoma of the skin, and Kaposi's sarcoma in this order (Penn, 1987; Penn and Brunson, 1989), but in the therapeutic doses used nowadays the incidence of these tumors is similar to that seen with other immunosuppressive regimes like azothioprine and prednisone (Ryffel 1992). Thus, possibly by virtue of its immunosuppressive effect chronic CyA administration may enhance tumor growth in some experimental models of disease and may elicit tumor growth in human allograft recipients (Penn, 1987; Penn and Brunson, 1989; Ryffel 1992). 
How then might the tumors in our model of CyA-AI be generated, and why did the tumors not metastasize? The model of CyA-AI has, been advocated as an anti-tumor treatment for a variety of hematologic (lymphohematopoietic) malignancies and solid tumors in man (Hess et al., 1992) because in this model cytotoxic lymphocytes can be demonstrated in vitro directed against public MHC class II determinants (Jones et al., 1989). Also in Lou/ $\mathrm{M}$ rats it has been shown that $\mathrm{CD} 8^{+} \mathrm{T}$ cells from animals with symptoms of acute $\mathrm{CyA}$ AI exerted in vitro tumor reactivity against a syngeneic plasmacytorna line which expressed MHC class II antigens (Hess et al., 185; Geller et al., 1989). The model of CyAAI was also assessed for anti-tumor effects in C57bl/6 mice. Mice were subjected to $\mathrm{X}$-irradiation, syngeneic bone marrow transplantation, and transient CyA therapy; although these mice did not develop clinically manifest CyA-AI they were capable of rejecting MHC class II bearing tumors provided interleukin-2 (IL-2) was infused as well (Charak et al., 1991). In contrast to the rat model, however, the IL-2-dependent antitumor effect was not mediated by cytotoxic T cells directed against MHC class II antigens, but by Thy $1^{+}$, asialo $\mathrm{GM}^{+}$cells. Furthermore, the antitumor effect of these killer cells was non-specific and not restricted to the tumor of the host only, unlike that seen with CyA alone. Thus, in this model two mechanisms that exert anti-tumor effects appear to be operative: IL-2 therapy supports the generation of killer cells with non-MHC-restricted cytotoxicity against most tumor cells, but not normal tissue (Charak et al., 1991), whereas CyA-AI induces killer cells with specificity against public MHC class Il determinants on both host and tumor cells (Hess et al., 1985; Jones et al., 1989; Geller et al., 1989; Hess et al., 1992).

Since the malignant tumors observed in our study expressed class I and/or class II MHC antigens (with the exception of the osteosarcoma with metastases) and because increased NK activity is present in the model of CyA-AI when compared to normal LEW rats both in the absence- (Wodzig et al., 1993) and presence of tumors, we suggest that the absence of metastases in MHC positive sarcomas is due to high NK activity and possibly antiMHC class II cellular cytotoxicity (Herberman, 1983; Hess et al., 1985, 1992; Reiter et al., 1991). NK-activity in a LEW/XCyA rat with a fibrosarcoma was increased 4-6 times (specific lysis $33.8 \%$ ) as compared to LEW/XCyA and nLEW rats (mean specific lysis $8.1 \%$ and $5.4 \%$ respectively)(data not shown).

How the tumors were generated is obscure but we offer the following explanation. Our hypothesis is based on the observation that no tumors were elicited in X-irradiated or CyA-treated rats, but that chronic inflammatory skin disease was present in $93 \%$ (25 out of 27) of all animals with tumors, the rat with the osteosarcoma excepted. Malignant neoplasms often develop in areas of chronic scarring, ulceration, or sinus formation, such as burn scar, chronic osteomyelitic sinus, decubitus ulcers, and in skin areas affected by lupus erythematosus (DeVita et al., 1989). With respect to inflammatory reaction and collagen deposition chronic CyA-AI shows strong similarity to human scleroderma, a frequently occurring manifestation of progressive systemic sclerosis (PSS)(Bos et al., 1989). In the acute phase of CyA-AI pathology encompassed diffuse infiltrates of mononuclear cells in the dermis, especially round small hair follicles in the upper dermis, and at the dermal/epidermal junction. Furthermore, myositis was frequently observed. 
Later on, folliculitis was the most conspicuous abnormality and affected small and large hair follicles in the dermis and subdermal fat. Fibrosis of the subdermal region usually developed around hair follicles with an inflammatory reaction. As the disease progressed from acute to chronic, the diffuse inflammation of the dermis decreased, but inflammation of hair follicles persisted; most prominently in hair follicles situated in the lower dermis or the subdermal fat. In the upper dermis, the number of hair follicles was reduced. In the dermis hyperplasia of sebaceous glands was frequently observed and fibrosis still progressed. The majority of rats with chronic CyA-AI showed persistence of the inflammatory reaction, manifesting as a folliculitis in the subdermal fat, and as an increase of collagen in the subcutaneous region. A minority of rats with chronic CyA-AI showed no longer inflammatory reactions, but an increase of collagen and complete absence of subcutaneous fat only; some rats showed no signs of chronic disease (Bos et al., 1989). The presence of these scleroderma-like lesions in chronic CyA-AI rats may have contributed to and enhanced growth of these neoplasms; malignant fibrous histiocytoma showed similarities to the "fibrohistiocytoid"cells in chronic inflammation (Imai $e$ al., 1989) and the genesis of the adenocarcinomas may also be related to inflammatory skinreactions around hair follicles and sebaceous glands. Furthermore, several observations support a relationship between cancer (carcinoma) and PSS, like occurrence of breast carcinoma at or near the time of onset of scleroderma (Lee et al., 1983), increased incidence of lung cancer (bronchogenic carcinoma) (Roumm et al., 1985), and rarely alveolar cell carcinoma (Talbot et al., 1979).

In the experimental model of CyA-AI tumors could be transplanted as explants or cell suspensions to normal LEW rats where they showed progressive, non-metastatic growth. This observation argues against the hypothesis that interference with thymic programming (resulting in aberrant immunosurveillance) (Melief and Kast, 1991) in conjunction with $\mathrm{X}$-irradiation-mediated DNA damage initiating a process of transformation causing the growth of sarcomas and to a lesser extent epithelial tumors. This view, in addition, is refuted by the fact that these tumors grow well in normal LEW rats with an unmanipulated thymus.

In conclusion, our hypothesis holds that in this experimental model tumors were caused by a combination of $\mathrm{X}$-irradiation and a chronic - cutaneous - inflammatory reaction and in this fashion were indirectly thymus-dependent. Further experiments are required to elucidate the mechanisms operative in this model.

\section{Acknowledgements}

The excellent technical assistance of Marie-Jose van de Gaar is gratefully acknowledged. We would like to thank Dr. A.T.M.G. Tiebosch (Department of Pathology) for histopathological and immunohistochemical analysis of tumors. 


\section{References}

Bacigalupo A, Malolino A, Van Lint MT, Occhini D, Gualandi F, Clavio M et al. (1990). Cyclosporin A and chronic graft-versus-host disease. Bone Marrow Transplant 6:341-344

Beschorner WE, Namnoun JD, Hess AD (1987). Immunopathology of rat thymus after Cyclosporine A. Transplant Proc 19: 1230-1235

Beschorner WE, Olson JL, Hess AD, DiGenarro KA, Santos GW (1988a), Cyclosporine-induced cell-mediated injury of the thymic epithelium. Transplantation 45: 797-803

Beschorner WE, Shinn CA, Fischer AC, Santos GW, Hess AD (1988b). Cyclosporine-induced pseudo-graft-versus-host disease in the early post-cyclosporine period. Transplantation 46 (Suppl.): 112S-117S

Bos GMJ, Majoor GD, Breda Vriesman PJC van (1988). Cyclosporin A induces a selective. reversible suppression of $T$-helper lymphocyte regeneration after syngeneic bone marrow transplantation: association with syngeneic graft-versus-host disease in rats. Clin Exp Immunol 74: 443-448

Bos GMJ, Majoor GD, WIllighagen RGJ, Van Breda Vriesman PJC (1989). Chronic cyclosporin-induced autoimmune disease in the rat: A new experimental model for scleroderma. J Invest Dermatol 93: 610-615

Bryson JC, Jennings CD, Caywood BE, Kaplan AM (1989). Induction of a syngeneic graftversus-host disease-like syndrome in DBA/2 mice. Transplantation 48: 1042-1047

Calne RY, Rolles K, White DJG, Thiru S, McMaster P, Craddock GN, Azdz S, Evans DB, Dunn DC, Henderson RG, Lewis P (1979). Cyclosporine A initially as the only immunosuppressant in 34 recipients of cadaveric organs: 32 kidneys, 2 pancreases, and 2 livers. Lancet 2: 1022-1033

Chang AE, Rosenberg SA, Glatstein EJ, Antman KH (1989). Sarcomas of soft tissue. In: Cancer. Principles and practice of oncology, eds. V.T. DeVita Jr., S. Hellman, S.A. Rosenberg, 3rd edition, J.B. Lippincott Company. Philadelphia, USA, 1989, pp 1345

Charak BS, Agoh R, Mazumder A (1992). Synergism of interleukin-2 and cyclosporine A in induction of graft-versus-tumor effect without graft-versus-host disease after syngeneic bone marrow transplantation. Blood 80: 179-184

Cheney RT and Sprent J (1985). Capacity of cyclosporine to induce auto-graft-versus-host disease and impair intrathymic $T$ cell differentiation. Transplant Proc 17: 528-530

Dehner LD (1988). Malignant fibrous histiocytoma. Nonspecific morphologic pattern, specific pathologic entity, or both? Arch Pathol Lab Med 112:236-237

Fischer AC and Hess AD (1990). Age-related factors in cyclosporine-induced graft-versus-host disease: regulatory role of marrow-derived T lymphocytes. J Exp Med 172: 85-94

Fischer AC, Laulis MK, Horwtz L, Hess AD (1991). Effect of cyclosporine on T lymphocyte development. Relationship to syngeneic graft-versus-host disease. Transplantation 51: 252-259

Gao E-K, Lo D, Cheney R, Kanagawa O, Sprent J (1988). Abnormal differentiation of thymocytes in mice treated with cyclosporin A. Nature 336: 176-179 
Geller RB, Esa AH, Beschorner WE, Frondoza CG, Santos GW, Hess AD (1989). Successful in vitro graft-versus-tumor effect against an Ia-bearing tumor using cyclosporin-induced syngeneic graft-versus-host disease in the rat. Blood 74: 1165-1171

Glazler A, Tutschka PJ, Farmer ER, Santos GW (1983). Graft-versus host disease in cyclosporin A-treated rats after syngeneic and autologous bone marrow reconstitution. J Exp Med 158: $1-8$

Hajdu SI (1979). In: Pathology of soft tissue tumors, Lea and Febiger, eds, Henry Kimpton Publishers, London, Great Brittain.

Hattori A, Perera MIR, Witkowsld LA, Kunz HW, GIll TJ, Shinozuka H (1986). Accelerated development of spontaneous thymic lymphomas in male AKR mice receiving cyclosporine. Transplantation 41: 784-787

Hattori A, Kunz HW, Gill TJ III, Shinoeuka H (1987). Thymic and lymphoid changes and serum immunoglobulin abnormalities in mice receiving cyclosporine. Am J Pathol 128: $111-120$

Hattori A, Kunz HW, Gill TJ, Pan SF, Shinozuka H (1988). Diversity of promoting action of cyclosporine on the induction of murine lymphoid tumors. Carcinogenesis 9: 1091

Herberman RB (1983). Immune surveillance hypothesis: updated formulation and possible effector mechanisms. Progr Immunol 5: 1157

Hess AD, Horwitz L, Beschorner WE, Santos GW (1985). Development of graft-versus-host disease-like syndrome in cyclosporine-treated rats after syngeneic bone marrow transplantation. I. Development of cytotoxic $\mathrm{T}$ lymphocytes with apparent polyclonal anti-La specificity, including autoreactivity. J Exp Med 161: 718-730

Hess AD, Colombanl PM, Esa AH (1986). Cyclosporine and the immune response: basic aspects. Crit Rev Immunol 6: 123-149

Hess AD and Fischer AC (1989). Immune mechanisms in cyclosporine-induced syngeneic graftversus-host disease. Transplantation 48: 895-900

Hess AD, Jones RJ, Morris LE, Noga SJ, Vogelsang GB, Santos GW (1992). Autologous graft-versus-host disease: A novel approach for antitumor immunotherapy. Human Immunol 34: 219-224

Hiramine C, Hojo K, Matsumoto H, Koseto M, Itoh M (1989). Differential effect of cyclosporine in vivo on the distribution of $T$ cell subsets in the thymus, spleen, and lymph nodes. Transplantation 47: 499-503

Hooghe R, Janowski M, Greimers R, Schaaf-Lafontalne N (1989). Radiation-induced lymphomas developing during cyclosporine treatment. Transplantation 48: 342-344

Imal Y, Yamakawa M, Sato T, Sudn A (1989). Malignant firbous histiocytoma: similarities to the "fibrohistiocytoid cells" in chronic inflammation. Virchows Archiv A Pathol Anat 414: 285-298

Jones RJ, Hess AD, Mann RB, Piantodosi S, Vogelsang GB, Farmer ER, Geller RB, Sentos GW (1989). Induction of graft-versus-host-disease after autologous bone marrow transplantation. Lancet 1: 754-757

Kelly GE, Meikle W, Shell AGR (1987). Effects of immunosuppressive therapy on the induction of skin tumors by ultraviolet irradiation in hairless mice. Transplantation 44: 429-434

Land CE (1987). Temporal distribution of risk for radiation-induced cancers. J Chron Dis 40 (Suppl.2): 45S-57S 
Lee P, Alderdice C, Wilkinson S et al., (1983). Malignancy in progressive systemic sclerosis. Association with breast carcinoma. J Rheumatol 10: 665-666

Melief CJM and Kast WM (1991). Cytotoxic T lymphocyte therapy of cancer and tumor escape mechanisms. Seminars in Cancer Biology 2: 347-354

Kosugi A, Zuniga-Pnucker JC, Sharrow SO, Kruisbeek AM, Shearer GM (1989). Effect of cyclosporin A on lymphopoiesis. II. Developmental defects of immature and mature thymocytes in fetal thymus organ cultures treated with cyclosporin A. J Immunol 143: 3134-3140

Penn I (1987). Cancers following cyclosporine therapy. Transplantation 43: 32-35

Penn I and Brunson ME (1989). Cancers after cyclosporin therapy. Transplant Proc 20: 885

Relter Z, Relter Y, Fishelson Z, Shinitzd M, Kessler A, Loyter A, Nussbaum O, Rubinstein M (1991). Resistance to NK cell-mediated cytotoxicity (in K-562 cells) does not correlate with class I MHC antigen levels. Immunobiol 183: 23-39

Roumm AD, Medsger TA (1985). Cancer and systemic sclerosis: An epidemiologic study. Arthritis Rheum 28: 344-360

Ryffel B, Donatsch P, Madörin M, Matter BE, Ruttimann G, Schön H, Stoll R, WIlson J (1983). Toxicological evaluation of cyclosporin A. Arch Toxicol 53: 107-141

Ryfrel B (1992). The carcinogenicity of cyclosporin. Toxicology 73: 1-22

Scharffetter K, Lankat-Buttgereit B, Krleg T (1988), Localization of collagen mRNA in normal and scleroderma skin by in situ hybridization. Eur J Clin Invest 18: 9-17

Schevach EM (1985). The effect of cyclosporin A on the immune system. Ann Rev Immunol 3: 397-423

Smith J (1987). Postirradiation sarcoma of bone in Hodgkin disease. Skeletal Radiol 16: 524-532

Sorokm R, Kimura H, Schroder K, Wilson DH, Wilson DB (1986). Cyclosporine-induced autoimmunity. Conditions for expressing disease, requirement for intact thymus, and potency estimates of autoimmune lymphocytes in drug-treated rats. J Exp Med 164: 1615-1625

StIller CR, Dupre J, Gent R, Jenner MR, Keown PA (1984). Effects of cyclosporine immunosuppression in insulin-dependent diabetes mellitus of recent onset. Science 223: 1362-1367

Talbot JH, Barrocas M (1979). Progressive systemic sclerosis (PSS) and malignancy, pulmonary and non-pulmonary. Medicine 58: 182-207

Tutschka PJ, Beschorner WE, Allison AC, Burns WH, Santos GW (1979). Use of cyclosporine $A$ in allogeneic bone marrow transplantation in the rat. Nature 280: 5718 5719

Upton A (1984). Biological aspects of radiation carcinogenesis. In: Radiation carcinogenesis: Epidemiology and biological significance. J.D. Boice Jr., J.F. Fraumeni, eds, 1984, pp 9

Von Graffenried B, Friend D, Shand N, Schiess W, Timonen P (1989). Cyclosporin A (Sandimmun $^{\mathbb{R}}$ ) in autoimmune discrders. In: Thomson AW, ed. Cyclosporin. Mode of action and clinical implications. London: Kluwer Academic, 1989, 213-250

Wodts KWH, Majoor GD, Breda Vriesman PJC van (1991). On the localization of effector cells in cyclosporin-induced autoimmunity. Autoimmunity 10: 275-283

Wodzig KWH, Majoor GD, Breda Vrlesman PJC van (1993). Susceptibility and resistance to cyclosporin A-induced autoimmunity in rats. Autoimmunity, in press 


\title{
Chapter 4
}

\section{Autoantibodies in}

\section{Cyclosporine A-induced}

\section{experimental autoimmune}

\author{
scleroderma
}

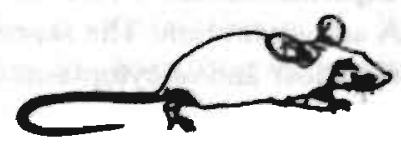




\section{Autoantibodies in Cyclosporine A - induced experimental autoimmune scleroderma}

\section{Abstract}

Lethally irradiated Lewis (LEW) rats given syngeneic bone marrow and Cyclosporine A (CyA) for 6 weeks develop, after withdrawal of $\mathrm{CyA}$, acute and chronic graft-versus-host diseaselike symptoms (CyA-induced autoimmunity, CyA-AI). Dermal lesions in rats with chronic CyA-AI are clinically and histologically similar to those of limited scleroderma in man. In patients with rheumatic diseases, circulating autoantibodies against nuclear or cytoplasmic antigens are frequently demonstrable. For example, $30 \%$ of patients with diffuse systemic sclerosis have anti-DNA-topoisomerase I (Scl-86) antibodies, and 70 to $80 \%$ of the patients with limited scleroderma develop anticentromere/kinetochore (CENP- or CR19) antibodies. The present study was performed to examine by means of Western Blots whether the sera of rats with $\mathrm{CyA}-\mathrm{AI}$ and scleroderma-like lesions contained autoantibodies to Scl-86 and/or CR19; and if so, whether these are associated with the scleroderma-like lesions observed in CyA-AI. In this study we report that human autoantibodies to $\mathrm{Scl}-86,56 \mathrm{~K}, \mathrm{SS}-\mathrm{B} / \mathrm{La}$, and $\mathrm{B}^{\prime} / \mathrm{B}$ antigens, but not to CR19, crossreacted with rat nuclear and cytoplasmic antigens of the same molecular weights. Furthermore, multiple autoantibodies to human nuclear and cytoplasmic antigens of various $\mathrm{M}_{w}$ 's ranging from 20 to $100 \mathrm{kD}$ were only demonstrable in sera from experimental LEW rats with manifest CyA-AI disease but not prior or during CyA administration. The rat cell fractions recognized by these rat autoantibodies are nuclear and/or cytoplasmic proteins of various $M_{w}$ 's 
ranging from 37 to $100 \mathrm{kD}$. None of the sera from LEW rats with chronic CyAAI, obtained on different weeks after withdrawal of CyA, showed autoantibodies comparable to those with diagnostic importance in human-mediated "connective tissue" diseases, i.e. Scl-86 or CR19. Thus, in this model the lesions of scleroderma appear to be dissociated from the presence of antibodies to Scl-86 or CR 19 . There was a striking resemblance with respect to the presence of autoantibodies between LEW rats with CyA-AI (to which the BN strain is resistant) and BN rats with mercurychloride $\left(\mathrm{HgCl}_{2}\right.$ )-induced autoimmune nephritis (to which $\mathrm{LEW}$ are resistant). However, $\mathrm{HgCl}_{2}$-treated $\mathrm{BN}$ rats developed hyperimmunoglobulinemia and showed elevated relative concentrations of $\gamma, B-$, and $\alpha 1$-globulins as compared to LEW rats with CyA-AI. Apparently, in the rat different autoimmune models may elicit antibodies to similar nuclear and cytoplasmic proteins, suggesting that analogous autoimmune mechanisms are involved.

\section{Introduction}

Scleroderma or (progressive) systemic sclerosis (SS) is a connective tissue disease characterized by fibrosis and degenerative changes in the skin, small arteries, several internal organs, and immunologic abnormalities (Bernstein et al., 1982). SS is believed to have an (auto)immune origin, although no clear pathogenetic relationships have been defined. The reasoning for an (auto)immune pathogenesis was based on immunogenetic associations, similarities between SS and chronic graft-versus-host disease, and cellmediated and humoral immune abnormalities in SS patients like decreased numbers of circulating $\mathrm{T}$ lymphocytes, hypergammaglobulinemia and the occurrence of auto-antibodies (Livingston et al., 1987).

Lesions analogous to those seen in scleroderma have been observed in association with a graft-versus-host reaction after allogeneic bone marrow transplantation in man (Shulman et al., 1978), but also after autologous bone marrow transplantation if the patient received ablative chemotherapy and/or total body irradiation prior to transplantation (Jones et al., 1989; Hess et al., 1992).

In the experimental rat model of Cyclosporine $\mathrm{A}(\mathrm{CyA})$-induced syngeneic graft-versushost disease (sGVHD)(Glazier et al., 1983), also referred to as CyA-induced autoimmunity (CyA-AI)(Sorokin et al., 1986), dermal lesions clinically and histologically similar to those observed in limited scleroderma (chronic scleroderma) of man can be reproducibly elicited (Bos et al., 1989). In this model, Lewis (LEW) rats are lethally irradiated, reconstituted with syngeneic bone marrow and treated for 6 weeks with CyA. After withdrawal of CyA medication an acute dermatitis develops which subsequently evolves into chronic scleroderma (Bos et al., 1989; Wodzig et al., 1991). CyA-AI can be reproducibly elicited in young rats (Fischer et al., 1990) or mice (Cheney et al., 1985; Bryson et al., 1989) and has also been observed in adult humans (Jones et al., 1989; Hess 
et al., 1992). Under these circumstances, CyA has been reported to prevent the re-establishment of tolerance to self and the development of CyA-AI appears to be associated with reappearance of CD4+ $\mathrm{T}$ cells (Bos et al., 1988; Fischer et al., 1991) and/ or the induction of cytolytic T lymphocytes (CTL's) recognizing a public MHC class II determinant (Hess et al., 1985). Several studies have demonstrated an essential role for the thymus in the induction of CyA-AI (Sorokin et al., 1986). Therefore, this model in terms of etiology is of (auto)immune origin, and in terms of pathogenesis manifests scleroderma-like skin lesions. In $95 \%$ of patients with SS circulating autoantibodies against nuclear or cytoplasmic constituents were detected (Bernstein et al., 1982; Krieg and Meurer, 1988). Antibody titer did not show a clinical correlation with disease activity (Krieg and Meurer, 1988). Despite the fact that there was some overlap, the specificity of certain autoantibodies correlated well with the syndrome in which they occur (Guldner et al., 1986). In patients suffering from SS several autoantibody specificities have been observed (Tan et al., 1980). Thirty percent of patients with diffuse SS (with severe skin, cardiac, and/or pulmonary involvement) had autoantibodies to DNA-topoisomerase I (Van Venrooij et al., 1985; Weiner et al., 1988). In 70-80\% of patients with limited scleroderma (CREST variant of scleroderma) anti-centromere/kinetochore antibodies could be detected (Tan et al., 1980; Kallenberg et al., 1982; Krieg et al., 1988). These autoantibodies recognized the centromere proteins A, B, and C (CENP-A or CR19, $17 / 19 \mathrm{kD}$; CENP-B, $80 \mathrm{kD}$; and CENP-C, $140 \mathrm{kD}$ )(Earnshaw et al., 1986).

The present study was performed to examine by means of Western blots whether sera from rats with CyA-AI and scleroderma-like lesions contained autoantibodies akin to those listed above and if so, whether these are associated with the scleroderma-like lesions observed in CyA-AI. Indeed rats with CyA-AI were found to develop autoantibodies to nuclear and non-nuclear constituents, but the scleroderma-like lesions developed independently of the presence of such autoantibodies.

\section{Materials and methods}

\section{Animals}

Female, specific pathogen-free (SPF) Lewis (LEW, RT1') rats were obtained from our own breeding stock (Department of animal facilities, Univ. of Limburg). Animals were used as bone marrow donors and recipients at the age of 4-6 weeks. Serum samples were obtained by retro-orbital puncture.

\section{Protocol for induction of CyA-AI}

LEW rats were given $8.5 \mathrm{~Gy}$ at $0.5 \mathrm{~Gy} / \mathrm{min}$. using a Röntgen irradiation machine (Philips MG320, Hamburg, Germany) one day prior to syngeneic bone marrow transplanta- 
tion (BMT). Marrow donor rats were killed by cervical dislocation under ether anesthesia. Bone marrow was collected from tibias and femurs in Dulbecco's balanced salt solution supplemented with $2 \%$ heat-inactivated fetal calf serum (iFCS), penicillin $(100 \mathrm{U} / \mathrm{ml})$ and streptomycin $(100 \mu \mathrm{g} / \mathrm{ml})$ (DBSS). Recipient rats received $6 \times 10^{7}$ viable syngeneic bone marrow cells in $1.0 \mathrm{ml}$ DBSS intravenously into a tail vein. CyA, a gift from Sandoz $\mathrm{Co}$. Ltd., Basel, Switzerland, was dissolved in olive oil at a concentration of $7.5 \mathrm{mg} / \mathrm{ml}$. Rats received $7.5 \mathrm{mg} / \mathrm{kg} /$ day CyA subcutaneously for 6 weeks starting on the day of BMT. CyA-AI usually developed 2-3 weeks after cessation of $\mathrm{CyA}$ administration.

\section{Experimental design}

Twenty LEW rats were subjected to the above mentioned protocol for induction of CyA$\mathrm{AI}$ and are referred to as LEW/XCyA. Control groups included: 6 LEW rats receiving Xirradiation, syngeneic bone marrow, and CyA-solvent (olive oil) for 42 days (LEW/XOil): 6 age-matched LEW treated with CyA for 42 days (cyaLEW); and 6 age-matched, nontreated LEW (nLEW). Serum samples were obtained prior to $\mathrm{X}$-irradiation and syngeneic bone marrow reconstitution, 6 weeks after BMT at the time of CyA or solvent withdrawal, and $2,4,6,8,10,12,18$, and 30 weeks after cessation of CyA or solvent administration.

\section{Scoring of macroscopic pathology}

After withdrawal of CyA, development of CyA-AI was assessed by examination of the rats twice a week for signs and symptoms of disease including red acra (hyperemia of the skin of the ears, feet and tail), inflammation of the eyelids, dermatitis, alopecia and weight loss (Wodzig et al., 1991).

\section{Preparation of nuclear and cytoplasmic extracts}

Nuclear extracts from either human HeLa or rat A8/B2 (a non-functional LEW T lymphoblast clone) cells were prepared according to Habets et al. (1983). All procedures were carried out at $4^{\circ} \mathrm{C}$ unless stated otherwise. In brief, cells were harvested, pelleted by centrifugation ( $5 \mathrm{~min}$ at $800 \mathrm{xg}$ ), washed with $130 \mathrm{mM} \mathrm{NaCl}, 1.5 \mathrm{mM} \mathrm{MgCl}, 10 \mathrm{mM}$ Tris$\mathrm{HCl} \mathrm{pH} \mathrm{7.4} \mathrm{(NKM),} \mathrm{and} \mathrm{pelleted} \mathrm{again.} \mathrm{Cells} \mathrm{were} \mathrm{resuspended} \mathrm{in} 10 \mathrm{mM} \mathrm{NaCl}, 1.5 \mathrm{mM}$ $\mathrm{MgCl}_{2}, 10 \mathrm{mM}$ Tris- $\mathrm{HCl} \mathrm{pH} 7.4$ supplemented with $0.5 \mathrm{mM}$ phenylmethylsulfonyl-fluoride (PMSF)(RSB10). After addition of a mixture of $0.5 \%$ sodium deoxycholate (DOC) and $1 \%$ Tween 40 , cells were homogenized by 10 strokes of a pestle. Cell nuclei were pelleted, washed once with RSB10 and resuspended in $110 \mathrm{mM} \mathrm{NaCl}, 1.5 \mathrm{mM} \mathrm{MgCl}$, $0.5 \mathrm{mM}$ PMSF, $10 \mathrm{mM}$ Tris- $\mathrm{HCl} \mathrm{pH} 7.4$ (RSB110) at a density of $10^{5}$ nuclei/ml. The nuclei were incubated with $500 \mu \mathrm{g} / \mathrm{ml}$ DNase I (type II) and $100 \mu \mathrm{g} / \mathrm{ml} \mathrm{RNase} \mathrm{A} \mathrm{(type}$ III-A; both Sigma, St. Louis, USA) for $1 \mathrm{~h}$ at room temperature. Finally, an equal amount of sample buffer ( $20 \%$ glycerol, $4 \%$ SDS, $10 \%$ 2-mercaptoethanol, $65 \mathrm{mM}$ Tris-HCl pH 6.8 ) was added to this total nuclear protein fraction and the suspension was boiled for 3 min. Nuclear extract of $7 \times 10^{7}$ cells ( $1.5 \mathrm{mg}$ protein) was loaded onto one polyacrylamide gel. 
Cytoplasmic extracts were prepared by swelling washed HeLa or A8/B2 cells in hypotonic buffer (1.5 mM MgCl, $0.5 \mathrm{mM}$ EDTA, $0.5 \mathrm{mM}$ PMSF, $10 \mathrm{mM}$ HEPES $\mathrm{pH} 7.9$ ) for 20 min. Next, the cells were homogenized with a Dounce homogenizer and 0.1 volume of a hypertonic solution (1.4 M KCl, $30 \mathrm{mM} \mathrm{MgCl}, 0.3 \mathrm{mM}$ HEPES $\mathrm{pH} 7.9$ ) was added. The cytoplasmic extract was cleared by centrifugation for $10 \mathrm{~min}$ at $3,000 \mathrm{xg}$ and diluted by adding $1 / 3$ volume of sample buffer ( $8 \%$ SDS, $40 \%$ glycerol, $20 \% 2$-mercaptoethanol, $125 \mathrm{mM}$ Tris-HCl pH 6.8) to the pellet; the resulting solution was boiled for $3 \mathrm{~min}$. Cytoplasmic extract of $4 \times 10^{7}$ cells ( $1.5 \mathrm{mg}$ protein) was loaded onto one polyacrylamide gel.

\section{Polyacrylamide gelelectrophoresis (PAGE) and protein blotting}

PAGE was performed on $1.4 \mathrm{~mm}$-thick slab gels in $192 \mathrm{mM}$ glycine, $25 \mathrm{mM}$ Tris- $\mathrm{HCl}$ pH $8.3,0.1 \%$ sodium-dodecyl-sulphate (SDS) with a $4 \%$ stacking gel and a $10 \%$ or $13 \%$ resolving gel. Proteins were loaded over the entire width of the gel and separated according to their molecular weight. After $4 \mathrm{~h}$ run at $40 \mathrm{~mA}$ per gel (limited to $75 \mathrm{~mA} / 300 \mathrm{~V}$ ) separated proteins were electrophoretically transferred onto nitrocellulose sheets $(0.45 \mu \mathrm{m}$; Schleicher and Schuell, Germany) in $192 \mathrm{mM}$ glycine, $25 \mathrm{mM}$ Tris- $\mathrm{HCl} \mathrm{pH}$ $8.3,0.015 \%$ SDS and $20 \%$ methanol at $30 \mathrm{~V} / 250 \mathrm{~mA}$ overnight at $4^{\circ} \mathrm{C}$. After transfer blots were dried and stored at room temperature.

\section{Detection of antigens}

All steps were carried out at room temperature unless stated otherwise. Free protein binding sites on the nitrocellulose sheets were blocked by pre-incubation buffer (PI; $350 \mathrm{mM}$ $\mathrm{NaCl}, 0.5 \mathrm{mM}$ PMSF, $3 \% \mathrm{BSA}, 10 \mathrm{mM}$ Tris- $\mathrm{HCl} \mathrm{pH} 7.6$ ) for $1 \mathrm{~h}$. Incubation with 1:20 diluted rat or human serum was performed overnight at $4^{\circ} \mathrm{C}$ in extractable nuclear antigen buffer (ENA; $150 \mathrm{mM} \mathrm{NaCl}, 0.1 \mathrm{mM}$ PMSF, $1 \%$ Triton X-100, 0.5\% DOC, $0.1 \%$ SDS, $0.3 \%$ BSA, $10 \mathrm{mM}$ Tris-HCl pH 7.6). After washing for $10 \mathrm{~min}$ with ENA-buffer and $2 \times 10$ min with PT ( $0.5 \%$ Triton X-100 in PBS) Ig or IgG immune complexes were detected by incubating the blots for $2 \mathrm{~h}$ with horseradish peroxidase (HRP)-conjugated rabbit anti-rat Ig (DAKO, Glostrup, Denmark) or goat anti-human IgG (Cappel/ Organon Teknika, Turnhout, Belgium) in 0.5\% BSA in PT. After washing for $2 \times 10$ min with PT and $2 \times 10$ min with PBS, immune complexes on nitrocellulose sheets were visualized by incubation in HRP substrate solution (PBS containing $0.5 \mathrm{mg} / \mathrm{ml}$ 4-chloro-1-naphtol and $0.012 \% \mathrm{H}_{2} \mathrm{O}_{2}$ ) for $10 \mathrm{~min}$.

Reference sera from patients with autoimmune diseases and from BN rats with $\mathrm{HgCl}_{2}$-induced autoimmunity

First, nuclear extract from HeLa cells and nuclear and cytoplasmic extracts from rat A8/ B2 cells were incubated with reference patient sera containing anti-B'/B (Sm) antibodies (a marker for systemic lupus erythematosus, SLE), anti-DNA-topoisomerase I (Scl86 or Scl-70) antibodies (a marker for diffuse systemic sclerosis), anti-centromere (CR19) antibodies (a marker for the CREST syndrome), anti-SS-B/La antibodies (predominantly found in sera from patients with SLE and Sjögren's syndrome), anti-56K antibodies (most commonly found in sera from patients with Sjögren's syndrome), and anti-ribo- 
nucleoprotein (RNP) antibodies (often associated with mixed connective tissue disease and SLE) respectively. In this way autoantibodies associated with certain human autoimmune diseases, i.e. directed to Scl-86 (or Scl-70), nuclear RNP, B'/B (Sm), SS-B/La, SS-A/Ro antigens and histones can, if present, be detected in rats with CyA-AI. Furthermore, the molecular weight of constituents detected by autoantibodies from rats with Cy A-Al can be estimated more precisely.

Furthermore, nuclear and cytoplasmic extracts from rat A8/B2 cells were incubated with sera from Brown Norway ( $\mathrm{BN})$ rats with mercuric chloride $\left(\mathrm{HgCl}_{2}\right)$-induced autoimmune nephritis. Inbred, $3-4$ months old $\mathrm{BN}$ rats, weighing $300 \mathrm{~g}$ received $\mathrm{HgCl}_{2}$ subcutaneously at a dose of $1 \mathrm{mg} / \mathrm{kg}$ body weight at day $1,3,5,7$, and $9 . \mathrm{HgCl}_{2}$ induces proliferation of $\mathrm{B}$ and $\mathrm{CD} 4^{+} \mathrm{T}$ cells, hyperimmunoglobulinemia and production of autoantibodies such as anti-nuclear and anti-glomerular basement membrane (GBM) antibodies. Anti-GBM antibcdies are responsible for an autoimmune glomerulonephritis resulting in proteinuria. Both anti-GBM autoantibody serum levels and proteinuria reached maximum values around day 15 and decreased gradually thereafter (Aten et al., 1988). Sera from $\mathrm{HgCl}_{2}$ treated BN rats were kindly donated by Dr. J.J. Weening (Dept. of Pathology, University of Amsterdam, The Netherlands).

\section{Results}

\section{Cross-reactivity of human autoantibodles to human and rat cell antigens}

In order to characterize extractable nuclear and cytoplasmic antigens in the rat in terms of known human equivalents Western blots of nuclear extract from Hela cells and niclear and cytoplasmic extracts from A8/B2 cells were incubated with patient sera cantaining anti-B' /B (Sm), anti-DNA-topoisomerase I (Scl-86 or Scl-70), anti-centromere (CR19), anti-SS-B/La, and anti-56K antibodies, respectively (Fig. 4.1). Human autoantibodies to Scl-86 (lane 10) cross-reacted with a rat nuclear antigen of the same molecular weight (lane 6). A mixture of human autoantibodies to $56 \mathrm{~K}\left(\mathrm{M}_{\mathrm{w}} 56 \mathrm{kD}\right)$ and La/SS-B (M $50 \mathrm{kD}$; lane 11) cross-reacted with rat antigens of the same molecular weights present in both nuclear (lane 8) and cytoplasmic (lane 7) fractions. Human autoantibodies to B'/B antigens $\left(M_{w} 29 / 28 \mathrm{kD}\right.$; lane 9) cross-reacted only with the lower molecular weight B-antigen $\left(M_{w} 28 \mathrm{kD}\right.$ ) present in both nuclear (lane 4 ) and cytoplasmic (lane 3) fractions in the rat. Furthermore, this anti-B'/B serum rocognized a rat nuclear antigen (lane 4) with a molecular weight of approximately $95 \mathrm{kD}$ which is not identical with the Scl-86 antigen (M, $95 \mathrm{kD}$; lanes 6 and 10$)$, because this serum contained no anti-Scl-86 antibodies (lane 9). Human autoantibodies to CR19 (lane 10) did not cross-react with rat nuclear and cytoplasmic antigens. Pooled $(n=5)$ normal human sera (lanes 1 and 2) showed only a weak background staining with rat nuclear extract, except for two antigens of low molecular weight, probably histones H2A and H2B (lane 2). 


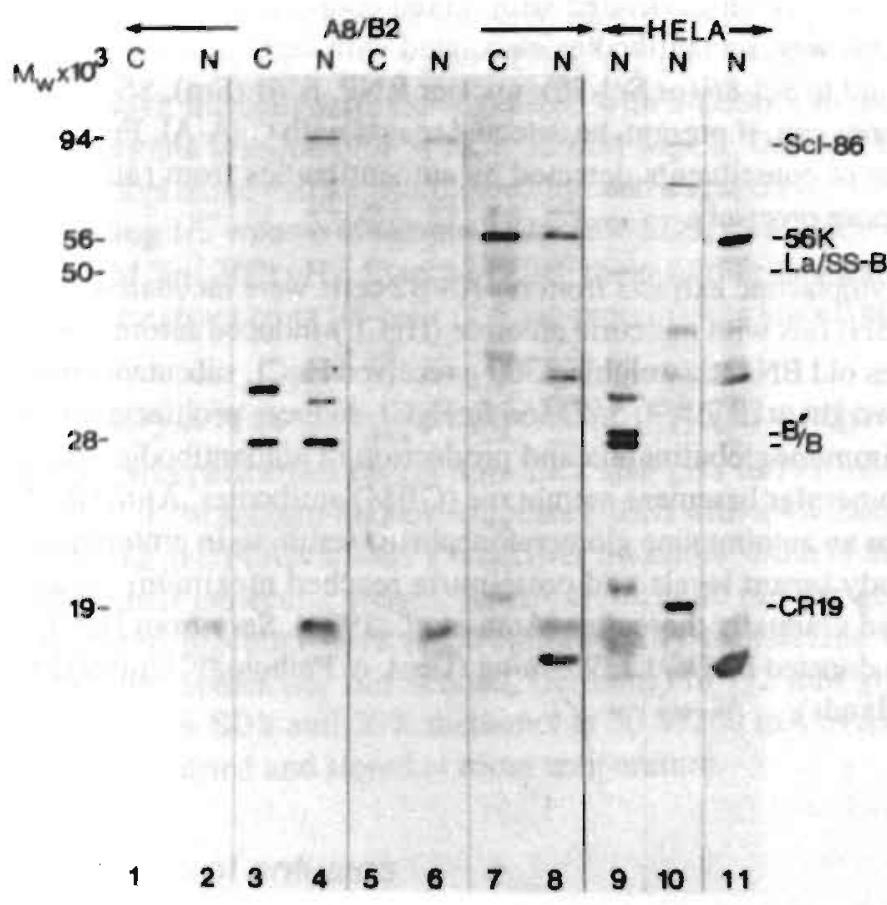

Figure 4.1: Detection of cross-reactivity of human autoantibodles to human and rat cell anthgens by immunoblotting. Nuclear (N) extracts from HoLa cells (tanes 9-11) and AB/82 rat colls Ranes 2, 4 , $6,8)$ and cytoplasmic $(C)$ extract from $A B / B 2$ colls (lanes 1, 3, 5, 7) were electrophoresed h a $13 \%$ polyacrylamide gel, transferred onto nitrocellulase and the resulting blot was incubated with. lenes 1, 2: normal human serum; kanes 3, 4, 9: human serum contalning ant- $B^{\prime} / B$ antbodies; anes 5, 6, 10 . human senum containing anti-SCl-86 and anti-CR19 antbodies; lanes $7,8,11$ : human senum containing ant-La/SS-B and anti-56K antibodies.

\section{Autoantibodies to human cell antigens in rats with CyA-A]}

Western blots of nuclear and cytoplasmic extracts from HeLa cells were incubated with reference patient sera (see legends Figs. 4.2A and 4.2B) and sera from LEW/XCyA $(n=20)$ obtained prior to the start of the experiment, 6 weeks after BMT at the time of CyA withdrawal, and 8 weeks after CyA withdrawal. Multiple autoantibodies to human nuclear and cytoplasmic antigens were only demonstrable at moderate titers (20-50) in sera from LEW/XCYA with manifest CyA-AI disease (9/20) but not prior or during CyA administration. In sera of LEW/XOil, cyaLEW or even nLEW controls natural autoantibodies against human nuclear and cytoplasmic antigens are demonstrable but these autoantibodies are also present in LEW/XCYA. Experimental LEW/XCYA developed autoantibodies directed to nuclear fractions with $\mathbf{M}_{w}$ 's of about 35 (Fig. 4.2A, lane 6), 37 (Fig. 4.2A, lanes 6 and 7; Fig. 4.2B, lane 3), 40 (Fig. 4.2A, lanes 4 and 6), 54 (Fig. 4.2B, lane 4), 80 (Fig. 4.2A, lane 6), and $100 \mathrm{kD}$ (Fig. 4.2A, lane 4). LEW/XCyA in addition developed autoantibodies to cytoplasmic fractions with $\mathrm{M}_{w}$ 's of about 20 (Fig. 4.2B, lane 11), 28 (Fig. 4.2A, lane 12), 35 (Figs. 4.2A/B, lane 12), 54 (Fig. 4.2A, lane 12), and $80 \mathrm{kD}$ (Fig. 4.2B, lanes 11 and 13). All sera from LEW/XCyA and LEW/XOil tested contained natural autoantibodies against a $60 \mathrm{kD}$ nuclear (Fig. 4.2A, lanes 2-9; Fig. 4.2B, lanes 2-7) and cytoplasmic (Fig. 4.2B, lanes 9-15) fraction. 
Flgurs 42: Detection of cutoentibodles to humen cell antigans in mbs with CyA-Al.

A. Nuclear (lanes 1-9) and cytoplasmic (lanes 10-17) extracts from HeLat cells were electrophoresed in a 10\% polyacrytamide gel, transferred onto nitrocellulase and the resulting blot was incubated' with: lane 1, 10: human reference sera (see Materials and Methods); lanes 2-7, 11-16: 6 LEW/ $X C Y A$ sera from rats with CyA-Al; lanes 8, 17: serum from a LEW/XOI control; lane 9: serum from a LEW/ $X C y A$ rat with CyA-Al and myasthenia gravis.

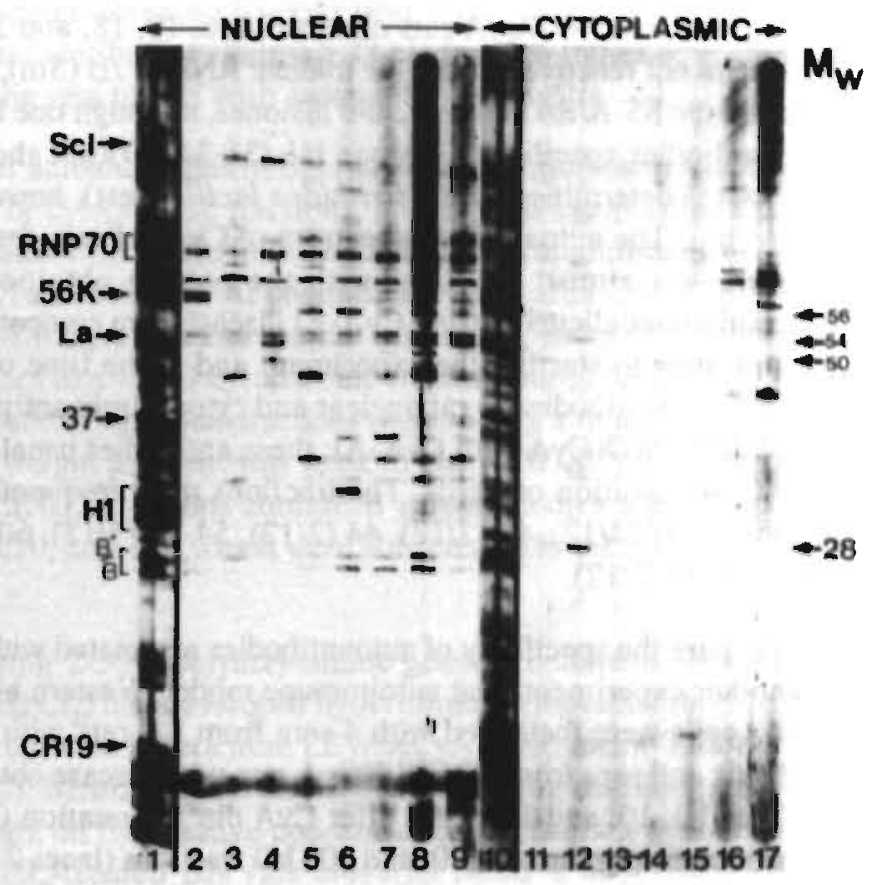

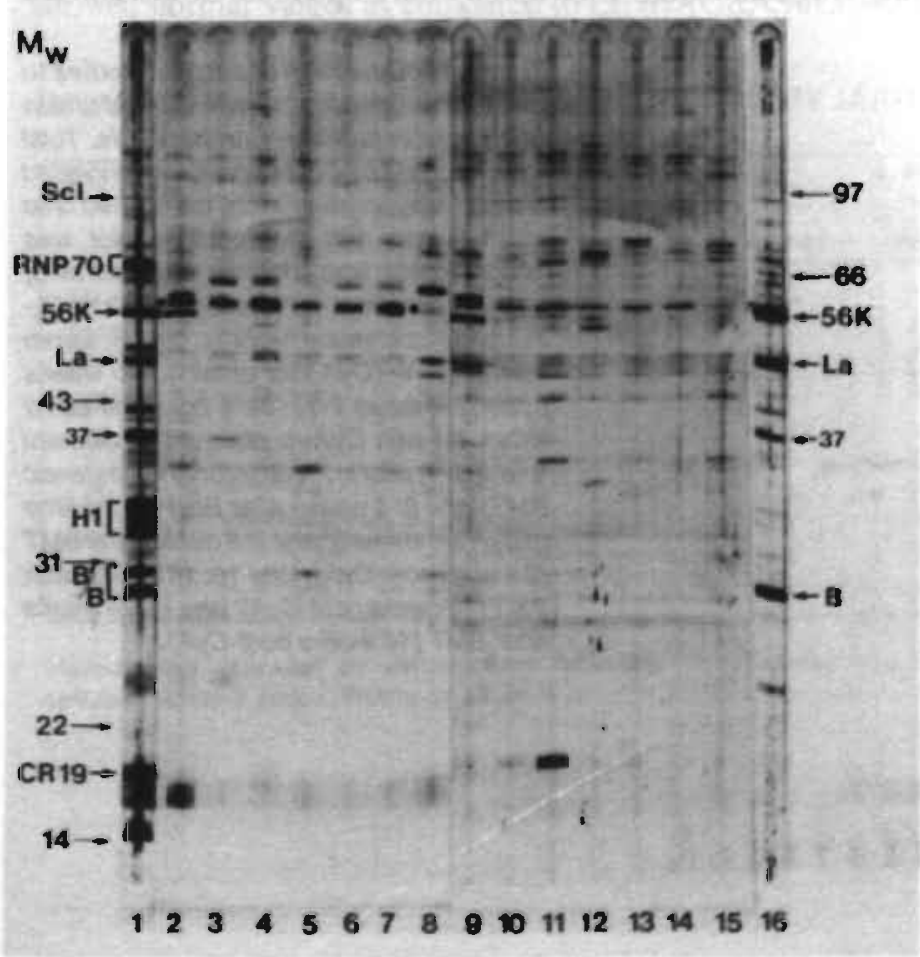

Figure 4.2: Detection of autoentibodles to humen cell entgens in mts with CyA-Al.

B. Nuclear (lanes 1-8) and cytoplasmic (lanes 9-16) axtracts from HeLacela wore electrophoresed $h$ a $10 \%$ polyacrytamide gol, transferred ontonitrocellubse and the resulting blot was Incubated with: lane 1, 16: human reference sera (seo Materials and Methods); lanes 3-7, 10-14: 5 LEWI XCYA sera from rats with CyA-Al; lanes 8, 15: serum from LEWXOII control; lane 2. 9: serum from a LEWI $X C y A$ rat whin CyA-Al and myasthenla gravis. 


\section{Autoantlbodles to rat cell antigens in rats with CyA-Al}

Sera from 20 LEW/XCyA rats obtained 2, 6, 10, 18, and 30 weeks after withdrawal of CyA were not reactive against the nuclear RNP, B'/B (Sm), Scl-86 (or Scl-70), SS-B/La, cytoplasmic SS-A/Ro antigens, and histones, although one LEW/XCyA serum contained autoantibodies specific for histone $\mathrm{H1}$ (31-34 kD)(not shown). Antibodies directed to dsDNA (as determined by the Crithidea lucillae test), however, could not be detected in this serum. The autoantibody spectrum of CyA-AI rats detected with human $\mathrm{HeLa}$ cell extracts was almost identical with the pattern obtained with rat $\mathrm{A} 8 / \mathrm{B} 2$ extracts. Autoantibodies elicited during CyA-AI disease were compared with autoantibody profiles present prior to starting the experiment and at the time of CyA withdrawal. Multiple specific autoantibodies to rat nuclear and cytoplasmic antigens were demonstrable in 12 out of 20 LEW/XCyA with CyA-AI; these antibodies usually appeared from 8-10 weeks after CyA cessation onwards. The fractions most frequently recognized had molecular weights of $37(4 / 12), 40(2 / 12), 44$ (2/12), 54-56 (5/12), 60 (1/12), 70 (1/12), 80 (2/12), and $100 \mathrm{kD}(2 / 12)$.

To compare the specificity of autoantibodies associated with CyA-AI with those elicited in another experimental rat autoimmune model, Western blots of total cell extracts from $\mathrm{A} 8 / \mathrm{B} 2$ cells were incubated with 4 sera from $\mathrm{BN}$ rats with $\mathrm{HgCl}_{2}$-induced autoimmune nephritis and sera from 2 LEW/XCYA rats with disease obtained on 0 and 6 weeks postBMT and 2,10, and 18 weeks after CyA discontinuation (Fig. 4.3). BN sera contained autoantibodies against 44,80 , and $100 \mathrm{kD}$ fractions (lanes 2-5) which were shared by sera of LEW/XCyA rats obtained on 10 (lanes 6,10) and 18 weeks (lane 11) after cessation of CyA. In LEW/XCyA rats, these autoantibodies mainly developed late in the natural

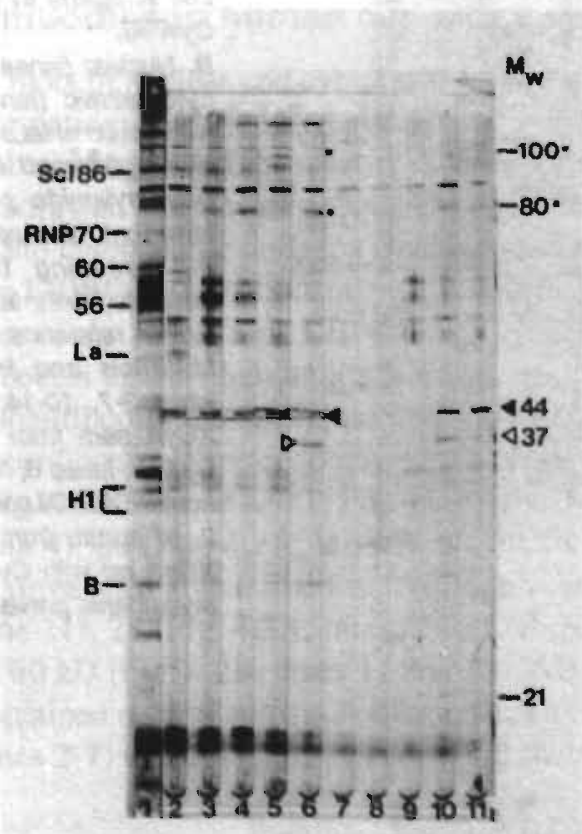

Figure 4.3: Dotectlon of autoantibodles to rat cell tractions in rats with CyA-AJ and in BN rats with autolmmune nephritls. Total extracts from AB/B2 cels were electrophoresed in a $10 \%$ polyacrylamide gel, transferred onto nitrocellubse and the resulting blot was incubated with: lane 1: human reference sera; lane 2-5: sera from 4 cifferent rats with $\mathrm{HgCl}_{2}$ induced autoimmune nephritis; lane 6: senum from a LEWIXCYA rats obtained 10 weoks post-CyA; lanes 7-11: sera from one LEW/ $X C Y A$ rat with CyA-Al obtained at dfferent time; tane 7: priorto $X$-irradiationand syngeneic BMT; lane 8: 6 wooks after BMT (at the time of CyA withdrawal); lane 9: 8 weeks afterBMT (2 weoks post-CyA); lane 10: 16 wooks after BMT (10weeks post-CyA); kne 11:24 weeks after BMT (18 woaks post-CyA). 
history of CyA-Al and could neither be detected prior to (lane 7) and during CyA administration (lane 8 ), nor during acute disease (2 weeks post-CyA)(lane 9). Sera from the LEW/XCy A rats contained autoantibodies against a $37 \mathrm{kD}$ fraction (lanes 6, 9, and 10). which were not detected in the sera of rats with autoimmune nephritis.

In order to determine whether autoantibodies in BN rats with autoimmune nephritis specifically recognized nuclear or cytoplasmic fractions, nuclear and cytoplasmic extracts from $A 8 / B 2$ cells were incubated with serum from one $B N$ rat with autoimmune nephritis and sera from 3 LEW/XCYA rats with CyA-AI obtained 10 weeks after cessation of CyA (Fig. 4.4). Two of these LEW/XCyA rats and the rat with $\mathrm{HgCl}_{2}$-induced autoimmune nephritis shared autoantibodies to a $44 \mathrm{kD}$ cytoplasmic fraction (lanes 6,8 , and 10 ), and to $80 \mathrm{kD}$ and $100 \mathrm{kD}$ nuclear and cytoplasmic fractions (lanes 5-10), although the staining of these two high molecular weight antigens was weak in one LEW/XCYA serum (lanes 9 and 10 ). Sera from all 3 LEW/XCYA rats contained autoantibodies against a $37 \mathrm{kD}$ cytoplasmic fraction (lanes 8,10 , and 12), which were not detected in the serum of the rat with autoimmune nephritis.

Separation of total serum using $2-30 \%$ polyacrylamide gelelectrophoresis showed that $\mathrm{HgCl}_{2}$-treated $\mathrm{BN}$ rats $\left(\mathrm{BN} / \mathrm{HgCl}_{2}\right.$ ) had developed hyperimmunoglobulinemia (Fig. 4.5; lanes 1-3) which was neither detected in sera from LEW/XCYA rats (lanes 4-7) nor in sera from control rats (lanes 8-10). Serum protein electrophoresis using cellulose acetate as support medium provided data on the relative concentrations of immunoglobulins and again demonstrated in $\mathrm{HgCl}_{2}$-treated $\mathrm{BN}$ rats elevated relative concentrations of $\gamma-, B-$, and $\alpha 1$-globulins as compared to $\mathrm{nBN}$ and nLEW. In contrast, LEW/XCYA rats showed normal values as compared to LEW/XOil, cyaLEW, and nLEW (Table 4.1).

Table 4.1: Fraction of total serum of $\mathrm{HgCl}_{2}$-treated $B N$, nomal $B N$, LEWXCYA and control LEW rats.

\begin{tabular}{|lcccccc|}
\hline \multirow{2}{*}{ Rat strain } & \multicolumn{5}{c|}{ Relative fraction of total serum (\%) } & \\
\cline { 2 - 6 } & Gamma & Beta & Alpha2 & Alpha1 & Albumin & A/G ratio \\
\hline BN/HoCl & 7.3 & 28.1 & 4.5 & 15.2 & 44.9 & 0.8 \\
BN/HoCl & 5.1 & 23.7 & 7.1 & 15.7 & 48.3 & 0.9 \\
nBN & 1.5 & 13.0 & 6.1 & 6.9 & 72.5 & 2.6 \\
nBN & 2.4 & 16.0 & 7.3 & 6.2 & 68.1 & 2.1 \\
& & & & & & \\
LEW/XCYA & 2.7 & 15.0 & 2.3 & 5.6 & 74.5 & 2.9 \\
LEW/XCYA & 2.8 & 17.1 & 3.3 & 4.9 & 71.8 & 2.6 \\
LEW/XOii & 2.3 & 15.5 & 2.7 & 5.3 & 74.1 & 2.9 \\
CYaLEW & 1.9 & 14.5 & 2.2 & 5.8 & 75.7 & 3.1 \\
nLEW & 3.0 & 12.8 & 2.0 & 5.8 & 76.3 & 3.2 \\
\hline
\end{tabular}

Values were assessed by densitomerer scanning of separated and visualized protein bands on cellulose acerare strips. Aatio of albumin to total globulin fraction. 


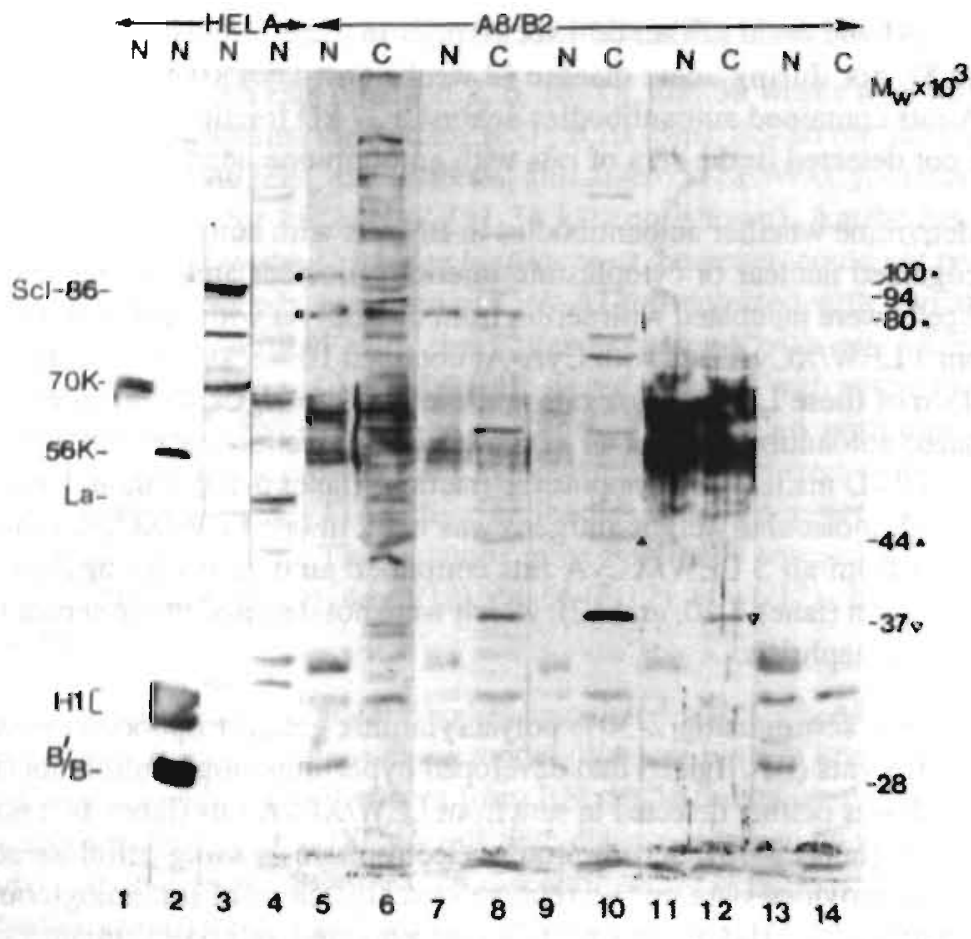

Flgure 4.4: Dotection of autoantibodles to rat cell fractions in rats with CyA-A/ and in a BN rat with autolmmune nephritls. Nuclear ( $N$ ) extracts from HeLa cells (lanes 1-4) and AB/B2 cells (lanes 5, 7, 9, 11, 13) and cytoplasmic (C) extract from ABBB2 cells (lanes 6, 8, 10,12, 14) were electrophoresed in a 10\% polyacrytamide gel, transferred onto nitrocellulose and the resulting blot was incubated with: lane 1: human serum containing anti-RNP antibodies; lane 2: human serum containing anti-56K, anti-histone $\mathrm{HI}$ and antiB'/B antibodies; lane 3: human serum containing ant-Scl-86 and anti-CR19 antibodies; lane 4: human senum containing anti-La/SS-B antibodies; lanes 5, 6: serum from a rat with $\mathrm{HgCl}_{2}$-induced autoimmune nephritis; lanes 7, 8, lanes 9, 10, and lanes 11, 12: serum from 3 diferent LEW/XCYA rats with CyA-Al; lanes 13, 14: normal LEW rat senum.

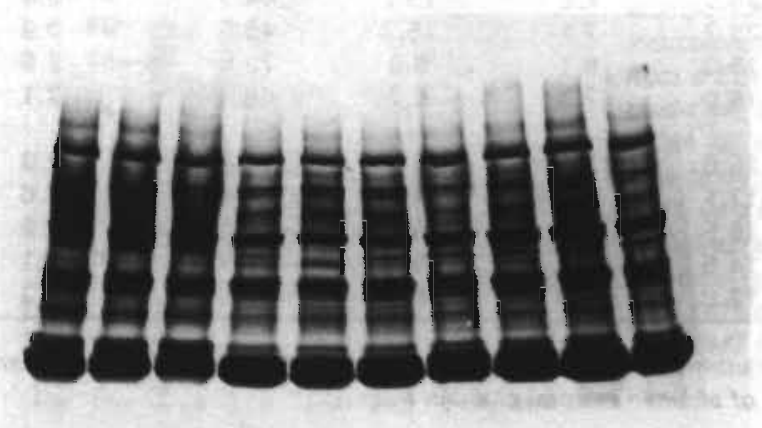

$\begin{array}{llllllllll}1 & 2 & 3 & 4 & 5 & 6 & 7 & 8 & 9 & 10\end{array}$
Flgure 4.5: Gradlent 2-30\% gelelectrophoresis of total serum from $L E W$ and $B N$ rats.

Lane 1-3:3 offerentserafrom $\mathrm{BN} / \mathrm{HgCl}_{2}$ rats; tane 4-7: 4 different sera from LEW/ XCyA rats with CyA-Al; lane 8: serum from a LEW/XOI rat; lane 9: senum from a nLEW rat; andlane 10: serum from a cyaLEW rat. 


\section{Discussion}

This study shows that autoantibodies to extractable nuclear and cytoplasmic fractions are elicited in rats with CyA-AI. Furthermore, it was demonstrated that these autoantibodies are not required for, nor pathological related to the development of chronic sclerodermalike lesions. Finally, the specificity of some of the autoantibodies detected in LEW rats with CyA-AI disease also occurred in $\mathrm{BN}$ rats with $\mathrm{HgCl}_{2}$-induced autoimmune glomerulonephritis, suggesting that analogous autoimmune mechanisms are involved.

Crucial to answering the question whether or not autoantibodies considered of clinical diagnostic importance in man are associated with chronic scleroderma-like lesions in the rat model of CyA-AI is the observation that human autoantibodies to $95 \mathrm{kD}$ (Scl-86), 56 $\mathrm{kD}, \mathrm{SS}-\mathrm{B} / \mathrm{La}$, and B'/B (Sm) cross-reacted with rat nuclear and cytoplasmic antigens, (Fig. 4.1). However, no such rat autoantibodies were observed in rats with CyA-AI. The molecular weight of Scl-86/topoisomerase I has been reported to be 67 to $100 \mathrm{kD}$ (Scl-70 or Scl-86 antigen); enzyme molecules of various $M_{w}$ 's ranging from 70 to $100 \mathrm{kD}$ have been found to be functionally active (Hildebrandt et al., 1990). The antigen present in HeLa and $\mathrm{A} 8 \mathrm{~B} 2$ cells was identified as a $95 \mathrm{kD}$ protein provided protease inhibitors were included in the extraction buffer (Guldner et al., 1986). Although human autoantibodies to the CR19 antigen (associated with CREST syndrome) extractable from HeLal cells do not recognize a 18-20 kD antigen in the rat, such antibodies may recognize a $50 \mathrm{kd}$ peptide in rat nuclear extracts (Kremer et al., 1988). In this study, however, antibodies to this $50 \mathrm{kD}$ peptide were not observed. One rat with CyA-AI and autoantibodies to histone H1 (31-34 kD) excepted, none of the rats with chronic CyA-AI showed autoantibodies comparable to those with diagnostic importance in human immune-mediated "connective tissue" diseases. Given the similarity of the skin lesions of chronic CyA-AI to those of scleroderma in man (Bos et al., 1989), these observations support the clinical observation that autoantibodies to the Scl-86 or CREST antigen are not causatively related to the pathogenesis of the lesions. In the rat model of $\mathrm{CyA}-\mathrm{AI}$ antibodies of pathogenetic significance may be elicited, e.g. to rat acetylcholine receptor with ensuing. myasthenia gravis (Verschuuren et al., 1989). In this respect the model is reminiscent of the myasthenia gravis occasionally seen also after bone marrow transplantation in man (Bolger et al., 1986; Grau et al., 1990; Melms et al., 1992). On the other hand, the model is clearly different from the CyA-AI disease models in certain mouse strains which are associated with autoimmune antibody-mediated endocrinopathies (Sakaguchi and Sakaguchi, 1988, 1989).

Hyperactivity of the immune system, especially of the B-cell compartment, resulting in polyclonal hypergammaglobulinemia is a constant feature of human and experimental autoimmunity (Marcos et al., 1986). Sakaguchi et al. (1989) showed that CyA administration to newborn BALB/c mice resulted in organ-specific autoimmune disease in multiple endocrine organs (thyroid, stomach, ovaries, or testes) with development of autoantibodies specific for gastric parietal cells and oocytes as assessed by indirect 
immunofluorescence. The incidence of gastritis and oophoritis was enhanced by removal of the thymus immediately after neonatal CyA treatment. Other autoimmune diseases developed in the CyA-treated and thymectomized mice as well: thyroiditis, insulitis, adrenalitis, sialoadenitis, and orchitis. These autoimmune diseases were accompanied by the appearance of serum autoantibodies specific for thyroglobulins, cell surface antigens of the Langerhans islet cells, adrenocortical cells, acinar cells of the salivary glands, and sperm respecti vely (Sakaguchi and Sakaguchi, 1989).

Administration of $\mathrm{CyA}$ after syngeneic bone marrow transplantation inhibited the development of both mature $\mathrm{CD}^{+}$and $\mathrm{CD}^{+}$single positive thymocytes in rodents, whereas the relative numbers of immature double positive and double negative cells were increased (Fischer $e t$ al., 1991). These effects on the thymus were also reflected by changes in the periphery with fewer $C D 4^{+} \mathrm{T}$ cells and a reduced CD4/CD8 ratio in X-irradiated and CyA-treated animals (Bos et al., 1988; Fischer $e t$ al., 1991). On the other hand, elevated relative numbers of cells expressing both CD4 and CD8 molecules were detected in the peripheral blood suggesting that these cells were prematurely released from the thymus (Hess et al., 1985). In the absence of counteractive regulatory $\mathrm{T}$ cells, these cells might differentiate into autoimmune effector $T$ cells. The latter cells might be $\mathrm{CD4} 4^{+} \mathrm{CD} 8$ - and destroy target organs by conducting cell-mediated immune reactions (i.e. effecting the scleroderma-like lesions) and/or promote activation of autoantibody-forming B cells (Sakaguchi and Sakaguchi, 1990).

The next observation of interest is the fact that the majority of sera from LEW rats with CyA-AI contained autoantibodies to a variety of human and rat nuclear and cytoplasmic fractions which were shared in part (Figs. 4.3 and 4.4) with autoantibodies present in sera from $\mathrm{BN}$ rats with $\mathrm{HgCl}_{2}$-induced autoimmune nephritis. $\mathrm{HgCl}_{2}$ administration elicits in BN rats a chronic but transient graft-versus-host disease associated with hypergammaglobulinemia and autoantibody-mediated glomerular basement membrane damage (Tournade et al., 1990; Goldman et al., 1991). In contrast to CyA-AI pathogenesis is not influenced by thymectomy (Pelletier et al., 1988a), and requires the presence of BN major and minor histocompatibility antigens (Pelletier et al., 1986, 1988b). Furthermore, this disease is associated with induction of autoreactive $\mathrm{CD4}^{+} \mathrm{T}$ cells against MHC class II antigens which cause - in an unknown fashion - B cell triggering (Pelletier et al., 1986, 1988b). The self limitation observed in this model is associated with both a decrease in the frequency of anti-MHC class II T cells and the emergence of $\mathrm{CD}^{+} \mathrm{T}$ cells able to suppress these autoreactive $\mathrm{T}$ cells (Pelletier et al., 1990). CyA treatment during $\mathrm{HgCl}_{2}$ administration was found to prevent the development of autoimmune reactivity and to induce a prolonged unresponsiveness (might be due to direct functional deletion of autoreactive $\mathrm{T}$ lymphocytes) to $\mathrm{HgCl}_{2}$, which is not mediated by active immune suppression (Aten et al., 1988). $\mathrm{HgCl}_{2}$ administered to LEW rats on the other hand causes no disease but non-antigen specific $\mathrm{CD}^{+} \mathrm{T}$ cell-dependent immune suppression (Pelletier et al., 1987); depletion of $\mathrm{CD}^{+} \mathrm{T}$ cells abrogated immunosuppression, however, did not allow the disease to occur in this strain (Pelletier et al., 1990). LEW rats could differ from BN rats in their response to $\mathrm{HgCl}_{2}$ either because they do not develop autoreactive $\mathrm{T}$ 
helper cells and/or because suppressor cells are preferentially induced preventing polyclonal activation of B cells (Pelletier et al., 1987).

The division of $\mathrm{CD}^{+} \mathrm{T}$ cells into distinct subsets [ $\mathrm{T}$ helper cell $1\left(\mathrm{~T}_{\mathrm{H}} 1\right)$ and $2\left(\mathrm{~T}_{\mathrm{H}^{2}}\right)$ ], based upon cytokine production, might be a clue to explain differences between the immune response of $\mathrm{BN}$ and $\mathrm{LEW}$ rats. $T_{\mathrm{H}} 1$-like cells produce IL-2 and IFN $\gamma$ upon stimulation and provide cell-mediated immune responses (delayed type hypersensitivity, DTH), whereas $\mathrm{T}_{\mathrm{H}}$ 2-like cells produce IL-4, IL-5, IL-6, and IL- 10 upon stimulation and are responsible for the provision of $B$ cell help and induction of suppression of cell-mediated immune responses (Mosmann and Moore, 1991). Antagonistic effects between $T_{H} 1$ and $\mathrm{T}_{\mathrm{H}} 2$ subsets have been described and depend on the production of IFN $\gamma-$ and IL-10 (Dubey et al., 1991). BN rats showed a predominance of the $T_{\mathrm{H}} 2$ subset over $\mathrm{T}_{\mathrm{H}} 1 ; \mathrm{HgCl}_{2}$ might induce an imbalance between $T_{H} 1$ and $T_{H} 2$ and the lymphokines produced by $T_{H} 2-$ like cells may prevent the development of $T_{H} 1$-type responses (Goldman et al., 1991). In contrast, $\mathrm{LEW}$ rats showed a preponderance of the $\mathrm{T}_{\mathrm{H}}$ 1-like subset, but CyA-AI impaired $T_{H}$ 1-dependent (IFN $\gamma$ ) DTH reactions (this thesis chapter 2; Wodzig et al., 1993). Therefore, in the CyA-AI model administration of CyA might suppress specific $T_{H}$ l-like lymphokines (IFN $\gamma$ and $\mathrm{IL}-2$ ) causing the balance between $\mathrm{T}_{\mathrm{H}} 1$ and $\mathrm{T}_{\mathrm{H}} 2$ to shift lowards specific $\mathrm{T}_{\mathrm{H}}$ 2-type responses (mediated by $\mathrm{IL}-4$ and $\mathrm{IL}-10$ ) and consequently (auto)antibody production. It is well known that this bias in $T_{H} 1$ and $T_{H} 2$ upon activation could determine the direction of the immune response (Goldman et al., 1991). Indeed, studies investigating in vitro responses of mice with chronic GVHD have demonstrated a selective loss of $T_{H} 1$ functions like production of IL-2 and IFN $\gamma$, but elevated $\mathrm{T}_{\mathrm{H}}$ 2-dependent $\mathrm{IL}-4$ production. In these animals, like in the CyA-AI model, $\mathrm{CD} 8^{+} \mathrm{T}$ cell functions remained intact (Hess et al., 1985; De Wit et al., 1993). This selective deficiency of $T_{H} 1$ is associated with hyperactivation of $B$ cell functions leading to production of autoantibodies, and hypergammaglobulinemia (De Wit et al., 1993). The common denominator in the CyA-AI disease of LEW [to which the BN strain is resistant (this thesis chapter 2; Wodzig et al., 1993)] and $\mathrm{HgCl}_{2}$-induced disease in $\mathrm{BN}$ [to which LEW is resistant (Pelletier et al., 1987; Dubey et al., 1991)] appears the presence of GHV-like disease and anti-MHC class II T cell responses (Hess et al., 1985; Sorokin et al., 1986; Pelletier et al., 1986, 1988b).

Hence, in these models of rodent disease autoantibodies to restricted nuclear and cytoplasmic fractions appear to be a sign of an ongoing "autoimmune" graft-versus-host disease brought about by apparently widely differing inducing protocols and thymus dependency of disease. The observation that procainamide induced SLE-like syndrome in man associated with autoantibodies to histone (Portanova et al., 1982; Tortoritis et al., 1988) which is also observed in CyA-AI suggests that elucidation of the mechanism(s) involved in CyA-AI may be pertinent to the pathogenesis of some autoantibody-mediated, natural or drug-induced, diseases of man. 


\section{Acknowledgements}

This study was financially supported by the Dutch League against Rheumatic Disease. We thank Professor Dr. J.J. Weening (Dept. of Pathology, University of Amsterdam, The Netherlands) for his gift of sera from $\mathrm{BN}$ rats with $\mathrm{HgCl}_{2}$-induced autoimmune nephritis. 


\section{References}

Aten J, Bosmon CB, De Heer E, Hoedemaeker PhJ, Weenlng, JJ (1988). Cyclosporin A induces long-term unresponsiveness in mercury chloride-induced autoimmune glomerulonephritis. Clin Exp Immunol 73: 307.

Bernsteln RM, Steigerwald JC, Tan EM (1982). Association of antinuclear and antinueleolar antibodies in progressive systemic sclerosis. Clin Exp Immunol 48: 43 .

Bolger GB, Sulliven KM, Spence AM (1986). Myasthenia gravis after allogeneic bone marrow transplantation: relationship to chronic graft-versus-host disease. Neurology 36: 1087.

Bos GMJ, Majoor GD, Van Bredn Vriesman PJC (1988). Cyclosporin A induces a selective, reversible suppression of $T$-helper lymphocyle regeneration after syngeneic bone nnarrow transplantation: association with syngeneic graft-versus-host disease in rats. Chin Exp Immunol 74: 443.

Bos GMJ, Majoor GD, Willighagen RGJ, Van Bredn Vrlesman PJC (1989). Chronic cyclosporin-induced autoimmune disease in the rat: $A$ new experimental model for scleroderma. J Invest Dermatol 93: 610.

Bryson JS, Jennings CD, Caywood BE, Kaplan AM (1989). Induction of a syngeneic graftversus-host disease-like syndrome in DBA/2 mice. Transplantation 48: 1042.

Cheney RT and Sprent J (1985). Capacity of cyclosporine to induce auto-graft-versus-host disease and impair intrathymic $T$ cell differentiation. Transplant Proc 17: 528.

De Wit D, Van Mechelen M, Zanin C, Doutrelepont J-M, Velu T, Gerard C, Abramowie. D, Scheerlinck J-P, De Baetseller P, Urbain J, Leo O, Goldman M, Mater M (1993). Preferential activation of Th2 cells in chronic graft-versus-host reaction. J Immunol 150: 361.

Dubey C, Bellon B, Hirsch F, Kuhn J, Vial MC, Golman M, Druet P (1991). Increased expression of class II major histocompatibility complex molecules on B cells in rats susceptible or rresistant to $\mathrm{HgCl}_{2}$-induced autoimmunity. Clin Exp Immunol 86: 118.

Earnshaw W, Boldwell B, Marino C, Rothfleld N (1986). Three human chromosomal autoantigens are recognized by sera from patients with anti-centromere antibodies. J Clin Invest 77: 426.

Fischer AC and Hess AD (1990). Age-related factors in cyclosporin-induced syngeneic graftversus-host disease: regulatory role of marrow-derived T lymphocytes. J Exp Med 172: 85.

Fischer AC, Laulis MK, Horwitz L, Hess AD (1991). Effect of cyclosporine on T lymphocyte development. Relationship to syngeneic graft-versus-host disease. Transplantation 51: 252.

Glader A, Tutschka PJ, Farmer ER, Santos GW (1983). Graft-versus-host disease in cyclosporine A-treated rats after syngeneic and autologous bone marrow transplantation. J Exp Med 158: 1.

Goldman M, Druet P, Gleichmann $\mathbf{E}$ (1991). $\mathrm{T}_{\mathrm{H}} 2$ cells in systemic autoimmunity: insights from allogeneic diseases and chemically-induced autoimmunity. Immunology Today 12: 223. 
Grau JM, Casademont J, Montforte R, Marin P, Granena A, Roeman C, Urbano-Marquez A (1990). Myasthenia gravis after allogeneic bone marrow transplantation: report of a new case and pathogenetic considerations. Bone Marrow Transplant 5: 435.

Guldner HH, Szosteckl C, Vosberg HP, Lakomek HJ, Penner E, Bautz FA (1986). Scl-70 autoantibodies from scleroderma patients recognized a $95 \mathrm{kDa}$ protein identified as DNA topoisomerase I. Chromosoma 94: 132.

Habets WJ, De Rooij DJ, Salden MH, Verhagen AP, Van Eekelen CA, Van de Putte LB, Van Venrooij WJ (1983). Antibodies against distinct nuclear matric proteins are characteristic for mixed connective tissue disease. Clin Exp Immunol 54: 265.

Hess AD, Horwitz L, Beschorner WE, Santos GW (1985). Development of graft-versus-host disease-like syndrome in cyclosporine-treated rats after syngeneic bone marrow transplantation. 1. Development of cytotoxic T Iymphocytes with apparent polyclonal anti-la specificity, including autoreactivity. J Exp Med 161: 718.

Hess AD, Jones RJ, Morris LE, Noga SJ, Vogelsang GB, Santos GW (1992). Autologous graft-versus-host disease: A novel approach for antitumor immunotherapy. Human Immunol 34: 219.

HIldebrandt S, Welner ES, Senecal J-L, Noell GS, Earnshaw WC, Rothfleld NF (1990). Autoantibodies to topoisomerase I (Scl-70): analysis by gel diffusion, immunoblot, and enzyme-linked immunosorbent assay. Clin Immunol Immunopathol 57: 399.

Jones RJ, Hess AD, Mann RB, Plantadosi S, Vogelsang GB, Farmer ER, Geller RB, Santos GW (1989). Induction of graft-versus-host disease after autologous bone marrow transplantation. Lancet 1: 754.

Kallenberg CGM, Pastoor GW, Wouda AA, The TH (1982). Antinuclear antibodies in patients with Raynaud 's phenomenon: clinical significance of anticentromere antibodies. Ann Rheum Dis 41: 382.

Kremer L, Del Mazo J, Avila J (1988). Identification of centromere proteins in different mammalian cells. Eur J Cell Biol 46: 196.

Krieg T and Meurer M (1988). Systemic scleroderma. Clinical and pathophysiologic aspects. J Am Acad Dermatol 18: 457.

Livingston JZ, Scott TE, Wigley FM, Anhalt GJ, Bias WB, McLean RH, Hochberg MC (1987). Systemic sčlerosis (scleroderma): clinical, genetic, and serologic subsets. J Rheumatol 14: 512.

Marcos MAR, De La Hera A, Gaspar ML, Marquez C, Bellas C, Mampaso F, Torbidio ML, Martinez-A C (1986). Modification of emerging repertoires by immunosuppression in immunodeficient mice results in autoimmunity. Immunol Rev 94: 51.

Melms A, Faul C, Sommer N, Wiethölter H, Müller CA, Ehninger G (1992). Myasthenia gravis after BMT: identification of patients at risk? Bone Marrow Transplant 9: 78.

Mosmann TR and Moore KW (1991). The role of $\mathrm{L}-10$ in crossregulation of $T_{H} 1$ and $T_{H} 2$ responses. Immunology Today 12: A49.

Pelletler L, Pasquier R, Hirsch F, Sapin C, Druet P (1986). Autoreactive T cells in mercuryinduced autoimmune disease: in vitro demonstration. J Immunol 137: 2548.

Pelletler L, Pasquler R, Rossert J, Druet $\mathbf{P}$ (1987). $\mathrm{HgCl}_{2}$ induces non specific immunosuppression in Lewis rats. Eur J Immunol 17: 49. 
Pelletier L, Pasquier R, Guettier C, Vial M-C, Mandet C, Nochy D, Bazin H, Druet P (1988a). $\mathrm{HgCl}_{2}$ induces $\mathrm{T}$ and $\mathrm{B}$ cells to proliferate and differentiate in $\mathrm{BN}$ rats. Clin Exp Immunol 71: 336.

Pelletier L, Pasquler R, Rossert J, Vial MC, Mandet C, Druet P (1988b), Autoreactive T cells in mercury-induced autoimmunity. Ability to induce the autoimmune disease. J Immunol 140: 750.

Pelletier L, Rossert J, Pasquier R, V/al MC, Druet P (1990). Role of CD8+ T cells in mercury-induced autoimmunity or immunesuppression in the rat. Scand J Immunol 31: 65.

Portonova JP, Rubin RL, Joslin FG et al. (1982). Reactivity of antihistone antibodies induced by procainamide and hydralazine. Clin Immunol Immunopathol 25: 67.

Sakaguchi S and Sakaguchi N (1988). Thymus and autoimmunity. Transplantation of the thymus from cyclosporin A-treated mice cause organ-specific autoimmune disease in athymic nude mice. J Exp Med 167: 1479.

Sakagucbl S and Sakaguchl N (1989). Organ-specific autoimmune disease induced in mice by elimination of $\mathrm{T}$ cell subsets. V. Neonatal administration of cyclosporin A causes autoimmune disease. J Immunol 142: 471.

Sakaguchl S and Sakaguchl $\mathbf{N}(1990)$. Thymus and autoimmunity. Capacity of the normal thymus to produce pathogenic self-reactive $\mathrm{T}$ cells and conditions required for their induction of autoimmune disease. J Exp Med 172: 537.

Shulman HM, Sale GE, Lerner KG, Barker EA, Weiden PL, Sullivan K, Gallucl B, Thomas ED, Storb R (1978). Chronic cutaneous graft-versus-host disease in man. Am J Pathol 91: 545.

Sorokin R, Kimura H, Schroder K, Wilson DH, WIIson DB (1986). Cyclosporin-induced autoimmunity. Conditions for expressing disease. Requirement for intact thymus, and potency estimates of autoimmune lymphocytes in drug-treated rats. J Exp Med 164: 1615.

Tan EM, Rodnan GP, Garcla I, Morol Y, Fritzler MJ, Peebles C (1980). Diversity of antinuclear antibodies in progressive systemic sclerosis. Arthritis Rheum 23: 617.

Tortoritis MC, Tan EM, MeNally EM et al. (1988). Association of antibody to histone complex H2A-H2B with symptomatic procainamide-induced lupus. N Engl J Med 318: 1431.

Tournade H, Pelletier L, Pasquier R, Vial MC, Mandet C, Druet P (1990). Graft-versus-host reactions in the rat mimic toxin-induced autoimmunity. Clin Exp Immunol 81: 334.

Van Venroolj WJ, Stapel SO, Houben H, Habets WJ, Kallenberg CGM, Penner E, Van de Putte LBA (1985). Scl-86, a marker antigen for diffuse scleroderma. J Clin Invest 75 : 1053.

Verschuurea JJGM, Bos GMJ, Majoor GD, DeBaets MH, Van Breda Vrieaman PJC (1989). Syngeneic bone marrow-dependent, cyclosporin A-mediated, myasthenia gravis. In Proceedings of the 7th International Congress of Immunology, 1989, Berlin, Germany, p.555.

Weiner ES, Earnshaw WC, Senecal J-L, Bordwell B, Johnson P, Rothfield NF (1988). Clinical associations of anticentromere antibodies and antibodies to topoisomerase I. Arthritis Rheum 31: 378.

Wodaig KWH, Majoor GD, Van Breda Vriesman PJC (1991). On the localization of effector cells in cyclosporin-induced autoimmunity. Autoimmunity 10: 275.

Wodaig KWH, Majoor GD, Van Breda Vriesman PJC (1993). Susceptibility and resistance to cyclosporine A-induced autoimmunity in the rat. Autoimmunity, in press. 
$\left.7 x^{7}+x^{3}\right)(40$

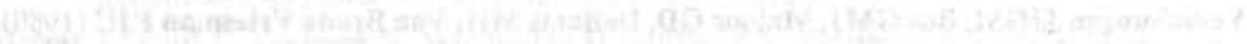

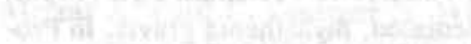

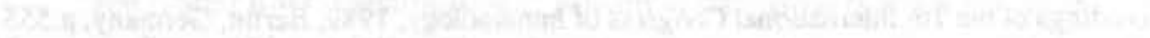

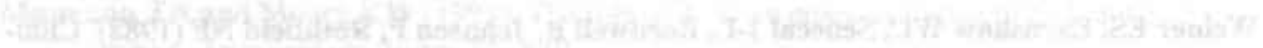

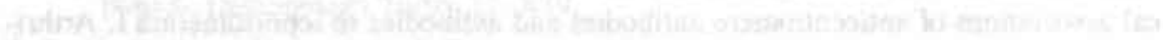

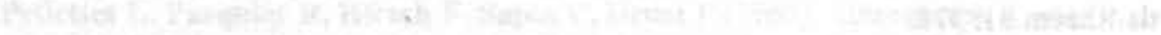

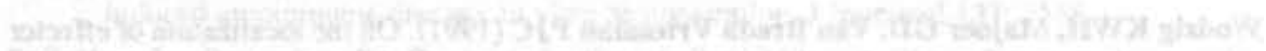
Foin

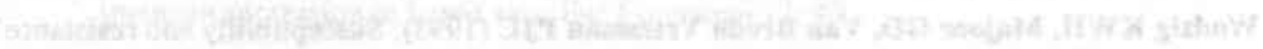

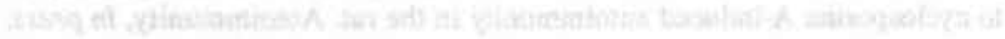




\title{
|Chapter 5
}

\section{On the localization of}

\author{
effector cells in
}

\section{Cyclosporine A - induced}

\author{
autoimmunity
}

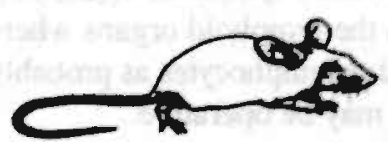




\section{On the localization of effector cells in Cyclosporine A - induced autoimmunity}

\section{Abstract}

Lethally irradiated rats, reconstituted with syngeneic bone marrow and given Cyclosporine $\mathrm{A}(\mathrm{CyA})$ for 6 weeks, developed disease resembling allogeneic graftversus-host disease 2 weeks after withdrawal of CyA. Other studies have demonstrated the pivotal role of the thymus in the etiology of this CyA-induced autoimmune disease (CyA-AI). In this study the question was addressed whether inducer/effector cells of CyA-AI are generated in the thymus during or after CyA administration; whether these cells stay in the thymus or, if they don't, whether they home to the secondary lymphoid organs.

Adoptive transfer of thymocytes from donors treated for induction of CyA-AI obtained one and 14 days after cessation of CyA administration did not elicit CyA$\mathrm{Al}$ in irradiated secondary recipients. Furthermore, adult thymectomy of rats immediately after the course of CyA did not influence the kinetics of development of skin pathology, although weight loss commenced later in thymectomized than in sham-thymectomized rats.

Lymph node and spleen cells obtained from donors treated for induction of CyA$\mathrm{AI}$ one and 14 days after withdrawal of CyA caused CyA-AI upon adoptive transfer to secondary recipients, but the symptoms of acute disease (dermatitis, alopecia and weight loss) were strikingly less severe upon transfer of lymphoid cells obtained one day after stopping CyA than 14 days thereafter. Therefore, this study demonstrates that $\mathrm{CyA}-\mathrm{AI}$ inducer/effector cells are generated in the thymus during the administration of CyA. These cells exit from the thymus during CyA administration; either they home predominantly peripherally (i.e. in the skin) rather than in the secondary lymphoid organs, or they leave the thymus as inducer cells which home in the lymphoid organs where they subsequently may trigger potentially autoreactive lymphocytes as probably also present in normal individuals, or both pathways may be operative. 


\section{Introduction}

Cyclosporine A (CyA), a fungal metabolite with potent immunosuppressive properties, is effective in preventing graft-versus-host disease (GVHD) secondary to allogeneic bone marrow transplantation (BMT), and in inhibiting progression of several autoimmune diseases (Tutschka et al., 1979; Von Graffenried er al., 1989; Bacigalupo et al., 1990). Paradoxically, under certain circumstances CyA may also induce autoimmune disease. Lethally irradiated rats reconstituted with syngeneic or autologous bone marrow and given CyA for some weeks following BMT develop, after withdrawal of CyA, symptoms of disease. These symptoms, as well as the histologic lesions, are similar to those seen in acute graft-versus-host disease (GVHD) after allogeneic BMT (Glazier et al., 1983a). This syngeneic GVHD (sGVHD) (Glazier et al., 1983a), CyA-induced autoimmune disease (Cy.A-AI) (Sorokin et al., 1986) or BMT-associated immune disease (BMT-ID) (Bos et al., 1990) can be elicited reproducibly in young rats (Fischer and Hess, 1990) or mice (Cheney and Sprent, 1985; Bryson et al., 1989) and has also been observed in adult humans (Jones et al., 1989).

Several studies have demonstrated an essential role for the thymus in the induction of CyA-AI. As shown by Glazier et al, shielding of the thymus during total-body irradiation prevents the induction of CyA-AI (Glazier et al., 1983b). Furthermore, CyA-AI could not be elicited in animals thymectomized prior to BMT (Sorokin et al., 1986). Two hypotheses prevail with respect to the role of the thymus in the kinetics of the generation of autoreactive T cells in CyA-AI. According to the first, inducer and/or effector T lymphocytes are generated during CyA therapy but remain ineffective due to the immunosuppressive activity of CyA (Wilson, 1989). The second hypothesis supposes that the generation of autoaggressive $\mathrm{T}$ lymphocytes takes place only after withdrawal of $\mathrm{CyA}$ and the ensuing decline of CyA levels in the hosts (Majoor et al., 1991). The onset of CyA$\mathrm{AI}$ is associated with the reappearance of $\mathrm{CD} 4^{+} \mathrm{T}$ cells in the peripheral blood about two weeks after cessation of CyA administration (Bos et al., 1988a; Fischer et al., 199I).

Data reported for mice indicated that thymocytes obtained immediately after a 6 weeks course of CyA from either lethally irradiated and reconstituted mice or from normal mice, were effective in adoptively transferring CyA-AI to secondary syngeneic recipients (Cheney and Sprent, 1985). Although these data suggest the presence of CyA-AI effector cells or their inducers in the thymus of CyA-treated mice, we failed to reproduce this result in a preliminary experiment using non-irradiated, CyA-treated donor rats. Since adoptive transfer of CyA-AI by thymocytes has only been described for the rat using thymocytes harvested 30 days after withdrawal of CyA (Beschorner et al., 1988a), an attempt was made to investigate in the rat model whether CyA-AI effector-or inducer cells are present in the thymus and the lymph nodes at the time of cessation of CyA administration. Both adoptive cell transfer studies and adult thymectomies were periformed to address this question experimentally. 
The results of the present study demonstrate that $\mathrm{CyA}-\mathrm{Al}$ inducer/effector cells are generated and leave the thymus during the course of CyA. Adoptive transfer studies showed that auto-aggressive cells are not likely to home preferentially in the lymph nodes.

\section{Materials and methods}

\section{Animals}

Female, specific pathogen-free Lewis (LEW, RT1') rats were used as donors and recipients. Rats were obtained from our own breeding stock. Animals were used at the age of 4.6 weeks.

\section{Protocol for induction of CyA-Al}

Rats were lethally irradiated one day prior to syngeneic BMT. CyA was administered for 6 weeks starting on the day of BMT. This procedure is referred to as the standard protocol. CyA-Al usually developed 2-3 weeks after cessation of CyA administration (Bos et al., 1988a).

\section{Irradiation}

Rats were given $8.5 \mathrm{~Gy}$ at $0.5 \mathrm{~Gy} / \mathrm{min}$. using a Röntgen irradiation machine (Philips MG320, Hamburg, Germany).

\section{Bone marrow transplantation}

Donor rats were killed by cervical dislocation under ether anesthesia. Bone marrow was collected from tibias and femurs in Dulbecco's balanced salt solution supplemented with $2 \%$ heat-inactivated fetal calf serum (iFCS), penicillin $(100 \mathrm{U} / \mathrm{ml})$ and streptomycin $(100 \mu \mathrm{g} / \mathrm{ml})$ (DBSS). Recipient rats received $6 \times 10^{7}$ viable syngeneic bone marrow cells in $1.0 \mathrm{ml}$ DBSS intravenously into a tail vein.

\section{Cyclosporine A}

CyA, a gift from Sandoz Co. Ltd., Basel, Switzerland, was dissolved in olive oil at a concentration of $7.5 \mathrm{mg} / \mathrm{ml}$. Rats were weighed daily and received $7.5 \mathrm{mg} / \mathrm{kg} /$ day subcutaneously from the day of BMT.

\section{Scoring of macroscopic pathology}

After withdrawal of CyA, development of CyA-AI was assessed by examination of the rats 1-2 times a week for signs and symptoms of disease: red acra (hyperemia of the skin of the ears, feet and tail), inflammation of the eyelids, dermatitis, and alopecia (Table 5.1) 
Table 5.1: Coding of macroscopic pathology in CYA - A.

\begin{tabular}{|c|c|}
\hline Code & Pathology \\
\hline . & No pathologr \\
\hline E & Erythroderma of the acra (hyperemia of the skin of the ears, feet and tail) \\
\hline D & $\begin{array}{l}\text { Dermatitis, usually starting around the eyes and with brown/red discoloring of } \\
\text { the fur of the neck, front and/or hind legs. Expansion is initially restricted } \\
\text { to the ventral part of the body. }\end{array}$ \\
\hline$A_{v}$ & Ventral alopecia \\
\hline$A_{0}$ & Generalizedi alopecia \\
\hline$T^{\prime}$ & $\begin{array}{l}\text { Thin fur, usually dorsal (consequence of slowly progressive disesese or recovery } \\
\text { from alopecia) }\end{array}$ \\
\hline
\end{tabular}

and the weights of the rats were determined (Bosi et al., 1989). The alopecia is akin to that described to occur in stable chimeras after allogeneic bone marrow transplantation without additional CyA therapy, although in this allogeneic model alopecia developed later than in the model of Cy A-AI (Beschorner et al., 1982; Bos et al., 1988b).

\section{Adoptive cell transfers}

Thymocytes, mesenterial and cervical lymph node cells, and splenocytes were harvested from animals one or 14 days after withdrawal of CyA. Animals taken 14 days after cessation of CyA manifested early signs of CyA-AI. Single cell suspensions were made by passing organ fragments through nylon gauze screens. Cells were collected in DBSS, washed, and their viability assessed by trypan blue exclusion. Putative effector cells were infused together with syngeneic bone marrow cells $\left(6 \times 10^{7}\right)$ into $8.5 \mathrm{~Gy}$ irradiated secondary recipients. Secondary recipients received either $10^{8}$ thymocytes or $3 \times 10^{7}$ lymph node cells, which were in one experiment partly replaced by spleen cells.

\section{Thymectomy}

Lewis rats treated according to the protocol for induction of $\mathrm{Cy} \mathbf{A}-\mathbf{A}$ were thymectomized (Tx) or sham-thymectomized (sham-Tx) on day one after cessation of CyA administration.

\section{Statistics}

Weight differences between groups of rats were tested for statistical significance by Wilcoxon's rank sum test. 


\section{Results}

\section{Development of CyA-AI In donor rats}

A 'primary' cohort of 12 rats received lethal irradiation, syngeneic BMT, and CyA for 42 days. Five out of these 12 rats were sacrificed one day after stopping CyA for adoptive transfer of either thymocytes or lymph node cells to irradiated secondary recipients. Two weeks after cessation of CyA the remaining 7 rats showed 2-22\% decrease in body weight as compared to their weights on day 6 after CyA withdrawal (Fig. 5.1). In contrast, a control group derived from another experiment consisting of 7 irradiated, bone marrow-reconstituted rats given the CyA-solvent only, showed on day 14 after cessation of injections a mean increase in body weight of $6 \mathrm{~g}$ (Range: $3-11 \mathrm{~g} ; 2-6 \%$ ). Three out of the 7 rats given CyA exhibited severe skin pathology like dermatitis, and ventral alopecia on day 14 after CyA withdrawal; the other 4 rats showed symptoms associated with the

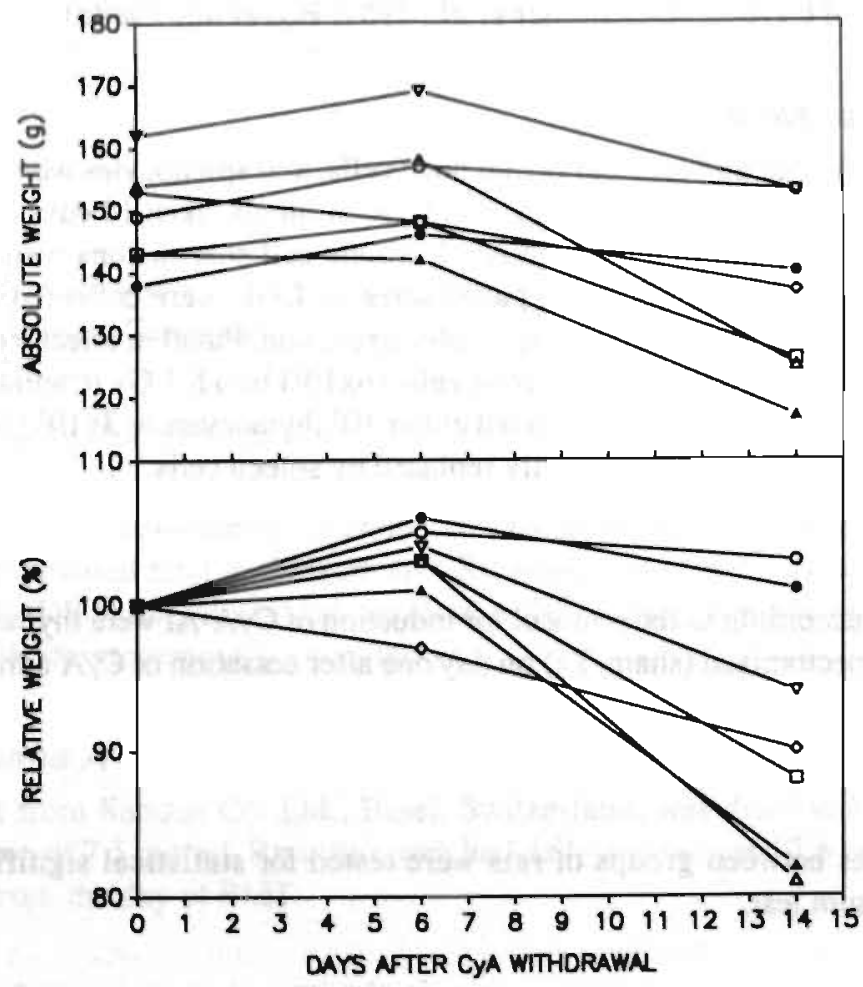

Figure 5.1: Absolute (upper panol) and relative weights (lower panel) of 7 rats traated for hocuctlon of CyA-Al ecconding to the standard protocol, aner CyA withdrawal. All 7 rats manifested symploms of CyA-Al on day 13 aner CyA withdrawal. Five additional rats from the same cohort were used for day 1 transfer of Mmphoid colls. 
onset of CyA-AI like erythroderma of the acra and dermatitis (Table 5.2, Group I). Therefore, also donors used one day after stopping CyA were accepted to be treated adequately for development of CyA-AI.

\section{Transfer of thymocytes}

To investigate whether autoreactive lymphocytes were present in the thymus at the time of cessation of CyA administration, pooled thymocytes obtained one day after withdrawal of CyA from 4 donors were transferred to 5 lethally irradiated secondary recipients along with normal syngeneic bone-marrow cells (Group II). For comparison, pooled thymocytes obtained 2 weeks after CyA withdrawal from 3 donors were transferred to 3 secondary recipients (Group III). The average yield of viable thymocytes per rat from donors taken one day after cessation of CyA was $5.8 \times 10^{8}$ and that from rats sacrified 14 days after stopping $\mathrm{CyA} 1.3 \times 10^{8}$; a reduction of $78 \%$.

Adoptive transfer of $10^{8}$ thymocytes, irrespective whether harvested one day or 14 days after CyA withdrawal, into secondary recipients elicited no manifestation of CyA-AI for over 100 days. In contrast, transfer of $3 \times 10^{7}$ lymph node cells and splenocytes, obtained

Tabie 5.2: Developrnent of autolmmune stin pathology.

\begin{tabular}{|c|c|c|c|c|c|c|c|c|c|c|}
\hline \multirow{2}{*}{$\begin{array}{l}\text { Group } \\
\text { (number } \\
\text { of rats) }\end{array}$} & \multirow[t]{2}{*}{ Treatment } & \multirow{2}{*}{$\begin{array}{l}\text { AT } \\
\text { or } \\
\text { CW }\end{array}$} & \multicolumn{8}{|c|}{ Skin pathology on day $n$ after $A T$ or $C W$} \\
\hline & & & 0 & $?$ & 10 & 13 & 21 & 28 & 35 & $42-63$ \\
\hline $1(7)$ & $\begin{array}{l}\text { Standard protocole: } \\
\text { donors for "day } 14 " \\
\text { transfers }\end{array}$ & $\mathrm{CW}$ & $7 x=$ & $\begin{array}{l}6 \times= \\
1 \times 0\end{array}$ & $\begin{array}{l}2 \times- \\
1 \times E \\
4 \times D\end{array}$ & $\begin{array}{l}4 \times 0 \\
3 \times A_{v}\end{array}$ & \multicolumn{4}{|c|}{ (rate sacrified on day 14) } \\
\hline $\mid v(5)$ & $\begin{array}{l}\text { Recipients of } \\
\text { "dey 1" LNC }\end{array}$ & AT & $5 x-$ & $5 x-$ & $5 x-$ & $5 x-$ & $5 \times E$ & $\begin{array}{l}1 \times- \\
4 \times D\end{array}$ & $5 \times 0$ & $5 \times T$ \\
\hline$v(3)$ & $\begin{array}{l}\text { Recipients of } \\
\text { "day } 14^{-} \text {LNC/SC }\end{array}$ & AT & $3 x-$ & $3 x-$ & $\begin{array}{l}1 \times- \\
2 \times D\end{array}$ & $3 \times 0$ & $3 \times 0$ & $3 \times A_{v}$ & $3 \times A_{v}$ & $3 \times T$ \\
\hline VII (4) & $\begin{array}{l}\text { Sundard protocol: } \\
\text { sham-Tx day } 0\end{array}$ & $\mathrm{CW}$ & $4 x-$ & $4 x-$ & Nod & $\begin{array}{l}1 \times- \\
3 \times 0\end{array}$ & $\begin{array}{l}1 \times- \\
3 \times A_{V}\end{array}$ & $\begin{array}{l}\text { 1x. } \\
3 \times A_{V}\end{array}$ & $\begin{array}{l}1 \% \\
3 \approx A_{V}\end{array}$ & $\begin{array}{l}3 \times A_{V} \\
1 \times T\end{array}$ \\
\hline VIII (5) & $\begin{array}{l}\text { Standard protocol: } \\
\text { Tx day } 0\end{array}$ & $\mathrm{cW}$ & $5 x-$ & $5 x-$ & ND & $\begin{array}{l}1 \times- \\
4 \times D\end{array}$ & $\begin{array}{l}3 \times 0 \\
2 \times A_{V}\end{array}$ & $\begin{array}{l}3 \times D \\
2 \times A_{v i}\end{array}$ & $\begin{array}{l}1 \times D \\
4 \times A_{v}\end{array}$ & $\begin{array}{l}1 \times 0 \\
4 \times A_{V}\end{array}$ \\
\hline $1 \times(30)$ & Standard protocol & $\mathrm{cW}$ & $39 x$ & $39 x$. & ND & $\begin{array}{l}26 x- \\
4 \times E \\
4 \times D \\
5 x \times A_{V}\end{array}$ & $\begin{array}{l}18 x- \\
2 \times E \\
10 \times[ \\
8 \times A_{v} \\
1 \times A_{0}\end{array}$ & tone & $\begin{array}{l}9 \times- \\
21 \times A_{V} \\
9 \times A_{g}\end{array}$ & $\begin{array}{l}4 \times * \\
3 \times 0 \\
18 \times A_{v} \\
10 \times A_{0} \\
4 \times T\end{array}$ \\
\hline
\end{tabular}

-AT, adopive transler; CW, CYA withdrawal. bScoring of skin pothology: see Table 5.1. CStandard protocol: Lethal $X$-irrodiation, BMT, and CYA for 42 days. dND: Na dote available. 
14 days after withdrawal of CyA, to lethally irradiated and reconstituted secondary recipients evoked CyA-AI as assessed by development of dermatitis and alopecia (Table 5.2, Group V) and concomitant weight loss within 2 weeks after cell transfer (Fig. 5.2). Differences in relative weights between combined thymocyte recipients and spleen- and lymph node cell recipients were significant on days $14-42$ after adoptive transfer (day 1435: $\mathrm{P}<0.02$; day 42: $\mathrm{P}=0.05$ ).

\section{Effect of thymectomy on development of CyA-A}

In a different aproach to the same question, 9 lethally irradiated rats reconstituted with syngeneic bone marrow and given CyA for 42 days, were thymectomized $(n=5)$ or shamthymectomized $(n=4)$ one day after stopping CyA. Symptoms of CyA-AI developed by the same kinetics in both groups (Table 5.2, Groups VII and VIII). However, the weight loss usually associated with acute CyA-AI occurred two weeks later in Tx rats than in sham$\mathrm{Tx}$ rats. The relative weights of $\mathrm{Tx}$ and sham-Tx rats differed significantly on days 7 and

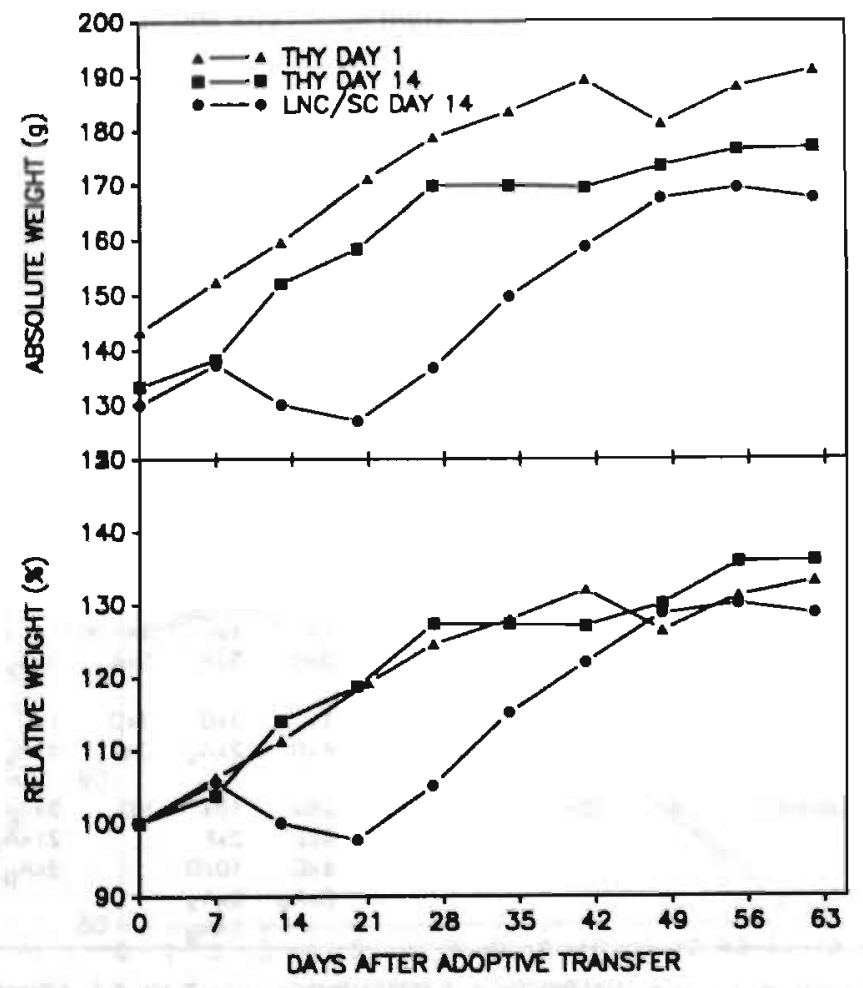

Floure 52: Effuct of edoptive transfor of $10^{\circ}$ thymocytes obtained from rats traeted for inctuction of CyA-Al on day 1 (A) end day 14 (a) afrar CyA withdrawal, on the welght of secondery reciplentis. For companison, the effect of transfor of $3 \times 10^{-}$lymph node and spleen cells obtained 14 days after withdrawa of CyA is shown ( 0 ). Upper panel, absolute weights; lower panel, rolative woights. 
14 after CyA withdrawal ( $\mathrm{P}<0.03)$ (Fig. 5.3). Kinetics of development of CyA-AI in sham-Tx rats were comparable to that in a control group derived from a separate experiment consisting of 39 female LEW rats that were lethally irradiated, reconstituted with syngeneic bone-marrow, and given CyA for 35 days (Table 5.2, Group IX), although the relative weights of both groups were significantly different on day 7 after CyA withdrawal. Onward from day 28 post-CyA withdrawal the relative body weights of the three groups of rats that received CyA were not significantly different (Fig. 5.3).

\section{Transfer of lymph node cells and spleen cells}

The average yield of viable lymph node cells from rats sacrificed one day after stopping CyA was $6 \times 10^{7}$, and that of spleen cells $12.5 \times 10^{7}$ per animal. For rats sacrified 2 weeks after CyA withdrawal these figures were $2.9 \times 10^{7}(=48 \%)$ and $4.5 \times 10^{7}(=38 \%)$ respectively. Therefore, in the adoptive transfer performed 2 weeks after CyA withdrawal lymph node cells were supplemented with spleen cells to match the number of lymphoid cells

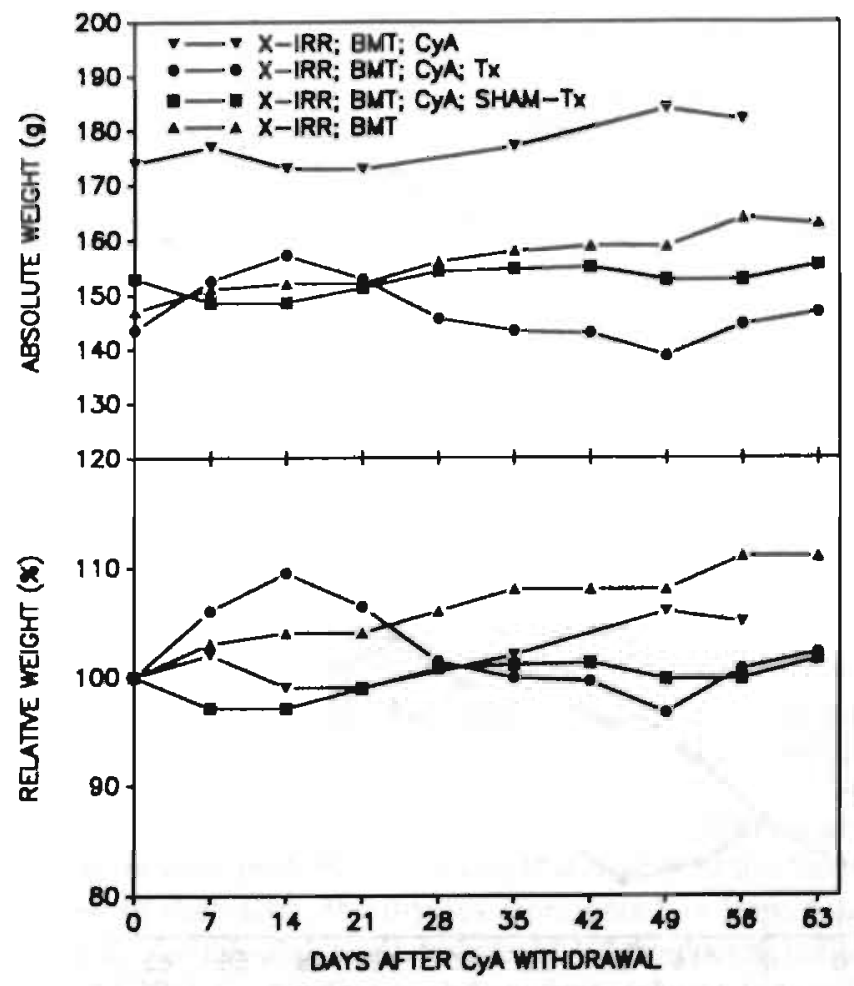

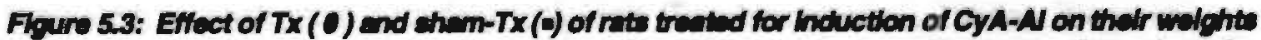

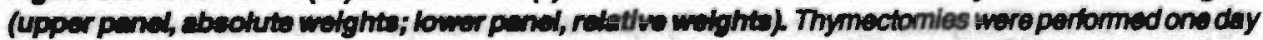
after CyA withdrawal. For comparison, from separate experiments the weight curves of 39 non-operated nats

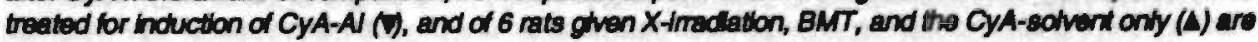
shown. 
transferred one day after stopping CyA. Transfer of this mixture of lymph node and spleen cells (2.75:1) obtained 14 days after CyA withdrawal from 3 donor rats exhibiting CyA-AI, to 3 irradiated and reconstituted secondary recipients readily elicited CyA-AI. Two weeks after cell transfer recipients developed symptoms of CyA-AI and showed a 4$7 \%$ decrease in body weight as compared to day 7 . In contrast, there was no reduction in the weights of 5 rats that received lymph node cells obtained one day after cessation of CyA administration. This difference was significant between 14 and 28 days after adoptive cell transfer $(\mathrm{P}<0.04)$ (Fig. 5.4). The symptoms of CyA-AI developed 2 weeks later and were less vehement in rats that received lymph node cells obtained from donors one day after cessation of CyA than in recipients of lymphoid cells harvested 14 days after CyA withdrawal. Ultimately, in rats from both groups acute pathology evolved to a "chronic", mild variety onward from day 42 after cell transfer (Table 5.2, Group IV and V).

Furthermore, an attempt was made to transfer CyA-AI to secondary recipients using donors that received CyA for 6 weeks, but without the preceding lethal X-irradiation and BMT (Group VI). Neither thymocytes (data not shown) nor pooled lymph node cells

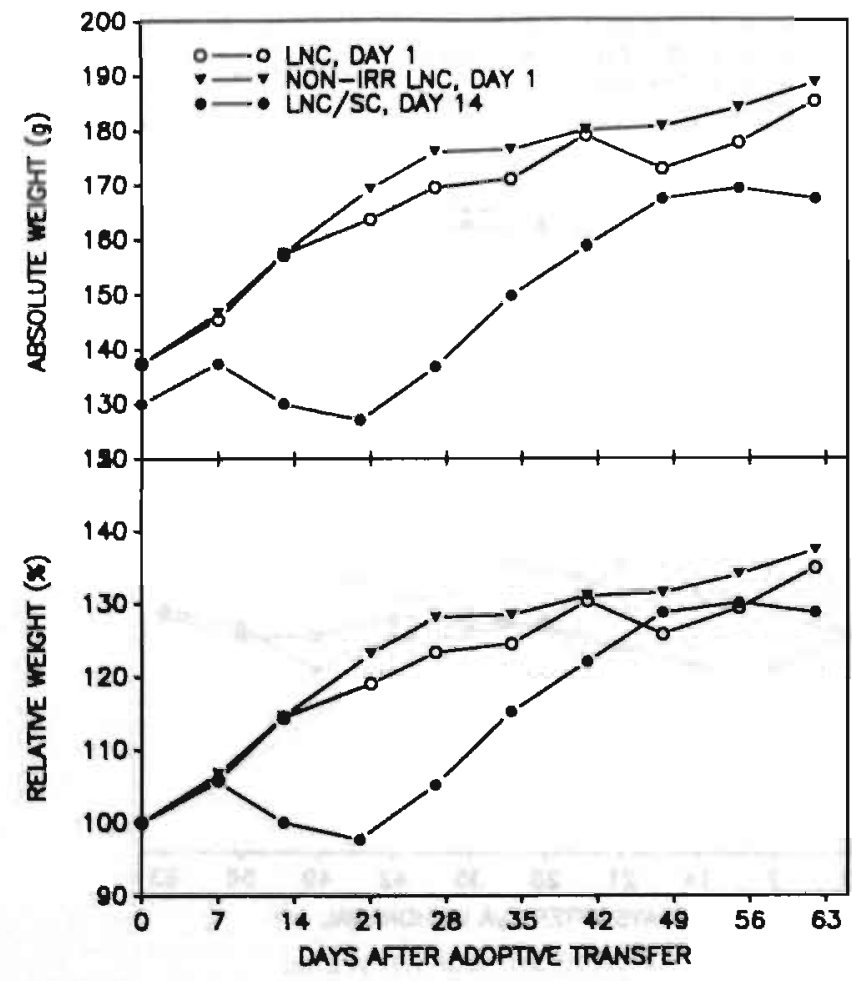

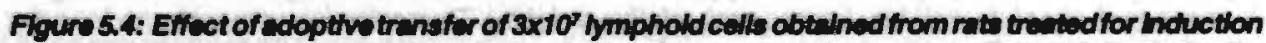
of CYA-A on day $1(0)$ and day 14 ( 0 ) after CyA withdrewal, on the wilght of excondery reciplents. Furthermore, the entect of transfer of hymph node cells obteined one day after withdrawel of CyA from rats only given CyA for 6 weeks, on the weight of secondary recipients is shown ( ) ). Upper panel, absolute weights; lower panal, relative woights. 
obtained from 4 of these donors one day after CyA withdrawal elicited CyA-AI in 5 irradiated and reconstituted secondary recipients (Fig. 5.4).

\section{Discussion}

The data presented in this study corroborate the hypothesis put forward by others, that in models of $\mathrm{CyA}-\mathrm{AI}$ autoreactive cells are generated during $\mathrm{Cy} A$ administration. Since CyA-AI is shown here to develop also if rats are thymectomized immediately after cessation of $\mathrm{CyA}$ administration, autoaggressive cells (or their inducers) already must reside extrathymically prior to CyA withdrawal.

The first arguments in favor of this hypothesis were provided by Cheney and Sprent, who demonstrated that adoptive transfer of spleen- and lymph node cells obtained from irradiated and reconstituted mice immediately after a 5-6 weeks course of CyA elicited acute, fatal CyA-AI in irradiated and reconstituted secondary recipients (Cheney and Sprent, 1985). In the present study, however, C.yA-AI-asscciated pathology elicited by this protocol was not severe and did not result in death of the animals but after the acute phase evolved to mild, chronic skin pathology. Although the dose of CyA used in the study of Cheney and Sprent was somewhat higher than that applied by us ( 10.0 versus $7.5 \mathrm{mg} / \mathrm{kg} /$ day), the difference in severity of the pathology observed is more likely to be due to the different experimental animals used and/or differences in their microbiological status (Sorokin et al., 1986).

A more striking difference, however, concerns the data from an experiment reported by Cheney and Sprent in which non-irradiated, CyA-treated mice were used as donors for adoptive transfer studies. Lymphoid cells obtained from these donors immediately after withdrawal of CyA also evoked severe, fatal CyA-AI upon transfer to irradiated, reconstituted mice (Cheney and Sprent, 1985). In the rat model, however, this experiment could not be reproduced. The possible reasons indicated above to explain the gradual differences in skin pathology observed using irradiated donors may also apply to the disconcordant findings regarding this protocol.

Both the results of our adoptive transfer studies using thymocytes, and the studies in which thymectomies were performed, indicate that neither at the time of CyA withdrawal, nor 2 weeks thereafter, the thymus represented an important reservoir of autoaggressive cells. On the other hand, transfer of $10^{8}$ thymocytes collected from rats exhibiting CyA-AI 30 days after CyA withdrawal were shown to transfer CyA-AI to irradiated, reconstituted secondary recipients (Beschorner $e t$ al., 1988a). We interpret this apparent discrepancy to reflect remigration of autoaggressive effector $\mathrm{T}$ cells to the thymus (Beschorner et al., 1988b). Their putative destructive action may be the cause of the reduced cell yield from the thymus and secondary lymphoid organs after CyA withdrawal, as also noticed by others (Beschorner et al., 1987a). 
Thymectomy one day after withdrawal of CyA did neither have an effect on the kinetics of development, nor on the severity of skin pathology. On the other hand, weight loss occurred about two weeks later in Tx than in sham-Tx rats. This discrepancy suggests that the generation of the effector cells causing skin pathology may proceed differently from the generation of the effector cells which indirectly cause the weight loss in these animals. The former may already arrive in situ during the course of $\mathrm{CyA}$, whereas the latter may still have to be generated and to home to the target organs after the decline of CyA levels in the rats.

Another model which yielded data pertinent to the subject of this study is that of transplantation of the thymus from CyA-treated $n w+$ mice to $n w / n u$ recipients (Sakaguchi and Sakaguchi, 1988). In this model, autoimmunity manifested itself by autoantibody-induced gastritis, oophoritis, thyroiditis and/or insulitis 3 months after thymus transplantation. Thymus graft donors were either neonatal mice treated for 7 days with $10 \mathrm{mg} / \mathrm{kg} \mathrm{CyA} \mathrm{or}$ (non-irradiated) adult mice given $20 \mathrm{mg} / \mathrm{kg}$ CyA for 14 days. The data from this study suggested that the thymus may harbor inducers of CyA-AI early after the start of administration of CyA, whereas our results indicated that the (rat) thymus did not contain significant numbers of CyA-AI effector- or inducer cells after 6 weeks of CyA administration. Since the nw/nu recipients of CyA-treated thymus grafts were not given CyA, and CyAinduced changes in the thymus commence to reverse within a few days after CyA withdrawal (Beschorner et al., 1987b), in the mouse thymus graft model a reservoir function of the thymus for autoreactive cells is more likely than de novo generation of such cells from precursors arriving from the recipient's bone marrow. Furthermore, phenotyping of thymocytes from irradiated mice treated with CyA for only 3 weeks demonstrated an arrest in the development of mature CD4 and CD8 single positive T lymphocytes and the occurrence of $\mathrm{T}$ cells expressing potentially autoreactive $\mathrm{T}$ cell receptors (Gao et al., 1988; Jenkins et al., 1988).

Taken together, our data and the studies referred to above suggest that the generation of autoreactive $\mathrm{T}$ cells may commence early after the start of CyA administration, but the continuous generation of these cells in the thymus under CyA administration is uncertain. As demonstrated in the present study, autoreactive cells leave the thymus during the course of CyA, but their targets for homing remain to be determined. The mild form of CyA-AI that developed after adoptive transfer of lymph node cells collected immediately after cessation of CyA administration suggested that autoreactive cells preferably home outside the secondary lymphoid organs (i.e. in the skin) or that inducer- rather than effector cells are exported from the thymus to the lymph nodes. In the latter case, expansion of autoaggressive clones (i.e. anti-MHC class II cytotoxic T cells (Hess et al., 1985)) would not yet have occurred at the time of adoptive transfer. This expansion may not take place until about two weeks after CyA withdrawal when CyA concentrations have decreased to biologically ineffective levels (Bos et al., 1988a). The discrepancy in the kinetics of weight loss and development of skin pathology in $\mathrm{Tx}$ rats as compared to sham-Tx rats suggests that both mechanisms may be operative. 


\section{Acknowledgements}

The excellent technical assistance of Marie--José van de Gaar is gratefully acknowledged. This study was supported by the Dutch League against Rheumatic Diseases. 


\section{References}

Bacigalupo A, Maiolino A, Van Lint MT, Occhini D, Gualandi F, Clavio M, el al. (1990). Cyclosporin A and chronic graft versus host disease. Bone Marrow Transplant 6: 341-344

Beschorner WE, Tutschka PJ, Santos GW (1982). Chronic graft-versus-host disease in the rat radiation chimera. I. Clinical features, hematology, histology, and immunopathology in long-term chimeras. Transplantation 33: 393-399

Beschorner WE, DI Gennaro KA, Hess AD, Santos GW (1987a). Cyclosporine and the thymus: Influence of irradiation and age on thymic immunopathology and recovery. Cell Immunol 110: 350-364

Beschorner WE, Namnoum JD, Hess AD, Shinn CA, Santos GW (1987b). Cyclosporin A and the thymus. Immunopathology. Am J Pathol 126: 487-496

Beschorner WE, Hess AD, Shinn CA, Santos GW (1988a). Transfer of Cyclosporine-associated syngeneic graft-versus-host disease by thymocytes. Resemblance to chronic graft-versushost disease. Transplantation 45: 209-215

Beschorner WE, Olson JL, Hess AD, DI Gennaro KA, Santos GW (1988b). Cyclosporineinduced cell-mediated injury of the thymic medullary epithelium. Transplantation 45: 797 803

Bos GMJ, Majoor GD, Van Breda Vriesman PJC (1988a). Cyclosporin A induces a selective, reversible suppression of $\mathrm{T}$-helper lymphocyte regeneration after syngeneic bone marrow transplantation: association with syngeneic graft-versus-host disease in rats. Clin Exp Immunol 74: 443-448

Bos G, Majoor G, Slaaf D, Reneman R, van Breda Vriesman P (1988b). In vivo demonstration of microvascular pathology by intravital micruscupy in experimental chronic graftversus-host disease: analogy with scleroderma. J Rheumatol 15: 1339-1345

Bos GMJ, Majoor GD, WIllighagen RGJ, van Breda Vriesman PJC (1989). Chronic Cyclosporine-induced autoimmune disease in the rat: a new experimental model for scleroderma. J Invest Dermatol 93: 610-615

Bos GMJ, Majoor GD, van Breda Vriesman PJC (1990). Graft-versus-host disease: the need for a new terminology. Immunol Today 11: 433-436

Bryson JS, Jennings CD, Caywood BE, Kaplan AM (1989). Induction of a syngeneic graftversus-host disease-like syndrome in DBA/2 mice. Transplantation 48: 1042-1047

Cheney RT and Sprent J (1985). Capacity of Cyclosporine to induce auto-graft-versus-host discase and impair intrathymic T cell differentiation. Transplant Proc 17: 528-530

Fischer AC and Hess AD (1990). Age-related factors in Cyclosporin-induced syngeneic graftversus-host disease: regulatory role of marrow-derived T lymphocytes. J Exp Med 172: 85 94

Fischer AC, Laulis MK, Horwitz L, Hess AD (1991). Effect of Cyclosporine on T lymphocyte development. Relationship to syngeneic graft-versus-host disease. Transplantation 51 : 252-259

Gao E-K, Lo D, Cheney R, Kanagawa O, Sprent J (1988). Abnormal differentiation of thymocytes in mice treated with Cyclosporin A. Nature 336: 176-179 
Glazier A, Tutschka PJ, Farmer ER, Santos GW (1983a). Graft-versus-host disease in Cyclosporin A-treated rats after syngeneic and autologous bone marrow iransplantation. J Exp Med 158: 1-8

Glazier A, Tutschka PJ, Farmer ER (1983b). Studies on the immunobiology of syngeneic and autologous graft-versus-host disease in Cyclosporine-treated rats. Transplant Proc 15: 3035-3041

Hess AD, Horwtt L, Beschorner WE, Santos GW (1985). Development of graft-versus-host disease-like syndrome in Cyclosporine-treated rats after syngeneic bone marrow transplantation. I. Development of cytotoxic T lymphocytes with apparent polyclonal antila specificity, including autoreactivity. J Exp Med 161: 71 8-730

Jenldns MK, Schwart RH, Pardoll DM (1988). Effects of Cyclosporine A on T cell development and clonal deletion. Science 241: 1655-1658

Jones RJ, Hess AD, Mann RB, Plantadosi S, Vogelsang GB, Farmer ER, Geller RB, Santos GW (1989). Induction of graft-versus-host disease after autologous bone marrow transplantation. Lancet 1: 754-757

Majoor GD, Wodzig KWH, van Breda Vriesman PJC (1991). Cyclosporin-induced autoimmunity. Kendall MD and Ritter MA, eds. London: Harwood Acadernic Publishers, Thymus Update 4, 1991: 179-200

Sakaguchi S and Sakaguchi N (1988). Thymus and autoimmunity. Transplantation of the thymus from Cyclosporin A-treated mice causes organ-specific autoimmune disease in athymic nude mice. J Exp Med 167: 1479-1485

Soroldn R, KImura H, Schroder K, Wilson DH, Wilson DB (1986). Cyclosporin-induced autoimmunity. Conditions for expressing disease. Requirement for intact thymus, and potency estimates of autoimmune lymphocytes in drug-treated rats. J Exp Med 164: 16151625

Tutschka PJ, Beschorner WE, Allison AC, Burns WH, Santos GW (1979). Use of Cyclosporine $A$ in allogeneic bone marrow transplantation in the rat. Nature 280: 5718-57 19

Von Graffenried B, Friend D, Shand N, Schless W, Timonen P (1989). Cyclosporin A (Sandimmun $^{\mathbb{R}}$ ) in autoimmune disorders. Thomson AW, ed. Cyclosporin. Mode of action and clinical applications. London: Kluwer Academic, 1989:213-250

Wilson DB (1989). Idiotypic regulation of T cells in graft-versus-host disease and autoimmunity. Immunol Rev 107: 159-177 



\title{
|Chapter 6
}

Kinetics of inducer/effector cell

\author{
generation in the thymus in \\ Cyclosporine A - induced
}

\author{
autoimmunity
}

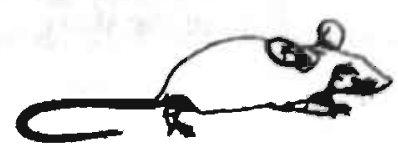




\section{Kinetics of inducer/effector cell generation in the thymus in Cyclosporine A - induced autoimmunity}

\section{Abstract}

Lethally irradiated Lewis (LEW) rats reconstituted with syngeneic bone marrow and given Cyclosporine A (CyA) for 6 weeks following BMT develop, 2 weeks after cessation of CyA administration, a thymus-dependent autoimmune disease (Cyclosporine A-induced autoimmune disease; $\mathrm{CyA}-\mathrm{AI}$ ) resembling graft-versushost disease (GVHD) after allogeneic BMT. The symptoms of disease include acute dermatitis and chronic scleroderma-like skin pathology. The role of the thymus in the etiology of CyA-AI has unequivocally been established. In the present study we investigated whether inducer/effector cells of CyA-AI are generated in the thymus and if so, at what time during CyA administration; whether these cells stay in the thymus.

Adoptive transfer of thymocytes obtained on different days after bone marrow transplantation from donors treated for induction of CyA-Al did not elicit CyAAI in irradiated secondary recipients. Furthermore, thymectomy or shamthymectomy of lethally irradiated, bone marrow reconstituted and CyA-treated rats after 12 (post-BMT) or more days of CyA therapy did elicit CyA-AI with development of skin pathology.

Therefore, this study demonstrates that CyA-AI inducer/effector cells are generated in the irradiated thymus within 12 days of CyA administration. These cells exit from the thymus within 12 days of $\mathrm{CyA}$ administration and reside elsewhere (i.e. in the skin). 


\section{Introduction}

Administration of Cyclosporine A (CyA) after syngeneic bone marrow transplantation (BMT) may induce autoimmune disease resembling the graft-versus-host disease (GVHD) secondary to allogeneic bone marrow transplantation (Glazier et al., 1983a). This syngeneic GVHD (sGVHD)(Glazier et al., 1983a), CyA-induced autoimmune disease (CyA-AI)(Sorokin et al., 1986), or BMT-associated immune disease (BMT-ID)(Bos et al., 1990) can be elicited reproducibly in young animals of certain rat (Fischer and Hess, 1990) or mouse (Cheney and Sprent, 1985; Bryson et al., 1989) strains and has also been observed in adult humans (Jones et al., 1989).

Several studies have demonstrated an essential role for the thymus in the induction of CyA-AI. Shielding of the thymus during total-body irradiation (TBI), as well as thymectomy prior to BMT, prevented the induction of CyA-AI (Glazier et al., 1983b; Sorokin et al., 1986) suggesting that the effector cells in CyA-Al are derived from the thymus. Rats thymectomized (Tx) 2, 4, and 6 weeks post-BMT developed CyA-AI disease, although somewhat delayed in terms of onset and time of death when compared to sham-Tx animals; suggesting a role for the thymus for several weeks after BMT (Sorokin et al., 1986). At 6 weeks post-BMT these data were essentially confirmed by one of our own studies; furthermore we demonstrated in this study that at that time point and 14 days after CyA withdrawal CyA-AI could not be transferred by thymocytes. However, lymph node and spleen cells obtained from donors treated for induction of $\mathrm{CyA}-\mathrm{Al}$ one and 14 days after cessation of CyA caused CyA-AI upon adoptive transfer to irradiated secondary recipients (Wodzig et al., 1991; chapter 5). These studies, however, provided no explanation concerning the role of the thymus within 2 weeks post-BMT; especially at which stage during this fortnight after irradiation and BMT autoreactive $T$ cells are generated in and released from the thymus under CyA administration. With respect to the kinetics of the thymic generation of autoreactive T cells in CyA-AI, it has been proposed that inducer and/or effector $\mathrm{T}$ lymphocytes are generated during CyA administration but remain inactive during CyA administration (Wilson, 1989). The disease becomes manifest only when CyA concentrations have declined to low levels. Manifestation of disease coincides with an increase of $\mathrm{CD}^{+}$cells in the peripheral blood, suggesting these cells to be involved in the pathogenesis as inducer or effector cells (Bos et al., 1988; Fischer et al., 1991). At this time the disease can be transferred adoptively by lymph node CD4+ $\mathrm{T}$ cells (Sorokin et al., 1986) and both $\mathrm{CD}^{+}$and $\mathrm{CD}^{+}$splenic $\mathrm{T}$ cells (Fischer $e t$ al., 1989; Hess et al., 1990).

Studies on the transfer of CyA-AI with thymocytes suggested that at least part of the inducer/effector cells might remain in the thymus (Beschorner et al., 1988a); after the decrease of the CyA concentrations in the hosts these autoreactive effector cells purportedly become active and destroy certain target cells (Majoor et al., 1991). At which point in time putative autoreactive cells leave the thymus for the periphery is not clear nor has it been established unequivocally whether CyA might not also mediate an effect by interfering peripherally with tolerance induction. 
The present study demonstrates that CyA-AI inducer/effector cells are generated within 12 days after BMT, most likely during the early phase of exponential thymocyte regeneration after irradiation. CyA-AI inducer/effector cells apparently leave the thymus (escape negative selection?) soon after their generation, and do not need the extrathymic presence of CyA in order to exert (auto-)reactive activity (Vanier and Prud'homme, 1992).

\section{Materials and methods}

\section{Animals}

Female, specific pathogen-free Lewis (LEW, RT $1^{1}$ ) rats were used as donors and recipients. Rats were obtained from our own breeding stock and were used at the age of 4-6 weeks.

\section{Protocol for induction of CyA-Al}

The experimental protocol has been described before (Bos et al., 1988). In brief, rats were given 8.5 Gy at $0.5 \mathrm{~Gy} / \mathrm{min}$ using a Röntgen irradiation machine (Philips MG320, Hamburg, Germany) one day prior to syngeneic BMT. Donor rats were killed by cervical dislocation under ether anesthesia. Bone marrow was collected from tibias and femurs of donor rats in Dulbecco's balanced salt solution supplemented with $2 \%$ heat-inactivated fetal calf serum (iFCS), penicillin $(100 \mathrm{U} / \mathrm{ml})$ and streptomycin $(100 \mu \mathrm{g} / \mathrm{ml})$ (DBSS). Recipients received $6 \times 10^{7}$ viable syngeneic bone marrow cells in $1.0 \mathrm{ml}$ DBSS intravenously into a tail vein. CyA, a gift from Sandoz Co. Ltd., Basel, Switzerland, was dissolved in olive oil at a concentration of $7.5 \mathrm{mg} / \mathrm{ml}$; rats received $7.5 \mathrm{mg} / \mathrm{kg} /$ day CyA subcutaneously for $4-42$ days starting on the day of BMT.

\section{Scoring of macroscopic pathology}

After withdrawal of CyA, development of CyA-AI was assessed by examination of the rats at least twice a week for signs and symptoms of disease: red acra (hyperemia of the skin of the ears, feet and tail), inflammation of the eyelids, dermatitis, alopecia and weight loss (Wodzig et al., 1991).

\section{Thymectomy}

Lewis rats treated according to the protocol for induction of CyA-AI were thymectomized (Tx) or sham-thymectomized (sham-Tx) on different days post-BMT when still treated with CyA. While under ketamine (Nimatek $50 \mathrm{mg} / \mathrm{kg}$, intramuscularly) and xylazine (Sedamun $6 \mathrm{mg} / \mathrm{kg}$, subcutaneously) anesthesia, rats were intubated and maintained on artificial respiration. The thorax was opened and all prepericardial soft tissue consistent with thymus was removed; the thorax and skin were closed using 4-0 suture. Rats under- 
going sham- $\mathrm{Tx}$ were anesthetized, intubated, and an anterior mediastinectomy was performed. CyA administration was either stopped on the day of Tx or sham-Tx or continued up to day 42 days post-BMT.

\section{Adoptive cell transfers}

Thymocytes were obtained from thymectomy specimen. Single cell suspensions were made by passing thymic organ fragments through a $100 \mu \mathrm{m}$ mesh width nylon gauze screen. Cells were collected in DBSS, washed, and their viability assessed by trypan blue exclusion. Hundred million viable thymocytes were administered either intravenously into a tail vein or intrathymically to 8.5 Gy irradiated and bone marrow-reconstituted secondary recipients. For intrathymic injection, rats were manipulated as for sham- Tx. The thorax was opened and fifty $\mu \mathrm{l}$ thymocyte suspension (concentration $10^{9}$ thymocytes/ml) in DBSS was injected in each thymic lobe. To check for leakage from the thymic lobe $0.02 \%$ methylene blue was added to the thymocyte suspension.

\section{Statistics}

Differences with respect to incidence and severity of symptoms of CyA-AI were tested for statistical significance by Fischer's exact probability test.

\section{Results}

\section{Recovery of thymocytes from CyA-Al rats}

To investigate the appearance of autoreactive effector cells in the thymus during CyA administration, thymocytes obtained from irradiated and CyA-treated rats were transferred to irradiated and bone marrow-reconstituted secondary recipients. Thymocytes were obtained on day $4,8,12,14,16,21,28$, and 35 after BMT from 5 donors per day. The mean yield of thymocytes from donor rats increased considerably between day 4 and day 8 after irradiation. On day $4,2.5 \times 10^{6}$ thymocytes per rat were recovered, and on day $8,3 \times 10^{8}$ thymocytes. Thereafter, mean thymocyte yields increased more slowly (day 12 : $5 \times 10^{8}$; day $28: 12.5 \times 10^{8}$ ) (Fig.6.1).

\section{Fallure to transfer CyA-Al with thymocytes}

Thymocytes from donors taken on any day were pooled and transferred intravenously or intrathymically to 5 secondary recipients. At no day tested, however, adoptive transfer of $10^{8}$ thymocytes, irrespective whether transferred intravenously or intrathymically to secondary recipients, elicited macroscopic symptoms of CyA-AI within 100 days. 


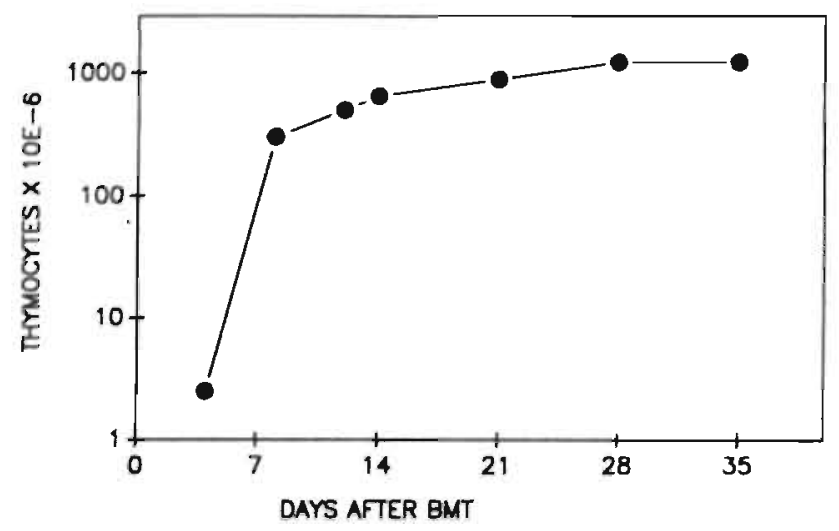

Flgure 6.1: Recovery of thymocytes from CyA - Al rats. Rats were treated for induction of CyA-Al and recelved CyA for 35 days. Each polnt represents the mean recovery from five rats.

\section{Effect of thymectomy and sham-thymectomy on development of CyA-A}

Irradiated and reconstituted rats were given $\mathrm{Cy} A$ and underwent $\mathrm{Tx}$ or sham-Tx on day $-1,4,8,12,14,16,21,28,35$, or 42 post-BMT. On each given day groups of 10 rats were Tx; CyA was continued up to day 42 post-BMT in 5 rats and discontinued on the day of $T x$ in the remaining 5 rats. The latter protocol was also applied when sham-Tx rats were available. Rats thymectomized on day $-1,4$, or 8 after BMT did not develop symptoms of CyA-AI for over 100 days, irrespective whether CyA was discontinued on the day of Tx or whether CyA was administered for 42 days (Table 6.1). Some rats thymectomized on day 12,14 , or 16 after BMT developed CyA-AI whereas other rats in these cohorts remained free of symptoms. In contrast, CyA-AI developed in almost all rats that underwent $T x$ or sham-Tx on days $21-42$ post-BMT, irrespective of the duration of CyA treatment. These data show that from day 12 after BMT Tx no longer interferes with the development of CyA-AI. Neither did abrogation of CyA administration on the day of Tx or continuation up to 42 days after BMT influences the development of CyA-AI.

\section{Dlscussion}

Our data document the generation of CyA-AI inducer/effector cells in LEW rats as early as within 12 days after irradiation and syngeneic bone marrow transplantation. Since at no time point tested after BMT CyA-AI could be adoptively transferred using $10^{8}$ thymocytes, the relative number of autoreactive $T$ inducer/effector cells residing in the thymus must be quite low. This finding may be explained by assuming that autoreactive $T$ cells exit from the thymus soon after their generation. It may be questioned, however, 
rable 6.1: Effect of thymectomy $(T x)$ on induction of CYA - $A^{m}$.

\begin{tabular}{|c|c|c|c|c|c|}
\hline Treatment & $\begin{array}{l}\text { Surgery derformed } \\
\text { on der post-BMT }\end{array}$ & N & $\begin{array}{l}\text { Course of CvA. } \\
\text { after BMT (davs) }\end{array}$ & $\begin{array}{l}\text { Incidence } \\
\text { CVA-A }\left.\right|^{\mathrm{B}}\end{array}$ & and symotoms of \\
\hline$T$. & 1 & 5 & 42 & 0.5 & \\
\hline Sham-7x & & 5 & 42 & $5 / 5$ & $D$ (S). A isi \\
\hline None & & 5 & 42 & $5 / 5$ & D (5), A (5) \\
\hline$T x$ & 4 & 5 & 42 & $0 / 5$ & \\
\hline$T_{x}$ & & 5 & 4 & $0 / 5$ & \\
\hline Tat & 8 & 5 & 42 & $0 / 5$ & \\
\hline $\mathrm{Tx}$ & & 5 & s: & $0 / 5$ & \\
\hline$T x$ & 12 & 5 & 42 & $2 / 5$ & E (2). D (2) \\
\hline$T_{x}$. & & 5 & 12 & $2 / 5$ & E (2), D (2) \\
\hline Sham- $T_{x}$ & & 5 & 12 & $3 / 5$ & $T(3)$ \\
\hline$T_{x}$ & $14.16 \mathrm{C}$ & 9 & 42 & 79 & $017, A 17)$ \\
\hline$T \times$ & & 9 & $14 \cdot 16$ & $6 / 9$ & E (11), D (5), A (5) \\
\hline Sham- Tx & & 9 & $14-16$ & $3 / 9$ & E $(2), 0(1), A, 11)$ \\
\hline $\mathrm{Tx}$ & $21-42^{d}$ & 17 & 42 & $17 / 17$ & D $1177, A 117)$ \\
\hline$T *$ & & 19 & 21.42 & $17 / 19$ & $0117, A 117)$ \\
\hline
\end{tabular}

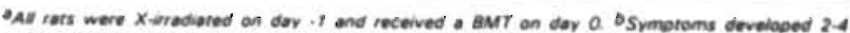

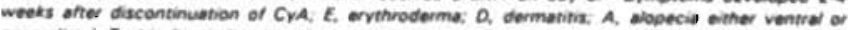
generalized: $T$, thin fur lindicative of very mild diseasel. CAooled data of dor 14 and 16 after $a M T$. dApoled dats of day 21, 28, 35, and 42 after BMT.

whether transfer of $10^{8}$ thymocytes would be enough to transfer CyA-AI. In another study (to be discussed below) following a different protocol, transfer of $10^{8}$ thymocytes sufficed to elicit CyA-AI in secondary recipients (Beschorner et al., 1988a). Furthermore, several studies have shown as few as $1-5 \times 10^{6}$ spleen-and lymph node cells to be adequate for transfer of disease from animals with CyA-AI to irradiated, and reconstituted secondary recipients (Sorokin et al., 1986; Fischer et al., 1991). Finally, usually about $10^{9}$ thymocytes are harvested from the thymus of young $\mathrm{LEW}$ rats that recovered from irradiation and BMT. Therefore, $10^{8}$ cells represent about $10 \%$ of all cells, making successful transfer of disease by larger amounts of thymocytes rather unlikely. Intrathymic introduction of thymocytes was attempted as an alternative route to see whether putative inducer/effector cells would need intrathymic processing in a CyA-free environment to become effective. However, the failure to transfer CyA-AI with thymocytes irrespective of the route of administration precludes any conclusion in this respect.

Apparently, autoreactive $\mathrm{T}$ cells are generated as unwanted by-products of the massive expansion of the number of thymocytes in the first 12 days of recovery after irradiation and reconstitution (a 200 -fold increase between day 4 and 12 post-BMT or about $5 \times 10^{8}$ cells). Since especially early after BMT, and under CyA administration, intrathymic MHC class II expression is strongly suppressed, thymic negative selection mechanisms regularly preventing the release of harmful autoreactive $T$ cells may not be operative (Boehmer von, 1986; Beschorner et al., 1987, 1988b; Kisielow et al., 1988). Although disease occurred after a regimen of CyA administration as short as 12-14 days after BMT, it manifested itself more frequently and more severely after prolongation of CyA administration for another week. The relative increase in thymocyte number in that period is only 2 -fold, but the absolute accretion of about $5 \times 10^{8}$ thymocytes in that week may still contribute to the generation of autoreactive cells. Extending the period of CyA admin- 
istration (even up to 12 weeks after BMT), however, has no clear effect on the incidence or severity of CyA-AI (Bos et al., 1988). Recovery of thymic negative selection mechanisms or generation of counteractive cellular circuits from about 3 weeks post-BMT onwards are possible explanations for this observation.

Our results may appear to be in contrast to those reported by Beschorner et al. (1988a). Their study established the possibility to transfer CyA-AI to secondary recipients using either $8 \times 10^{7}$ or $1.8 \times 10^{8}$ thymocytes. In their study, however, thymocytes were harvested 30 days after discontinuation of $\mathrm{CyA}$. At that time, dormant autoreactive cells have usually started to attack target structures. Possibly, migrating effector cells re-enter the thymus to destroy target cells, i.e. expressing MHC class II antigens (Hess et al., 1985). Therefore, we explain the discrepancy with our present study by the presence of effector cells re-migrated to the thymus some weeks after discontinuation of CyA (Majoor et al., 1991).

Another issue addressed in this study is whether the generation of CyA-AI effector cells is completed in the thymus, or whether extra-thymic effects of CyA contribute to effector cell generation. Rats thymectomized at days $12,14-16$ or 21-42 after BMT and given CyA for $\mathbf{4 2}$ days showed no statistically significant differences with respect to incidence and severity of symptoms of CyA-AI as compared to rats in which CyA was discontinued on the day of $\mathrm{Tx}$. These results do not support a role for additional extrathymic processing of autoreactive $\mathrm{T}$ cells under CyA administration.

\section{Acknowledgements}

The excellent technical assistance of Marie-José van de Gaar is gratefully acknowledged. This study was supported by the dutch league against Rheumatic Diseases. 


\section{References}

Beschomer WE, Di Gennaro KA, Hess AD, Santos GW (1987). Cyclosporine and the thymus: Influence of irradiation and age on thymic immunopathology and recovery. Cell Immunol 110: $350-364$

Beschorner WE, Hess AD, Shinn CA, Santos GW (1988a). Transfer of Cyclosporine-associated syngeneic graft-versus-host disease by thymocytes. Resemblance to chronic graft. versus-host disease. Transplantation 45: 209-215

Beschorner WE, Olson JL, Hess AD, DI Gennaro KA, Santos GW (1988b). Cyclosporine-induced cell-mediated injury of the thymic medullary epithelium. Transplantation 45: 797. 803

Boehmer H Von (1986). The selection of the , B heterodimeric T-cell receptor for antigen. Immunology Today 7: 333-336

Bos GMJ, Majoor GD, Van Breda Vriesman PJC (1988). Cyclosporin A induces a selective, reversible suppression of T-helper lymphocyte regeneration after syngeneic bone marrow transplantation: association with syngeneic graft-versus-host disease in rats. Clin Exp Immunol 74: 443-448

Bos GMJ, Majoor GD, van Breda Vriesman PJC (1990). Graft-versus-host disease: the need for a new terminology. Immunol Today 11: 433-436

Bryson JS, Jennings CD, Caywood BE, Kaplan AM (1989). Induction of a syngeneic graft-versus-host disease-like syndrome in DBA/2 mice. Transplantation 48: 1042-1047

Cheney RT and Sprent J (1985). Capacity of Cyclosporine to induce auto-graft-versus-host disease and impair intrathymic T cell differentiation. Transplant Proc 17: 528-530

Fischer AC, Laulis MK, Horwitz L, Beschorner WE, Hess A (1989). Host resistance to Cyclosporine induced syngeneic graft-versus-host disease. Requirement for two distinct lymphocyte subsets. J Immunol 143: 827-832

Fischer AC and Hess AD (1990). Age-related factors in Cyclosporin-induced syngeneic graftversus-host disease: regulatory role of marrow-derived T lymphocytes. J Exp Med 172: 85 94

Fischer AC, Laulis MK, Horwitz L, Hess AD (1991). Effect of Cyclosporine on T lymphocyte development. Relationship to syngeneic graft-versus-host disease. Transplantation 51: 252-259

Glayer A, Tutschka PJ, Farmer ER, Santos GW (1983a). Graft-versus-host disease in Cyclosporin A-treated rats after syngeneic and autologous bone marrow transplantation. J Exp Med 158: $1-8$

Glazier A, Tutschka PJ, Farmer ER (1983b). Studies on the immunobiology of syngeneic and autologous graft-versus-host disease in Cyclosporine-treated rats. Transplant Proc 15: 3035-3041

Hess AD, Horwitz L, Beschomer WE, Santos GW (1985). Development of graft-versus-host disease-like syndrome in Cyclosporine-treated rats after syngeneic bone marrow transplantation. I. Development of cytotoxic T lymphocytes with apparent polyclonal anti-Ia specificity, including auto reactivity. J Exp Med 161: 718-730 
Hess AD, Fischer AC, Beschorner WE (1990). Effector mechanisms in Cyclosporine A-induced syngeneic graft-versus-host disease. Role of $\mathrm{CD}^{+}$and $\mathrm{CD}^{+}{ }^{+} \mathrm{T}$ lymphocyte subsets. $\mathrm{J}$ Immunol 145: 526-533

Jones RJ, Hess AD, Mann RB, Piantadosi S, Vogelsang GB, Farmer ER, Geller RB, Santos GW (1989). Induction of graft-versus-host disease after autologous bone marrow tranplantation. Lancet $1:$ 754-757

Klsielow P, Bluthmann H, Staerz UD, Steinmetz M, Boehmer von H (1988). Tolerance in Tcell-receptor transgenic mice involves deletion of nonmature $\mathrm{CD} 4^{+} 8^{+}$thymocytes. Nature 333: 742-746

Majoor GD, Wodzdg KWH, van Breda Vriesman PJC (1991). Cyclosporin-induced autoimmunity. Kendall MD, Ritter MA (eds), In: Thymus Update 4, 1991: 179-200

Soroldn R, KImura H, Schroder K, Wilson DH, WIlson DB (1986). Cyclosporin-induced autoimmunity. Conditions for expressing disease. Requirement for intact thymus, and potency estimates of autoimmune lymphocytes in drug-treated rats. J Exp Med.164: 16151625

Vanler LE and Prud'homme GJ (1992). Cyclosporin A markedly enhances superantigen-induced peripheral $T$ cell deletion and inhibits anergy induction. J Exp Med 176: 37

Wilson DB (1989). Idiotypic regulation of T cells in graft-versus-host disease and autoimmunity. Immunol Rev 107: 159-177

Wodadg KWH, Majoor GD, Van Breda Vriesman PJC (1991). On the localization of effector cells in Cyclosporin A-induced autoimmunity. Autoimmunity 10: 275-283 


\section{Summary and general discussion}

Cyclosporine $\mathrm{A}(\mathrm{Cy} \mathrm{A})$ is a potent immunosuppressive drug that is widely used clinically in the management of both alloimmune and autoimmune disorders. CyA, however, exerts a paradoxical effect on the immune system; it may also disturb the establishment of self-tolerance and induce autoimmune disease in animals.

In chapter 1, one form of CyA-induced autoimmunity which affects the thyroid, pancreas, gonads, adrenal gland, stomach, and salivary glands is described. In this model neonatal mice are given a 7-days course of CyA (Sakaguchi and Sakaguchi, 1989). Another form of autoimmunity may arise in lethally X-irradiated rats and mice of certain strains that are reconstituted with syngeneic bone marrow and treated daily with CyA for several weeks. After CyA is withdrawn, the vast majority of these rats develop a T cell-dependent autoimmune syndrome with pathology resembling in the acute phase that of graftversus-host disease (GVHD) as seen after allogeneic bone marrow transplantation (BMT). In the chronic phase scleroderma-like lesions may develop. This syndrome has been referred to as Cyclosporine A-induced autoimmunity (CyA-AI)(Sorokin et al., 1986) or syngeneic GVHD (Gilazier et al., 1983). A similar disease occurs in humans following withdrawal of CyA treatment in recipients of autologous or syngeneic bone marrow (Jones et al., 1989; Hess et al., 1992). It should be stressed that syngeneic GVHD has also been reported to occur incidentally in the absence of CyA therapy in both humans (Hood et al., 1987) and experimental animals (Van Bekkum et al., 1990). However, the occurrence of SGVHD is unpredictable in subjects that have not received CyA, and the disease may be mild and transient. Therefore, CyA treatment after lethal irradiation and bone marrow reconstitution provides a reproducible method of inducing a severe form of sGVHD.

Based on the fact that LEW rats are susceptible for several cell-mediated autoimmune diseases to which $B N$ rats are resistant, and since $L E W$ and $(\mathrm{LEWXBN}) \mathrm{F} 1$ rats are susceptible for induction of CyA-AI, the aim of the study, as outlined in chapter 2 , was to document whether susceptibility or resistance to CyA-AI is genetically a dominant trait. Susceptibility and resistance was established by macroscopic scoring of signs of disease like dermatitis, alopecia, weight loss, and histological examination of the skin. The resistance of the BN strain to the induction of CyA-AI versus the susceptibility of the LEW strain is demonstrated. Cell-mediated immune mechanisms were in part affected by $\mathrm{CyA}$ administration after $\mathrm{X}$-irradiation and syngeneic bone marrow reconstitution. Delayed-type hypersensitivity (DTH) reactions were transiently strongly suppressed in the acute phase of CyA-AI in LEW rats but not so in CyA-AI resistant BN rats. On the other hand, immunohistochemical examination of the skin, with respect to cells involved in DTH reactions, and thymus of experimental animals revealed no differences between susceptible and resistant strains. Natural killer (NK) cell activity was also unaffected in both 
strains. These findings are in agreement with the results from studies on the development of experimental allergic encephalomyelitis (EAE) in LEW rats treated with myelin basic protein (MBP), to which the BN strain is resistant (Mason, 1991). In contrast, BN rats are susceptible to some antibody-mediated autoimmune diseases (e.g. mercury chlorideinduced glomerulonephritis) to which LEW rats are resistant. It has been shown recently that in the rat the $\mathrm{CD}^{+} \mathrm{T}$ cells can be divided into two subpopulations based on the expression of cell surface markers CD45RC (as recognized by monoclonal antibody OX-22) and RT6. The CD45RC ${ }^{+} R T 6$ subset of rat $C D 4^{+} T$ cells has a $T$ helper $1\left(T_{H} 1\right)$-like lymphokine repertoire (high $\mathrm{IL}-2$ and IFN $\gamma$, but low $\mathbb{L}-4$ production) and provides cellmediated immune responses, whereas the CD45RC $\mathrm{RT}^{+}{ }^{+}$population has characteristics of $T$ helper $2\left(T_{H} 2\right)$-type cells ( $I L-4$ but low $\mathrm{LL}-2$ and IFN $\gamma$ production, provision of $B$ cell help, and suppression of cell-mediated responses)(Fowell et al., 1991; Fowell and Mason, 1993). In this context, it is interesting to note that normal BN rats (known to respond in a $T_{H}$ 2-like fashion) have a preponderance of the $T_{H}$ 2-like subset over $T_{H} l$, whereas for LEW rats (known to respond in a $\mathrm{T}_{H} 1$-like fashion) the opposite is the case (Groen et al., 1993). The repertoire of cytokines produced can promote the development of either $T_{H} 1$ or $T_{H}$ 2-type responses. Most significantly, $\mathbb{L}-4$, a product of $T_{H}$ 2-type $T$ cells, inhibits the induction of $T_{H} 1$-type responses, suggesting that a potent $T_{H} 2$ reaction, as present in $B N$ rats, is likely to decrease cell-mediated immunity (Fowell and Mason, 1993).

LEW rats subjected to the protocol for induction of CyA-AI initially showed symptoms akin to those seen in acute GVHD and in the chronic phase scleroderma-like lesions. Chapter 3 describes an experiment in which $77 \%$ of the experimental animals developed rapidly progressive subcutaneous and/or intracutaneous malignancies, notably sarcomas. These soft-tissue tumors developed late in the history of CyA-AI and appeared to be specifically associated with CyA-AI. No malignancies were observed in X-irradiated and syngeneic bone marrow-reconstituted or in CyA-treated control animals. How the tumors were generated is obscure, but we offer the following explanation. Our hypothesis is based on the observations that thymic inflammatory skin disease was present in virtually all animals with tumors, and that the tumors could be transplanted as explants or as a cell suspension to normal LEW rats. Furthermore, with respect to the collagen deposition chronic CyA-AI shows strong similarity to human (progressive) systemic sclerosis (SS) or scleroderma (Bos et al., 1989) and several observations support a relationship between the development of cancer and the presence of SS (Medsger, 1985). Therefore, our hypothesis holds that these tumors were caused by a combination of $\mathrm{X}$-irradiation and a chronic - cutaneous - inflammatory reaction and in this fashion are indirectly thymus-dependent.

Based on the similarities between SS and chronic GVHD, scleroderma or SS is believed to have an (auto)immune origin. Frequently, in patients with immune-mediated connective tissue diseases, and especially in SS, circulating autoantibodies against nuclear and/ or cytoplasmic constituents were detected (Krieg and Meurer, 1988). Autoantibodies to DNA-topoisomerase I (Scl-86, Scl-70) and to centromere/kinetochore (CR19, CENP A-, B-, and C-antigens) were of prognostic and diagnostic importance for diffuse SS or limited sclerodertna (Weiner et al., 1988; Krieg and Meurer, 1988). Chapter 4 shows that 
autoantibodies to extractable nuclear and cytoplasmic fractions are elicited in rats with CyA-AI. Furthermore, it was demonstrated that these autoantibodies are not required for, nor pathologically related to the development of scleroderma-like lesions. Finally, the specificity of some of the autoantibodies detected in LEW rats. with CyA-Al disease also occurred in $\mathrm{BN}$ rats with mercury chloride-induced autoimmune nephritis, suggesting that analogous autoimmune mechanisms are involved.

Chapter 5 and 6 deal with the localization of effector cells and the kinetics of inducer/ effector cell generation in the thymus in CyA-AI respectively. Several studies have demonstrated the pivotal role of the thymus in the etiology of CyA-Al. Shielding of the thymus during total body irradiation (Glazier et al., 1983) or thymectomy prior to BMT prevented the induction of CyA-AI (Sorokin et al., 1986). The onset of CyA-AI is associated with the reappearance of $\mathrm{CD}^{+} \mathrm{T}$ cells in the peripheral blood about two weeks after cessation of CyA administration (Bos et al., 1988; Fischer et al., 1991) and the development of $\mathrm{CD}^{*}$ cytotoxic $\mathrm{T}$ cells recognizing a public determinant of $\mathrm{MHC}$ class II antigen, preferentially the I-A subregion ( RTI B) of the MHC class II antigen complex (Hess et al., 1985, 1993). In chapter 5 the question is addressed whether inducer/ effector cells of CyA-Al are generated in the thymus during or after CyA administration; whether these cells stay in the thymus and, if they don't, whether they home to the secondary lymphoid organs. Adoptive transfer of thymocytes from donor rats treated for induction of CyA-AI obtained one and 14 days after cessation of CyA administration did not elicit CyA-Al in secondary recipients. In contrast, studies by Beschorner et al., (1988) on the transfer of CYA-AI with thymocytes harvested 30 days after discontinuation of CyA suggested that at least part of the inducer/effector cells might remain in the thymus. At that time, how-ever, autoreactive cells have usually already started to attack target structures. Probably, migrating effector cells re-enter the thymus to destroy target cells, i.e. expressing MHC class II antigens. Therefore, we explain the discrepancy between the study of Beschorner et al., (1988) and our study by effector cells re-migrated to the thymus some weeks after discontinuation of CyA. Furthermore, adult thymectomy of rats immediately after the course of CyA did not influence the kinetics of development of skin pathology, although weight loss commenced later in thymectomized than in sham. thymectomized rats.

Lymph node and spleen cells obtained from donors treated for induction of CyA-AI one and 14 days after withdrawal of $\mathrm{CyA}$ caused $\mathrm{CyA}$-AI upon adoptive transfer to secondary recipients, but the symptoms of acute disease were strikingly less severe upon transfer of lymphoid cells obtained one day after stopping CyA than 14 days thereafter. Therefore, chapter 5 demonstrates that CyA-AI inducer/effector cells are generated in the thymus during the administration of CyA. These cells exit from the thymus during $\mathrm{CyA}$ administration; either they home predominantly peripherally (i.e. into the skiri) rather than in the secondary lymphoid organs, or they leave the thymus as inducer cells which home in the lymphoid organs where they subsequently may trigger potentially autoreactive lymphocytes as probably also present in normal individuals, or both pathways may be operative. Furthermore, there is considerable debate concerning the potency of Tlymphocyte subsets from CyA-AI rats in transferring disease to secondary recipients. 
Hess et al, (1990) demonstrated the requirement for both splenic CD4 ${ }^{+}$and CD8 ${ }^{+} \mathrm{T}$ lymphocytes (both $7.5 \times 10^{6}$ ) to transfer CyA-Al effectively. Transfer of large numbers $\left(>3 \times 10^{7}\right)$ of $\mathrm{CD}^{+}$cells from animals with acute CyA-AI resulted in the induction of CyA-AI in the secondary recipients. However, lower numbers of CD8 $8^{+}$cells could only transfer CyA-AI if accompanied by small numbers of $\mathrm{CD4}^{+}$cells from donors with $\mathrm{CyA}$ AI. The $\mathrm{CD}^{+}$subset cells harvested during acute $\mathrm{CyA}-\mathrm{AI}$ were ineffective by themselves. On the other hand, Sorokin et al. (1986) were able to transfer disease with as few as $3 \mathrm{x}$ $10^{5} \mathrm{CD}^{+}$lymph node cells from animals with acute CyA-AI; $\mathrm{B}$ cells and $\mathrm{CD} 8^{+}$cells were far less effective. It is of great importance to investigate in our setting whether the subset(s) of $\mathrm{T}$ lymphocytes causing $\mathrm{CyA}-\mathrm{AI}$ are $\mathrm{CD} 4^{+}$and/or $\mathrm{CD} 8^{+} \mathrm{T}$ lymphocytes, and whether the same cells mediate the changes of chronic scleroderma observed in our model but not by others who have reported acute dermatitis only (Glazier et al., 1983). In the rat, division of the $\mathrm{T}$ helper compartment into two functionally distinct subsets (see above) showed that the $\mathrm{CD} 4{ }^{+} \mathrm{CD} 45 \mathrm{RC}^{+}$helper subset was associated with lethal CyA-AI (and responsible for the production of IL-2), whereas the CD4 ${ }^{+} \mathrm{CD} 45 \mathrm{RC}^{-}$helper subset appeared to be critical for effective autoregulation (Fischer et al.,1989; Hess et al., 1990).

Chapter 6 describes that adoptive transfer of thymocytes obtained on different days after BMT from donors treated for induction of CyA-AI did not elicit CyA-AI in irradiated secondary recipients. Furthermore, thymectomy of lethally irradiated, bone marrowreconstituted and CyA-treated rats after 12 or more days of CyA therapy post-BMT still permitted development of $\mathrm{CyA}$-AI with skin pathology. Therefore, chapter 6 demonstrates that $\mathrm{CyA}-\mathrm{AI}$ inducer/effector cells are generated in the irradiated thymus within 12 days of CyA administration, most likely during the early phase of exponential thymocyte regeneration after $\mathrm{X}$-irradiation. These cells exit from the thymus (escape negative selection?) within these 12 days and migrate elsewhere (i.e. to the skin). These cells do not require the extrathymic presence of CyA in order to exert their (auto-)reactive activity. As demonstrated in this chapter, autoreactive cells leave the thymus during the course of CyA, but their targets for homing remain to be determined. 


\section{References}

Bekkm DW van (1990). Comments on syngeneic GVHD. Immunology Today 11: 107

Beschomer WE, Hess AD, Shinn CA, Santos CW (1988). Transfer of cyclosporine-associated syngeneic graf-versus-host disease by thymocytes. Resemblance to chronic graft-versushost disease. Transplantation 45: 209-215

Bas GMJ, Majoor GD, Breda Vriesmen PJC van (1988). Cyclosporin A induces a selective, reversible suppression of $\mathbf{T}$-helper lymphocyte regeneration after symgeneic bone marrow transplantation: association with syngeneic graft-versus-host disease in rats. Clin Exp Immunol 74: $443-448$

Bos GMJ, Majoor GD, Willghagen RGJ, Bredn Vriesman PJC van (1989). Chronic cyclosporine-induced autoimmune disease in the rat a new experimental model for scleroderma. I lnvest Dermatol 93:610-615

Fischer AC, Laulis MK, Horwitz L, Beschorner WE, Hess AD (1989). Host resistance to cyclosporine induced syngeneic graft-versus-host disease. Requirement for two distinct lymphocyte subsets. J Immunol 143: 827-832

Fischer AC, Laulis MK, Horwitz L, Hess AD (1991). Effect of cyclosporine on T lymphocyte development. Relationship to syngeneic graft-versus-host disease. Transplantation 51 : 252-259

Fowell D, McKnight AJ, Powrie F, Dyke R, Masco D (1991). Subsets of CD4 ${ }^{+} \mathrm{T}$ cells and their roles in the induction and prevention of autoimmunity. Immunol Rev 123: 37-64

Fowell D and Mason D (1993). Evidence that the T cell repertoire of normal rats contains cells with the potential to cause diabetes. Characterization of the $\mathrm{CD}^{+} \mathrm{T}$ cell subset that inhibits this autoimmune potential. J Exp Med 177: 627-636

Glojier A, Tutschka PJ, Farmer ER, Santos GW (1983). Graft-versus host disease in cyclosporin A-treated rats after syngeneic and autologous bone marrow reconstitution. J Exp Med 158: 1-8

Groen H, Klatter FA, Van Petersen AS, Pater JM, Nieuwenhuis P, Kampinga J (1993). Composition of rat $\mathrm{CD}^{+}$resting memory $\mathrm{T}$ cell pool is influenced by MHC. Transplant Proc 1993: in press

Hess AD, Horwitz L, Beschorner WE, Santos GW (1985). Development of graft-versus-host disease-like syndrome in cyclosporine-treated rats after syngeneic bone marrow transplantation. 1. Development of cytotoxic $T$ lymphocytes with apparent polyclonal anti-la specificity, including autoreactivity. J Exp Med 161: 718-730

Hess AD, Fischer AC, Beschorner WE (1990). Effector mechanisms in Cyclosporine A-induced graft-versus-host disease. Role of $\mathrm{CD}^{+}$and $\mathrm{CD}^{+} \mathrm{T}$ lymphocyte subsets. J Immunol 145 : 526-533

Hess AD, Jones RJ, Morris LE, Noga SJ, Vogelsang GB, Santos GW (1992). Autologous graft-versus-host disease: A novel approach for antitumor immunotherapy. Human Immunol 34: 219-224 
Hess AD, Horwitz LR, Laulls MK (1993). Cyclosporine-induced syngeneic graft-versus-host disease: Recognition of self MHC class II antigens in vivo. Transplant proc. 25: 1218

Hood AF, Vogelsang GB, Black LP, Farmer ER, Santos GW (1987). Acute graft-vs-host disease. Development following autologous and syngeneic bone marrow transplantation. Arch Dermatol 123: 745-750

Jones RJ, Hess AD, Mann RB, Plantadosi S, Vogelsang GB, Farmer ER, Geller RB, Santos GW (1989). Induction of graft-versus-host-disease after autologous bone marrow transplantation. Lancet 1: 754-757

Krieg T and Meurer M (1988). Systemic scleroderma. Clinical and pathophysiologic aspects. J Am Acad Dermatol 18: 457-481

Mason DW (1991). Genetic variation in the stress response: susceptibility to experimental allergic encepahlomyclitis and implications for human inflammatory disease. Immunology Today 12: 57-60

Medsger Jr. TA (1985). Systemic sclerosis and malignancy - Are they related?. J Rheumatol 12: 1041-1043

Sakaguchl S and SakaguchI N (1989). Organ-specific autoimmune disease induced in mice by elimination of $T$ cell subsets. V. Neonatal administration of cyclosporin A causes autoimmune disease. J Immunol 142: $471-480$

Sakaguchi S, Sakaguchi N (1992). Causes and mechanisms of autoimmune disease: Cyclosporin $A$ as a probe for the investigation. J Invest Dermatol 98: 70S-76S

Sorokln R, KImura H, Schroder K, WILson DH, Wilson DB (1986). Cyclosporine-induced autoimmunity. Conditions for expressing disease, requirement for intact thymus, and potency estimates of autoimmune lymphocytes in drug-treated rats. J Exp Med 164: 1615-1625

Weiner ES, Earnshaw WC, Senecal J-L, Bordwell B, Johnson P, Rothfleld NF (1988). Clinical associations of anticentromere antibodies and antibodies to topoisomerase I. Arthritis Rheurn 31: 378-385 


\title{
Samenvatting en algemene discussie
}

\begin{abstract}
Cyclosporine A (CyA) is een immunosuppressieve stof, die klinisch veel gebruikt wordt voor zowel het onderdrukken van transplantaat-afstoting als voor de behandeling van autoimmuunziekten. Het effect van CyA op het immuunsysteem is echter tegenstrijdig; het kan namelijk de tolerantie voor lichaams-eigen antigenen verstoren, hetgeen in dieren leidt tot de inductie van autoimmuunziekten.
\end{abstract}

In hoofdstuk 1 wordt een orgaan-specifieke vorm van CyA-geïnduceerde autoimmuniteit beschreven, waarbij de schildklier, alvleesklier, geslachtsorganen, bijnier, maag en speekselklieren worden aangedaan. In dit model wordt CyA gedurende 7 dagen aan pasgeboren muizen toegediend (Sakaguchi and Sakaguchi, 1989, 1992).

Een andere vorm van autoimmuniteit kan worden opgewekt na letale Röntgen bestraling van bepaalde ratte- en muizestammen, die worden gereconstitueerd met syngeen beenmerg en dagelijks gedurende enkele weken met CyA worden behandeld. Het merendeel van de ratten ontwikkelt een T-cel afhankelijk autoimmuun syndroom, nadat men de CyA-medicatie stopt, dat pathologisch gezien gelijkenis vertoont met de acute fase van een graft-versus-host ziekte (GVHD) na allogene beenmerg-transplantatie (BMT). In de chronische fase van de ziekte kunnen zich scleroderma-achtige afwijkingen ontwikkelen. Dit syndroom noemt men Cyclosporine A-geïnduceerde autoimmuniteit (CyA-AI) (Sorokin et al., 1986) oftewel syngene GVHD (sGVHD)(Glazier et al., 1983). In patiënten, die autoloog of syngeen beenmerg ontvingen, kan zich na het stoppen van de CyAtherapie een soortgelijke ziekte ontwikkelen (Jones et al., 1989; Hess et al., 1992). Het voorkomen van een syngene GVHD zonder CyA-therapie is zowel in de mens (Hood et al., 1987) als in proefdieren (Van Bekkum et al., 1990) zeer incidenteel en onvoorspelbaar, en de ziekte is mild en van voorbijgaande aard. Het toedienen van CyA aan immuun-gecompromitteerde individuen is dan ook een goede reproduceerbare methode orn een ernstige vorm van syngene GVHD oftewel CyA-AI te induceren.

Het blijkt dat LEW ratten gevoelig zijn voor inductie van verscheidene cel-gemediëerde autoimmuunziekten waarvoor BN ratten resistent zijn. Aangezien LEW en (LEWxBN)F1 ratten gevoelig zijn voor inductie van CyA-AI, is het doel van hoofdstuk 2, te onderzoeken of induceerbaarheid of resistentie voor CyA-AI een genetisch dominante eigenschap is. Gevoeligheid en resistentie werden bepaald aan de hand van macroscopische score van ziekteverschijnselen zoals dermatitis, alopecia, gewichtsverlies en histologisch onderzoek van de huid. In dit hoofdstuk wordt de resistentie van de BN stam voor inductie van CyA-AI versus de gevoeligheid van de LEW stam aangetoond. Cel-gemediēerde immuunmechanismen worden ten dele door CyA-medicatie, na Röntgen bestraling en reconstitutie met syngeen beenmerg, aangetast. Vertraagd-type-overgevoeligheid (DTH) reakties worden in LEW ratten tijdelijk sterk onderdrukt in de akute fase van CyA-AI maar niet in CyA-AI resistente BN ratten. In de thymus oftwel zwezerik van experi- 
mentele dieren vindt men immunohistochemisch geen verschil tussen gevoelige en resistente stammen tijdens en vroeg na de CyA-therapie. Tevens blijkt dat de huid van beide stammen voor wat betreft de cellen, noodzakelijk voor het ontstaan van dan wel betrokken zijn bij de DTH reaktie, geen verschillen vertoont. De NK-cel aktiviteit is in beide stammen onaangetast. Bovenstaande bevindingen zijn in overeenstemming met de resultaten verkregen uit andere studies. LEW ratten, die behandeld worden met het eiwit myeline ontwikkelen experimentele allergische encephalomyelitis (EAE). BN ratten zijn resistent voor de inductie van deze T-cel gemediëerde autoimmuunziekte (Mason, 1991). Het blijkt echter dat BN ratten gevoelig zijn voor inductie van antichaam-gemediëerde autoimmuunziekten zoals de door $\mathrm{k}$ wikchloride geïnduceerde ontsteking van de glomeruli.

Recentelijk is aangetoond dat de $\mathrm{CD} 4^{+} \mathrm{T}$ cellen in de rat, op basis van expressie van de celoppervlakte markers CD45RC (herkend door monoclonaal antilichaam OX-22) en RT6, kunnen worden onderverdeeld in twee subpopulaties. De CD45RC ${ }^{+} \mathrm{RT}$ - subset van de ratten $\mathrm{CD}^{+} \mathrm{T}$ cellen produceert een $\mathrm{T}$ helper $1\left(\mathrm{~T}_{\mathrm{H}} 1\right)$-achtig lymfokine repertoir (hoge IL-2 en IFN $\gamma$, maar lage IL-4 productie) en is betrokken bij cel-gemediëerde immuun responsen, terwijl de CD45RC- $\mathrm{RT}^{+}$populatie kenmerken bezit van de $\mathrm{T}$ helper $2\left(\mathrm{~T}_{\mathrm{H}} 2\right)$ type cellen (hoge IL-4 maar lage IL-2 en IFN $\gamma$ productie, ondersteunen van B cel hulp, en suppressie van cel-gemediëerde responsen)(Fowell et al., 1991; Fowell and Mason, 1993). In relatie tot bovenstaande is het interessant op te merken dat bij normale BN ratten (reagerend op een $\mathrm{T}_{\mathrm{H}}$ 2-achtige manier) de $\mathrm{T}_{\mathrm{H}} 2 \mathrm{~T}_{\mathrm{H}} 1$-ratio sterk in het voordeel van de $\mathrm{T}_{\mathrm{H}} 2$ subset is, terwijl dit voor $\mathrm{LEW}$ ratten (reagerend op een $\mathrm{T}_{\mathrm{H}} 1$-achtige manier) veel minder geldt (Groen et al., 1993). Afhankelijk van het geproduceerde lymfokine repertoir kan de ontwikkeling van $T_{H} 1$ - of juist $T_{H}$ 2-type responsen gestimuleerd worden. Zo kan $I L-4$, een produkt van $T_{H} 2$-type $T$ cellen, de inductie van $T_{H} 1$-type responsen remmen. Dit suggereert dat een sterke $T_{H} 2$ reaktie, zoals aanwezig bij $B N$ ratten, de cel-gemediëerde immuniteit verlaagt (Fowell and Mason, 1993).

LEW ratten die onderworpen worden aan het protocol voor inductie van CyA-AI vertonen in beginsel symptomen identiek aan akute graft-versus-host ziekte (GVHD) en in de chronische fase scleroderma-achtige afwijkingen. Hoofdstuk 3 beschrijft een experiment waarin $77 \%$ van de experimentele dieren snel progressieve onderhuidse maligniteiten (neoplásmata) ontwikkelen, met name sarcomen. Deze weke-delen tumoren ontwikkelen zich laat in het verloop van CyA-AI en lijken specifiek geassociëerd te zijn met CyA-AI. $\mathrm{E} r$ worden geen maligniteiten gezien na Röntgen bestraling en reconstitutie met syngeen beenmerg of in CyA-behandelde controle ratten. Het is onduidelijk hoe de tumoren veroorzaakt worden maar we poneren de volgende hypothese welke is gebaseerd op de observatie dat bijna alle ratten met tumoren ook thymus-afhankelijke huidontstekingen hadden. De tumoren konden als explant of celsuspensie naar normale LEW ratten worden getransplanteerd. Bovendien blijkt in de rat, dat met betrekking tot de collageen depositie, CyA-AI sterke overeenkomsten vertoont met (progressieve) systemische sclerosis (SS) bij de mens (Bos et al., 1989). Verscheidene observaties ondersteunen een relatie tussen de ontwikkeling van maligniteiten en de aanwezigheid van SS (Medsger, 1985). Concluderend zegt onze hypothese dat deze tumoren worden veroorzaakt door een 
combinatie van Röntgen bestraling en chronische - huid - ontstekingsreakties en op deze wijze dus indirekt thymus-afhankelijk. zijn.

Op basis van overeenkomsten tussen SS en chronische GVHD wordt verondersteld dat sclerodermie of SS veroorzaakt wordt door een (auto)immuun-reaktie. Bovendien blijkt dat patiënten met immuun-gemediěerde bindweefselziekten, en vooral SS, circulerende autoantilicharnen hebben tegen kern- en/of cytoplasmatische macromoleculen (Krieg and Meurer, 1988). Autoantilichamen tegen DNA-topoisomerase I (Scll-86, Scl-70) en tegen de centromeer/kinetochoor (CR19, CENP A-, B-, en C-antigenen) zijn van prognostische en diagnostische waarde voor diffuse SS of gelimiteerde sclerodermie (Weiner et al., 1988; Krieg and Meurer, 1988). Hoofdstuk 4 beschrijft dat auto-antilichamen tegen extraheerbare kern- en cytoplasmatische fracties worden opgewekt in ratten met CyA-AI. Verder wordt gedemonstreerd dat deze autoantilichamen niet noodzakelijk zijn voor. noch pathologisch gerelateerd zijn aan de ontwikkelling van de scleroderma-achtige afwijkingen. Tenslotte blijkt dat de specificiteit van enkele van deze autoantilichamen in LEW ratten met CyA-AI ziekte ook voorkomt in BN ratten met kwikchloridegeïnduceerde autoimmuun ontstekingen van de glomeruli, hetgeen suggereert dat analoge autoimmuun-mechanismen hierbij betrokken zijn.

De hoofdstukken 5 en 6 beschrijven enerzijds de localisatie van effector cellen en anderzijds de kinetiek van het genereren van inducer/effector cellen in de thymus bij CyA-AI. Verscheidene studies hebben de centrale rol van de thymus in de etiologie van CyA-AI beschreven. Afscherming van de thymus tijdens de totale lichaamsbestraling (Glazier $e t$ al., 1983) of verwijdering van de thymus voor de beenmergtransplantatie voorkomt de inductie van CyA-AI (Sorokin et al., 1986). Het begin van CyA-AI is enerzijds geassociëerd met het terugkeren van $\mathrm{CD}^{+} \mathrm{T}$ cellen, ongeveer twee weken na het beëindigen van de CyA-behandeling, in het perifere bloed (Bos et al., 1988; Fischer et al., 1991) en anderzijds met de ontwikkeling van $\mathrm{CD} 8^{+}$cytotoxische $\mathrm{T}$ cellen die een gemeenschappelijke determinant van het MHC klasse II antigeen herkennen (Hess et al., 1985). In hoofdstuk 5 komt de volgende vraag aan de orde: worden inducer/effector cellen in CyA-AI tijdens of na het beëindigen van de CyA behandeling in de thymus gegenereerd; blijven deze cellen in de thymus en, zo niet, gaan ze preferentiëel naar de secundaire lymfoide organen ? Transfer experimenten met thymocyten, geïsoleerd 1 en 14 dagen na het stoppen van de CyA-medicatie uit donor ratten behandeld voor inductie van CyA-AI, wekken geen CyA-AI op in bestraalde ontvanger ratten.

In tegenstelling tot onze resultaten suggereren de studies van Beschorner et al., (1988), waarin CyA-AI wordt overgebracht met behulp van thymocyten die 30 dagen na stoppen van de CyA-behandeling werden geïsoleerd, dat tenminste een deel van de inducer/effector cellen in de thymus aanwezig blijven. Op dit tijdstip zijn autoreaktieve cellen in de regel echter al begonnen met het aanvallen van hun doelwit. Het is waarschijnlijk dat migrerende effector cellen de thymus opnieuw binnen dringen en de doelwit cellen, die MHC klasse II antigenen tot expressie brengen, vernietigen. Daarom verklaren we het verschil tussen de studie van Beschorner et al., (1988) en onze resultaten door effector cellen, die enkele weken na de beëindiging van de CyA-behandeling naar de thymus terug migreren. Bovendien blijkt een thymectomie meteen na de kuur van CyA bij volwassen 
ratten de kinetiek van de ontwikkeling van huid pathologie niet te beïnvloeden, hoewel gewichtsverlies in gethymectomeerde ratten later plaats vindt dan in schijn-gethymectomeerde dieren. Transfer van lymfeklier- en miltcellen, geïsoleerd 1 en 14 dagen na het stoppen van de CyA-medicatie uit donor ratten behandeld voor inductie van CyA-AI, wekken CyA-AI op in bestraalde ontvanger ratten. Echter de symptomen van akute ziekte bij de ontvanger ratten zijn veel minder ernstig bij transfer van lymfoide cellen die 1 dag na het stoppen van CyA uit donor ratten werden verkregen in vergelijking met cellen verkregen 14 dagen na het beèindigen van de CyA-behandeling. Hoofdstuk 5 demonstreert dat CyA-AI inducer/effector cellen gedurende de CyA-medicatie in de thymus worden gegenereerd. Deze cellen verlaten de thymus gedurende de CyA-behandeling om vervolgens enerzijds bij voorkeur naar perifere organen (bijvoorbeeld de huid) te gaan i.p.v. naar de secundaire lymfoide organen of anderzijds verlaten ze de thymus als inducer cellen, die naar de lymfoide organen toe gaan en mogelijkerwijs potentieel autoreaktieve cellen, die ook in normale individuen aanwezig zijn, aanzetten. Het is echter ook mogelijk dat een combinatie van beide mechanismen van toepassing is. Er bestaat onenigheid omtrent de potentie van $\mathrm{T}$-lymfocyt subsets om CyA-AI naar secundair bestraalde ontvanger ratten te transfereren. Hess et al. (1990) heeft aangetoond, dat zowel CD4 ${ }^{+}$als CD8 ${ }^{+} \mathrm{T}$ lymfocyten (beide $7.5 \times 10^{6}$ ) verkregen uit de milt, vereist zijn om CyA-AI effectief over te brengen. Transfer van hoge aantallen $\left(>3 \times 10^{7}\right) \mathrm{CD} 8^{+}$cellen verkregen uit dieren met akute CyA-AI leidt tot inductie van CyA-AI in de bestraalde ontvangers. Lage aantallen $\mathrm{CD} 8^{+}$cellen kunnen $\mathrm{CyA}-\mathrm{Al}$ echter alleen over brengen samen met lage aantallen $\mathrm{CD} 4^{+}$ cellen uit donoren met CyA-Al. De CD4 ${ }^{+}$cellen, die geïsoleerd werden tijdens akute CyAAl, zijn zelf niet in staat om CyA-AI over te brengen. Sorokin et al. (1986) was echter wel in staat om met slechts $3 \times 10^{5} \mathrm{CD}^{+}$lymfeklier cellen, uit dieren met akute CyA-Al, de ziekte te transfereren; $B$ cellen en $C D 8^{+}$cellen zijn veel minder effectief. Het is dan ook belangrijk om in ons model te onderzoeken of de T lymfocyt subsets, die CyA-AI veroorzaken, $\mathrm{CD}^{+}$en/of $\mathrm{CD}^{+}$lymfocyten zijn en of deze cellen tevens een rol spelen bij de veranderingen tijdens chronische scleroderma, terwijl andere studies alleen akute dermatitis constateren (Glazier et al., 1983). Verdeling van het $T$ helper compartiment in de rat in twee functioneel verschillende subsets (zie boven) suggereert dat de $\mathrm{CD}^{+}{ }^{+} \mathrm{CD} 45 \mathrm{RC}^{+}$helper subset geassociëerd is met letale CyA-AI (en verantwoordelijk voor IL-2 produktie), terwijl de CD $4{ }^{+}$CD45RC helper subset kritisch lijkt voor de effectieve regulatie van de ziekte (Fischer et al., 1989; Hess et al., 1990).

Hoofdstuk 6 beschrijft dat transfer experimenten van thymocyten, geïsoleerd op verschillende dagen na beenmergtransplantatie uit donoren behandeld voor inductie van CyA$\mathrm{AI}$, niet in staat zijn CyA-AI op te wekken in bestraalde ontvangers. Bovendien blijkt dat bestraalde, beenmerg gereconstitueerde en $\mathrm{CyA}$-behandelde ratten, die gethymectomeerd worden na 12 of meer dagen van CyA-therapie na BMT, CyA-AI met huid-pathologie ontwikkelen. In dit hoofdstuk wordt aangetoond dat CyA-AI inducer/effector cellen in de bestraalde en CyA-behandelde thymus binnen 12 dagen, voornamelijk tijdens de vroege fase van exponentiêle regeneratie van thymocyten na Röntgen bestraling, worden gegenereerd. Deze cellen verlaten de thymus (en ontsnappen aan negatieve selectie?) binnen 12 dagen en migreren naar elders (bijvoorbeeld de huid). Bovendien blijkt dat deze cellen om hun (auto-)reaktiviteit uit te oefenen geen extrathymale aanwezigheid van CyA vereisen. 


\section{Referenties}

Beldrum DW van (1990). Comments on syngeneic GVHD. Immunology Today 11: 107

Beschorner WE, Hess AD, Shinn CA, Santos GW (1988). Transfer of cyclosporine-associated syngeneic graft-versus-host disease by thymocytes. Resemblance to chronic graft-versushost disease. Transplantation 45: 209-215

Bos GMJ, Majoor GD, Breda Vresman PJC van (1988). Cyclosporin A induces a selective, reversible suppression of $\mathrm{T}$-helper lymphocyte regeneration after syngeneic bone martow transplantation: association with syngeneic graft-versus-host disease in rats. Clin Exp Immunol 74: 443-448

Bos GMJ, Majoor GD, Willighagen RGJ, Breda Vrlesman PJC van (1989). Chronic cyclosporine-induced autoimmune disease in the rat: a new experimental model for scleroderma. J Invest Dermatol 93: 610-615

Fischer AC, Laulis MK, Horwitz L, Beschorner WE, Hess AD (1989). Host resistance to cyclosporine induced syngeneic graft-versus-host disease. Requirement for two distinct lymphocyte subsets. J Immunol 143: 827-832

Fischer AC, Laulis MK, Horwitz L, Hess AD (1991). Effect of cyclosporine on T lymphocyte development. Relationship to syngeneic graft-versus-host disease. Transplantation 51: 252-259

Fowell D, McKnight AJ, Powrie F, Dyke R, Mason D (1991). Subsets of CD4+ $T$ cells and their roles in the induction and prevention of autoimmunity. Immunol Rev 123: 37-64

Fowell D and Mason D (1993). Evidence that the T cell repertoire of normal rats contains cells with the potential to cause diabetes. Characterization of the $\mathrm{CD} 4^{+} \mathrm{T}$ cell subset that inhibits this autoimmune potential. J Exp Med 177: 627-636

Glazier A, Tutschka PJ, Farmer ER, Santos GW (1983). Graft-versus host disease in cyclosporin A-treated rats after syngeneic and autologous bone marrow reconstitution. J Exp Med 158: 1-8

Groen H, Klatter FA, Van Petersen AS, Pater JM, Nleuwenbuls P, Kampinga J (1993). Composition of rat $\mathrm{CD}^{+}{ }^{+}$resting memory $\mathrm{T}$ cell pool is influenced by MHC. Transplant Proc 1993: in press

Hess AD, Horwitz L, Beschorner WE, Santos GW (1985). Development of graft-versus-host disease-like syndrome in cyclosporine-treated rats after syngeneic bone marrow transplantation. I. Development of cytotoxic $\mathrm{T}$ lymphocytes with apparent polyclonal anti-Ia specificity, including autoreactivity. J Exp Med 161: 718-730

Hess AD, Fischer AC, Beschorner WE (1990). Effector mechanisms in Cyclosporine A-induced graft-versus-host disease. Role of $\mathrm{CD}^{+}$and $\mathrm{CD}^{+} \mathrm{T}$ lymphocyte subsets. J Immunol 145: 526-533

Hess AD, Jones RJ, Morrls LE, Noga SJ, Vogelsang GB, Santos GW (1992). Autologous graft-versus-host disease: A novel approach for antitumor immunotherapy. Human Immunol 34: 219-224 
Hood AF, Vogelsang GB, Black LP, Farmer ER, Santos GW (1987). Acute graft-vs-host disease. Development following autologous and syngeneic bone marrow transplantation. Arch Dermatol 123: 745-750

Jones RJ, Hess AD, Mann RB, Piantadosi S, Vogelsang GB, Farmer ER, Geller RB, Santos GW (1989). Induction of graft-versus-host-disease after autologous bone marrow transplantation. Lancet 1: 754-757

Krieg T and Meurer M (1988). Systemic scleroderma. Clinical and pathophysiologic aspects. J Am Acad Dermatol 18: 457-481

Mason DW (1991). Genetic variation in the stress response: susceptibility to experimental allergic encepahlomyelitis and implications for human inflammatory disease. Immunology Today 12: 57-60

Medsger Jr. TA (1985). Systemic sclerosis and malignancy - Are they related?. J Rheumatol 12: 1041-1043

Sakaguchl S and Sakaguchl N (1989). Organ-specific autoimmune disease induced in mice by elimination of $T$ cell subsets. V. Neonatal administration of cyclosporin A causes autoimmune disease. J Immunol 142: 471-480

Sakaguchi S, Sakaguchi N (1992). Causes and mechanisms of autoimmune disease: Cyclosporin $A$ as a probe for the investigation. J Invest Dermatol 98: 70S-76S

Sorokdn R, Kimura H, Schroder K, WIlson DH, Wilson DB (1986). Cyclosporine-induced autoimmunity. Conditions for expressing disease, requirernent for intact thymus, and potency estimates of autoimmune lymphocytes in drug-treated rats. J Exp Med 164: 161 5-1625

Weiner ES, Earnshaw WC, Senecal J-L, Bordwell B, Johnson P, Rothfield NF (1988). Clinical associations of anticentromere antibodies and antibodies to topoisomerase I. Arthritis Rheum 31: 378-385 


\section{Publications}

Wodzig KWH, Majoor GD, Van de Gaar M-JWH, Van Breda Vriesman PJC (1990). Autoantibodies in Cyclosporine A-induced autoimmune disease. Transplantation Proceedings 22: 2586-2587

Majoor GD, Wodzig KWH, Van Breda Vriesman PJC. (1991). Cyclosporin-induced autoimmunity. In: Thymus Update, volume 4, edited by MD Kendall and MA Ritter, London: Harwood Academic Publishers, pp 179-200

Wodzig KWH, Majoor GD, Van Breda Vrlesman PJC (1991). On the localization of effector cells in Cyclosporin-induced autoimmunity. Autoimmunity 10: 275-283

Wodzig KWH, Majoor GD, Van Breda Vrieman PJC (1993). Susceptibility and resistance to Cyclosporin A-induced autoimmunity in rats. Autoimmunity, in press.

Wodzig KWH, Majoor GD, Van Breda Vriesman PJC (1993). Kinetics of inducer/ effector cell generation in the thymus in Cyclosporine A-induced autoimmunity in rats. Transplantation Proceedings, in press

Wodzig KWH, Majoor GD, Tiebosch ATMG, Van Breda Vriesman PJC (1993). Malignant neoplasms in Cyclosporine A-induced autoimmunity in rats. Transplantation Proceedings, in press \& Manuscript in preparation.

Wodzig KWH, Majoor GD, Van Breda Vriesman PJC (1993). Autoantibodies in Cyclosporine A-induced experimental autoimmune scleroderma. Submitted for publication 
12 


\section{Dankwoord}

\section{Bedankt!}

Het is al zo vaak gezegd, promoveren doe je niet alleen: promoveren is teamwerk. Gelukkig maar, want het is reuze interessant om met een club van unieke individuen, die elk een eigen bijdrage hebben aan een groter geheel, een team te vormen waarin en waarmee je kunt presteren, terwijl tegelijkertijd de individualiteit blijft bestaan. Zij die mij goed kennen weten dat ik met zeer veel plezier aan dit proefschrift heb gewerkt. Behalve de wetenschappelijke uitdaging, speelde ook de prettige samenwerking met anderen hierbij een belangrijke rol.

De leden van de beoordelingscommissie dank ik voor de moeite die zij hebben willen nemen voor de beoordeling van het manuscript.

Dat ik het onderzoek kon uitvoeren heb ik mede te danken aan de financiele steun van het Reumafonds.

Graag wil ik iedereen danken die heeft bijgedragen aan de totstandkoming van dit proefschrift. Zonder iemand te kort te willen doen, wil ik een aantal betrokkenen met name noemen.

Een speciaal woord van dank gaat uit naar mijn promotor Prof. Dr. P.J.C. van Breda Vriesman. Beste Peter, zonder jou was dit proefschrift er niet gekomen. Jouw belangstelling, helder inzicht en kennis van de literatuur zijn, evenals de enthousiaste en motiverende begeleiding, voor mij van onschatbare waarde geweest. De karakteristieke - direkte - wijze waarop jij mijn onderzoek benaderde was voor mij altijd boeiend en leerzaam. Bij jou staat de deur aitijd wagenwijd open om, soms vele malen per dag, zaken te bespreken of gewoon te kletsen, ook al stapelt het werk zich op. Bedankt voor alle hulp, maar vooral voor je wijze woorden, niet alleen als promotor, maar ook als mens. Zowel wetenschappelijk als persoonlijk gezien was het een zeer plezierige samenwerking. Dr. G.D. Majoor als mijn co-promotor - nu coordinator Internationalisering, Rijksuniversiteit Limburg - wil ik zeker noemen. Beste Gerard, jouw kritische kijk op het onderzoek, waardoor je uitstekend hoofd- van bijzaken wist te onderscheiden, was essentiëel om de grote lijn te blijven volgen. Ondanks al je reizen naar verre landen - als gevolg van jouw nieuwe functie - heb je steeds tijd gevonden voor het leveren van kritiek op publikaties en dit proefschrift. Voor deze extra inzet en de enorme directheid van kritiek, dank! Naast de werkinspanningen en vele discussies hebben we samen ook menige pijp en sigaar gerookt in kamer 1442, alias rookhol, van het Biomedisch Centrum. Nu blijft het laatste evenement helaas beperkt tot de woensdagochtend, omdat jij jammer genoeg de vakgroep immunologie verliet. 
De gehele vakgroep immunologie dank ik voor de belangstelling en kritische opmerkingen tijdens de vele werkbesprekingen. Extra dank gaat bovenal uit naar de mensen van het eerste uur en naar diegenen die nauw bij het onderzoek betrokken waren. Allereerst ex-promovendus Dr. G. Bos, beste Gerard, bedankt voor het wegwijs maken aan het begin van het onderzoek. Mijn kamergenote tijdens de eerste twee jaren Dra. Ronneke MeijersJellema wil ik bedanken voor de gezelligheid en haar goed humeur, dat zij ook wist te behouden als niet-rookster, als ik weer eens een sigaar opstak. Dr. Jan Damoiseaux voor zijn kritische, maar altijd positief bedoelde opmerkingen.

Mijn paranimfen hebben allebei, zij het op verschillende manier, positieve invloed op mijn proefschrift gehad. De collega Drs. L. Beijleveld, beste Leo, bedankt voor jouw goede en verfrissende ideeën en het prettige gezelschap tijdens de diverse congresbezoeken, waarin we de hotelkamer meer dan eens hebben gedeeld. Ook in de privé uurtjes hebben we gezellig gekletst over het onderzoek en het leven van een promovendus, ik hoop dat we dit ook na de promotie kunrien voortzetten. Marie-José van de Gaar, lieve José, het was een groot genoegen om tijdens het promotie-onderzoek met jou samen te werken. Jouw enthousiaste manier van werken, liefde voor de ratten en kennis van zaken zijn onmisbaar geweest voor het totstand komen van dit proefschrift. Ik wil je daarom in het bijzonder bedanken voor de bergen werk die jij verzette en jouw flexibiliteit als er weer eens een groot experiment uitgevoerd moest worden. Verder voor het fijne gezelschap dat je was op het lab en in de deprimerende bestralingsruimte van het BMC, waarin we veel tijd samen hebben doorgebracht. Bedankt!

Dank ben ik verschuldigd aan de medewerkers van de Centrale Proefdiervoorzieningen, die op nauwgezette wijze de proefdieren hebben verzorgd en altijd even kontakt opnamen als er iets vreemds met de ratten aan de hand was.

Graag wil ik Marc Kok - studentassistent bij de vakgroep immunologie - bedanken voor de electronische verwerking van het WP5.1-proefschrift, hetgeen de huidige vormgeving tot resultaat heeft.

Ik wil graag alle familie en vrienden bedanken voor hun steun en interesse voor het onderzoek.

In de afgelopen jaren heb ik geleerd dat de "thuisbasis" heel belangrijk is. Mijn ouders hebben mij vrij gelaten in mijn keuzes en altijd gestimuleerd om verder te studeren, bedankt!

Lieve Gertie, zonder jouw hulp, steun, vertrouwen en vooral geduld zou het vaak allemaal veel moeilijker zijn geweest. Jij kent de spanningen en irritaties. Jij hebt me geleerd te relativeren en steeds weten te motiveren, waardoor ik de energie heb weten op te brengen om dit proefschrift succesvol af te kunnen ronden. Dank je! 


\section{Curriculum vitae}

Will Wodzig werd op 5 februari 1963 geboren in Kerkrade. In 1981 werd, na het behalen van het Atheneum-B diplona aan het St. Antonius Doctor College te Kerkrade, begonnen met de studie Biologie aan de Katholieke Universiteit Nijmegen. In 1982 en 1984 respectievelijk werd het propedeutisch en kandidaats examen Biologie (B4) met goed gevolg afgelegd. De doctoraalstudie omvatte het hoofdvak Biochemie (Dr. W.J. van Venrooij; Dr. W.J. Habets) en de bijvakken Cytologie (Dr. A.M. Pieck) en Immunologie (Prof.Dr. P.J.C. van Breda Vriesman, vakgroep Immunologie, Rijksuniversiteit Limburg, Maastricht). Het doctoraal examen Biologie werd in november 1988 behaald.

Van 1 januari 1989 tot 31 december 1992 is hij als wetenschappelijk onderzoeker met financiele steun van het Reumafonds werkzaam geweest bij de vakgroep Immunologie van de Rijksuniversiteit Limburg. Onder leiding van Prof.Dr. P.J.C. van Breda Vriesman en Dr. G.D. Majoor werd gedurende deze periode het onder7 oek verricht beschreven in dit proefschrift. Tijdens de promotieperiode is het diploma Proefdierdeskundigheid behaald. 
